\title{
EVALUATION OF THE 1994 PREDICTIONS OF THE RUN-TIMING OF WILD MIGRANT YEARLING CHINOOK IN THE SNAKE RIVER BASIN
}

\author{
Prepared by: \\ Richard Townsend \\ Peter Westhagen \\ Dean Y asuda \\ John R. Skalski \\ Center for Quantitative Science \\ School of Fisheries \\ University of Washington \\ Seattle, WA
}

Prepared for:

U.S. Department of Energy

Bonneville Power Administration

Environment, Fish and Wildlife

P. 0. Box 3621

Portland, OR 9720x-362 1

Project Number 9 1-05 1

Task Number DE-AT79-9 1 BP 16570

Contract Number DE-AI79-87BP35885

February 1995 


\section{Table of Contents}

Tital

Page

Executive Summary

Introduction

2

Methods

3

Description of Data

3

Prediction Models

4

$\begin{array}{ll}\text { Least-Squares Method } & 4\end{array}$

$\begin{array}{lr}\text { Synchronized Historical Pattern Matching } & 5\end{array}$

$\begin{array}{lc}\text { Alternative Method \#1 } & 6\end{array}$

Alternative Method \#2

$\begin{array}{lr}\text { Calculation of Comparison Scores } & 6\end{array}$

$\begin{array}{lr}\text { Resul } & 8\end{array}$

$\begin{array}{ll}\text { Discussion } & 12\end{array}$

Appendix A

Performance Plots for the 1994 Outmigration Season $\quad 14$

$\begin{array}{ll}\text { PIT Forecaster Plots } & 14\end{array}$

$\begin{array}{ll}\text { Alternative Method \#1 Plots } & 31\end{array}$

Alternative Method \#2 Plots $\quad 48$

Appendix B

Instructions on the use of the forecasting software 


\section{List of Tables}

Table

Title

Page

1 The four stream aggregates used in evaluating the predictive performance of PIT-Forecaster program. The individual streams which were included in the aggregates are listed below their respective aggregate.

2 The twelve individual rivers used in evaluating the predictive performance of PITForecaster program.

3 The number of smolt released and detected at Lower Granite dam. The ratio is the number of detected smolt divided by the total number tagged

4 Comparison of mean absolute deviances (MAD) for selected stream aggregates for the entire 1994 outmigration.

5 Comparison of mean absolute deviances (MAD) for selected single streams for the entire 1994 outmigration.

6 Comparison of mean absolute deviances (MAD) for selected stream aggregates for the first half of the observed 1994 outmigration.

7 Comparison of-mean absolute deviances (MAD) for selected single streams for the first half of the observed 1994 outmigration.

8 Comparison of mean absolute deviances (MAD) for selected stream aggregates for the last half of observed 1994 outmigration.

9 Comparison of mean absolute deviances (MAD) for selected single streams for the last half of the observed 1994 outmigration. 


\section{List of Figures}

Appendix A Page

PIT Forecaster Plots. 14

Aggregate Streams

$\begin{array}{ll}\text { Pahsimeroi } & 15\end{array}$

upper salmon River 16

$\begin{array}{ll}\text { Salmon River South Fork } & 17\end{array}$

$\begin{array}{ll}\text { Salmon River Upper Middle Fork } & 18\end{array}$

Individual Streams

Bear Valley Creek $\quad 19$

BigCreek $\quad 20$

Catherine Creek 21

ElkCreek $\quad 22$

Imnaha River 23

Lostine River $\quad 24$

Marsh Creek $\quad 25$

Salmon River $\quad 26$

Salmon River East Fork $\quad 27$

Salmon River South Fork $\quad 28$

Secesh River $\quad 29$

Valley Creek $\quad 30$

Alternative Method \#I Plots 31

Aggregate Streams

$\begin{array}{ll}\text { Pahsimeroi } & 32\end{array}$

Upper Salmon River 33

Salmon River South Fork $\quad 34$

Salmon River Upper Middle Fork $\quad 35$

Individual Streams

Bear Valley Creek $\quad 36$

$\begin{array}{ll}\text { Big Creek } & 37\end{array}$

Catherine Creek $\quad 38$

$\begin{array}{ll}\text { Elk Creek } & 39\end{array}$ 
$\begin{array}{ll}\text { Imnaha River } & 40\end{array}$

Lostine River 41

$\begin{array}{ll}\text { Marsh Creek } & 42\end{array}$

Salmon River $\quad 43$

Salmon River East Fork $\quad \mathbf{4 4}$

Salmon River South Fork $\quad 45$

$\begin{array}{ll}\text { Secesh River } & 46\end{array}$

$\begin{array}{lr}\text { Valley Creek } & 47\end{array}$

Alternative Method \#2 Plots 48

Aggregate Streams

Pahsimeroi $\quad 49$

$\begin{array}{lr}\text { Upper Salmon River } & \mathbf{5 0}\end{array}$

Salmon River South Fork

Salmon River Upper Middle Fork

Individual Streams

Bear Valley Creek 53

$\begin{array}{ll}\text { Big Creek } & 54\end{array}$

Catherine Creek $\quad 55$

Elk Creek 56

Imnaha River $\quad 57$

Lostine River $\quad 58$

$\begin{array}{lr}\text { Marsh Creek } & 59\end{array}$

$\begin{array}{ll}\text { Salmon River } & 60\end{array}$

$\begin{array}{ll}\text { Salmon River East Fork } & 61\end{array}$

Salmon River South Fork $\quad 62$

Secesh River $\quad 63$

$\begin{array}{lc}\text { Valley Creek } & 64\end{array}$ 


\section{Executive Summary}

Since 1988, wild salmon have been PIT-tagged under programs conducted by the National Marine Fisheries Service, Idaho Department of Fish and Game, Oregon Department of Fish and Game and the U.S. Fish and Wildlife Service. The detection of tagged individuals at Lower Granite Darn provides a measure of the temporal and spatial distribution of the wild populations. PIT Forecaster was developed to take advantage of this historical data to predict the proportion of a particular population which had arrived at the index site in real-time and to forecast elapsed time to some future percentile in a migration.

This report evaluates the performance of the Least Squares (LS) method and the Synchronized historical pattern matching (SYNC) method used in the PIT Forecaster and two other possible methods of prediction reminiscent of methods recommended by the Fish Passage Center (FPC) (Alternatives \#1 and \#2). Alternative \#1 bases predictions on the historical proportion of PITTags recovered in a specific year and Alternative \#2 uses the historical cumulative distribution of smolt predicted of a previous season. The 1994 predictions from these methods were compared to the observed distribution at the end of the 1994 season. Appendix A contains plots of the migration season comparing each predictive method to the actual proportion observed passing Lower Granite Dam.

Over the entire 1994 season, the LS method had the best prediction performance for both aggregate (mean average deviance $(\mathrm{MAD})=8 \%$ ) and individual (MAD $=11 \%$ ) streams. However. for the first half of the season, Alternative \#1 was clearly a better predictor, with aggregate stream mean MADs of 2-6\% and individual stream mean MADs of 4-5\%. This performance deteriorated for the last half of the season, and the LS method improved to an $8 \%$ mean MAD for aggregate streams and $11 \%$ mean MAD for the individual streams. The algorithms used by PIT Forecaster determine the distribution pattern and provide a better prediction as the season progresses. Alternatives $\# 1$ and $\# 2$ depend on the year chosen as the index, without a similar correcting mechanism for a bad initial choice. For the first half of the season, though, Alternative \#1 did very well for both index years selected. For the 1995 season, Alternative \#1 will be combined with the LS method to create an improved predictor. 


\section{Introduction}

Three Ecologically Significant Units (ESU) of Pacific salmon have been designated as either threatened or endangered (T\&E) under the Endangered Species Act (ESA) in the Snake River Basin: spring/summer chinook, fall chinook and sockeye salmon. The tributary populations of spring/summer chinook reside primarily in the Salmon and Grande Ronde drainages and Imnaha River, all of which are situated upstream of Lower Granite Dam. Additionally, a small population resides in the Tucannon River, which enters the Snake River between Lower Granite and Hell's Canyon dams. The sockeye reside in the uppermost portion of the main Salmon River in the Stanley Basin. Except for the Tucannon River population, all others reside upstream from Lower Granite Dam on the Snake River.

Regulating the timing and volume of water released from storage reservoirs (flow augmentation) has become a central mitigation strategy for improving downstream migration conditions for juvenile salmonids in the Snake River. Threatened and endangered salmon stocks have received increased priority with regard to the timing of this flow augmentation. The optimum is to release water from the storage reservoirs at times when the listed stocks are in geographic locations where they encounter the augmented flow.

In the Snake River Basin, regulated water enters the system at two locations, below Hell's Canyon Dam on the Snake River and below Dworshak Dam on the Clearwater River. The preponderance of regulated water available for fish passage is provided by Dworshak Reservoir. None of the listed stocks are located in the Clearwater drainage, and thus listed stocks must migrate to below the confluence of the Clearwater and Snake Rivers before they are fully exposed to augmented flows. The confluence forms the approximate upper boundary of the Lower Granite Reservoir. Determining when stocks are in the vicinity of Lower Granite Dam and reservoir is a chief consideration in requesting flow augmentation.

Since 1988, wild salmon have been PIT-tagged under programs conducted by the National Marine Fisheries Service, Idaho Department of Fish and Game, Oregon Department of Fish and Game and the U.S. Fish and Wildlife Service. The detection of tagged individuals at Lower Granite Dam provides a measure of the temporal and spatial distribution of the wild populations. PIT Forecaster was developed to take advantage of this historical data to predict the proportion of a particular population which had arrived at the index site in real-time and to forecast elapsed time to some future percentile in a migration.

This report is a post-season analysis of the accuracy of the 1994 predictions from the PIT Forecaster program. Observed 1994 data were compared to the predictions made by PIT Forecaster for the spring outmigration of wild spring chinook observed at Lower Granite Dam through-out the season. In addition, two alternative methods were compared to PIT Forecaster. Alternative method \#1 is based on the historical proportion of PIT-tags recovered for a stream for a specific year, and Alternative method \#2 is based on the historical cumulative distribution of smolt passage for a specific year. These alternatives were included to give a bench-mark for the performance of the PIT Forecaster versus some possible simple methods of run estimation. Appendix A contains plots of the migration season comparing each predictive method to the 
actual proportion observed passing Lower Granite Dam..

A user's manual for the 1994 RealTime PIT Forecaster is included in Appendix B. It provides samples of the various information displays provided by the program, beyond those included in Appendix A (comparison plots of predicted versus actual season migration proportions observed). Possible displays include historical and current season plots for individual and user-defined composite streams. The PIT Forecaster's data graphical capabilities are tremendous assets in addition to its predictive functions.

\section{M ethods}

\section{Description of Data}

The spring outmigration of wild spring chinook from four stream-aggregates and twelve individual streams were used in evaluating the 1994 performance of the four algorithms. The four stream aggregates include all fish tagged within a certain region, designated by its "epa-reach" (Table 1). Note that some of the individual streams were also included in the larger aggregates (Table 2). These specific aggregates and streams were chosen for their persistent recovery numbers, each having at least three years with a minimum of 30 detections per year. This was the minimum amount of historical data considered necessary in the formulation of the PIT Forecaster.

Table 1: The four stream aggregates used in evaluating the predictive performance of the PIT-Forecaster program. The individual streams which were included in the aggregates are listed below their respective aggregate.

\begin{tabular}{|c|c|c|c|}
\hline Aggregate Name & \multicolumn{2}{|c|}{ epa-reach 1 AggregateName } & epa-reach \\
\hline T) Pansimerol RIVer & 17060202 & 14) Upper salmon River & 17060201 \\
\hline -HerdC reek & 17060202 & -Alturas Lake Creek & 17060201 \\
\hline - salmon River. East Fork $\underline{a}$ & 17060202 & -FourthofJulyCreek & 17060201 \\
\hline 2) Salmon River, Upper Middle Fork & 17060205 & -Frenchman Creek & 17060201 \\
\hline - Bear Valley Creeka & 17060205 & -H uckleberryCreek & 17060201 \\
\hline - Capehorn Creek & 17060205 & -Pettit Lake Creek & 17060201 \\
\hline -Elkcreek & 17060205 & -Pole Creek & 17060201 \\
\hline -LoonCreek & 17060205 & -Red Fish Lake Creek & 17060201 \\
\hline -M arshCreek & 17060205 & - Smiley Creek & 17060201 \\
\hline 3) Salmon River south Fork & 17060208 & -Valley Creek ${ }^{\mathbf{a}}$ & 17060201 \\
\hline - Johnson Creek & 17060208 & & \\
\hline -LakeCreek & 17060208 & & \\
\hline - Salmon River South Forka & 17060208 & & \\
\hline -SeceshRiverª & 17060208 & & \\
\hline
\end{tabular}

a Also used in separate stream analysis. 


\section{Table 2: The twelve individual rivers used in evaluating the predictive performance of the PIT-Forecaster program.}

\begin{tabular}{lc}
\hline Stream Name & epa-reach \\
\hline \hline Bear Valley Creek & $\mathbf{1 7 0 6 0 2 0 5}$ \\
Big Creek & 17060206 \\
Catherine Creek & 17060104 \\
Elk creek & 17060205 \\
Imnaha River & 17060102 \\
Lostine River & 17060105 \\
Marsh Creek & 17060205 \\
Salmon River & 17060209 \\
Salmon River. East Fork & 17060202 \\
Salmon River South Fork & 17060208 \\
Secesh River & 17060208 \\
valley creek & 17060201 \\
\hline
\end{tabular}

\section{Prediction Models}

The following is a brief synopsis of the four methods used in this report. PIT Forecaster has two methods of prediction. A least-squares (LS) method and a synchronized historical patternmatching (SYNC) method. The two other methods are based on a simple assumption that the run for the present year is directly related to a previous outmigration pattern.

\section{Least-Squares M ethod}

For a given day in the run, the LS algorithm computes the predicted percentage $(\hat{p})$ of the outmigration by finding the value of $\hat{p}$ that minimizes the squared error according to historical runs. The squared error (SS) for each $\hat{p}$ is summed over the historical years for which data are available. Each outmigration pattern is divided into 100 equal portions and the slopes at each corresponding point are computed. The sum of squares for a prediction compares the slopes for the current year $\left(s_{o j}\right)$ versus the respective slopes for the historical years $\left(s_{i j}\right)$. The total squared error for each predicted percentage of outmigration $\hat{p}$ is calculated according to the formula

$$
S S(\hat{p})=\sum_{i=1}^{n} \sum_{j=0}^{p}\left(s_{o j}-s_{i j}\right)^{2} w_{i j}
$$

where $s_{o j}=$ observed slope at the $j$ th percentile $(j=0, \ldots p)$ for the current year of prediction,

$s_{i j}=$ slope at the $j$ th percentile $(j=0, \ldots p)$ for the ith historical year $(i=1, \ldots \mathrm{n})$, and

$w_{i j}=$ weight for the $j$ th percentile for the $i t h$ historical year.

For example, letting $\hat{\boldsymbol{p}}=30 \%$, the present run will be compared to the first $30 \%$ of the outmigration for each historical year. Similar calculations are performed for each percentage from 0 to 100 percent. The percentage that minimizes the sum of squares (1) is the best prediction for the cur- 
rent outmigration timing. The weighting factor is included to more evenly distribute the squared error contribution throughout the outmigration distribution. The weights are

$$
w_{i j}=\frac{D_{o i}+D_{i j}}{R_{o}+R_{i}}
$$

where $D_{o j}=$ estimated number of days between the $(j-1)$ and $j$ th percentile for the present year,

$D_{i j}=$ number of days between the $(j-1)$ and $j$ th percentile for the ith historical year $(i=1$, $\ldots, n)$,

$R_{o} \quad=$ range in days of the current observed outmigration, and

$\boldsymbol{R}_{\boldsymbol{i}} \quad=$ range in days of the ith historical year outmigration $(i=1, \ldots n)$.

The effect of $w_{i j}$ is to give more weight to the errors generated from the tails of the distribution, where the slopes tend to be flat and the number of days between each percentile point are high. Less weight is given to the mid-season, where large slopes are more likely. The total sum of the weights adds to one.

\section{Synchronized Historical Pattern Matching}

The SYNC method selects the $\hat{p}$ which minimizes the error between the present year and a historical-year aggregate. The algorithm finds the first significant peak in the density of each historical run and then aligns each of the densities on these peaks To determine the peak, the local minima' in the first half of the historical-run density are determined. The area between each of these minima is calculated, and the significant peak lies within the area where $i$ is minimized (i.e. the earliest qualifying occurrence in the outmigration pattern) in the equation

$$
A_{(i-1, i)}>0.2 B_{i-1}
$$

where $A_{(i-1, i)}=$ the area under the historical-run density between the $(i-1)$ and $i$ th local minima $(i=1, \ldots n)$, and

$B_{i-1}=$ the area under the historical-run density between the (i-1)th local minima and the 50th percentile.

The local maximum between the local minima determined by (3) is the significant peak the historical years are aligned on. The average of these aligned historical densities is the historical aggregate density. The squared error for each $\hat{p}$ is calculated according to the formula

$$
\operatorname{SS}\left(\hat{p}_{i}\right)=\sum_{i=O}^{\hat{p}}\left(S_{o i}-S_{a i}\right)^{2}
$$

where $S_{o i}=$ slope at the $i^{\text {th }}$ percentile $(i=0, \ldots \hat{\boldsymbol{p}})$ in the current year outmigration density, and $S_{a i}=$ slope at the $i^{t h}$ percentile $(i=0, \ldots \hat{p})$ in the aggregate outmigration density.

1. A minima is a point on the density line where the first derivative of the density at that point equals zero and the second derivative is positive. 


\section{Alternative \#1}

Alternative \#1 makes a prediction of run timing by using the total recapture proportion observed in a previous season and then assuming that proportion to be consistent for the present year. The predicted percent of the run is calculated according to the formula

$$
\hat{p}=\frac{x_{d}}{p_{y} \times N}
$$

where $\hat{\boldsymbol{p}}=$ the estimated proportion of the outmigration passed on day $d$,

$\boldsymbol{x}_{\boldsymbol{d}}=$ the total observed smolt to day $d$,

$p_{y}=$ the total proportion of outmigration observed for historical year $\mathrm{y}$, and

$\mathrm{N}=$ the total number of smolt tagged for the present year.

The number of fish tagged for the present year for a given stream or stream aggregate is multiplied by the recapture ratio $\left(p_{y}\right)$ of a previous year (Table 3 ) to determine the total number of fish expected. The proportion passed is then estimated. For example, the Pahsimeroi River observed a recapture ratio of $5.1 \%$ in 1992 and $4.3 \%$ in 1993. The expected total number of smolt for 1994 based on 1992 data would be 133.67 smolt (2621 x 0.051$)$ or, based on 1993, 112.7

(2621 x 0.043) smolt. The observed recovery proportions for each of the 1992 and the 1993 seasons were used to make predictions for the 1994 season.

\section{Alternative \#2}

In method \# 2 the prediction was the historical proportion observed on a given day of outmigration for a specified historical year.

$$
\hat{p}=p_{y d}
$$

where $\hat{p}=$ the estimated proportion of the outmigration observed on day a, and

$p_{y d}=$ the proportion of outmigration passed on day $d$ for historical year $\mathrm{y}$.

Both 1992 and 1993 recapture proportions were used to make prediction for 1994. For a given day of run, the proportion predicted is given by the proportion observed in the index year on that day of the run (i.e. for a run estimated to be in its 15th day, the percentage passed by day 15 in the historical run of 1992 or 1993 is the estimated present percentage observed).

\section{Calculation of Comparison Scores}

The results presented in Tables 4 through 9 contain the mean absolute deviance (MAD) of the predictions from the observed 1994 data for each stream and stream aggregate. The MAD is calculated by the formula 


$$
\operatorname{MAD}=\frac{\sum_{i=1}^{n}\left|\hat{p}_{i}-p_{i}\right|}{n}
$$

where $\hat{p}_{i}=$ predicted cumulative percentage of run completed for day $\mathbf{i}$,

$p_{i}=$ observed cumulative percentage of run completed for day $i$, and

$n=$ total number of days in run for 1994 season.

The methods are compared three ways: the MAD over the entire run, the MAD over the first half of the run (i.e. cumulative run to the 50\%). and the MAD over the last half of the run.

\section{Table 3: The $\mathbf{N}$ umber of smolt released and detected at Lower Granite dam. The proportion $\left(\hat{p}_{v}\right)$ is the number of detected smolt divided by the total number tagged.}

\begin{tabular}{|c|c|c|c|c|c|c|c|c|c|}
\hline \multirow{2}{*}{ Tagging Site } & \multicolumn{3}{|c|}{1992} & \multicolumn{3}{|c|}{1993} & \multicolumn{3}{|c|}{1994} \\
\hline & $\begin{array}{c}\# \\
\text { Tagged }\end{array}$ & $\begin{array}{c}\# \\
\text { Detected }\end{array}$ & $\begin{array}{c}\text { Proportion } \\
\hat{\boldsymbol{p}}_{v}\end{array}$ & $\begin{array}{c}\# \\
\text { Tagged }\end{array}$ & $\begin{array}{c}\# \\
\text { Detected }\end{array}$ & $\begin{array}{c}\text { Proportion } \\
\hat{p}_{y}\end{array}$ & $\begin{array}{c}\# \\
\text { Tagged }\end{array}$ & $\begin{array}{c}\# \\
\text { Detected }\end{array}$ & $\begin{array}{c}\text { Proportion } \\
\hat{p}_{\mathbf{v}}\end{array}$ \\
\hline \multicolumn{10}{|l|}{ Aggregate Streams } \\
\hline Pahsimeroi River & 979 & 50 & 0.051 & 2365 & 101 & 0.043 & 2621 & 145 & 0.055 \\
\hline Salmon River Upper Middle Fork & 2694 & 191 & 0.071 & 2797 & 330 & 0.118 & 10180 & 541 & 0.053 \\
\hline Salmon River South Fork & 2039 & 121 & 0.059 & 3067 & 343 & 0.112 & 6559 & 481 & 0.073 \\
\hline Upper Salmon River & 2303 & 57 & 0.025 & 4122 & 140 & 0.034 & 2515 & 59 & 0.023 \\
\hline \multicolumn{10}{|l|}{ Individual Streams } \\
\hline Bear Valley Creek & 1042 & 69 & 0.066 & 1015 & 79 & 0.078 & 934 & 63 & 0.067 \\
\hline Big Creek & 1002 & 57 & 0.057 & 733 & 70 & 0.095 & 721 & 40 & 0.055 \\
\hline Catherine Creek & 940 & 67 & 0.071 & 1095 & 119 & 0.109 & 1000 & 77 & 0.077 \\
\hline Elk Creek & 462 & 36 & 0.078 & 628 & 48 & 0.076 & 998 & 54 & 0.054 \\
\hline Imnaha River & 815 & 94 & 0.115 & 1237 & 180 & 0.146 & 1747 & $1 \%$ & 0.112 \\
\hline Lostine River & 1107 & 92 & 0.083 & 1000 & 132 & 0.132 & 725 & 67 & 0.092 \\
\hline MarshCreek & 981 & 67 & 0.068 & 949 & 139 & 0.146 & 3249 & 393 & 0.121 \\
\hline Salmon River & $23 \%$ & 65 & 0.027 & 1498 & 40 & 0.027 & 736 & 40 & 0.054 \\
\hline Salmon River East Fork & 669 & 33 & 0.049 & 843 & 40 & 0.047 & 883 & 45 & 0.051 \\
\hline Salmon River South Fork & 1027 & 81 & 0.079 & 2106 & 245 & 0.116 & 5885 & 442 & 0.075 \\
\hline Secesh River & 1012 & 40 & 0.040 & 327 & 31 & 0.095 & 422 & 39 & 0.092 \\
\hline Valley Creek & 969 & 34 & 0.035 & 1026 & 36 & 0.035 & 848 & 39 & 0.046 \\
\hline
\end{tabular}




\section{R esults}

Comparing the performance of the prediction methods across the entire season indicates that, on average, the LS procedure performed the best for 1994 (Tables 4-5). For the four aggregate streams (Table 4) $\mathrm{mS}$ had the smallest mean MAD (8\%) and median MAD (6\%) of all methods. The SYNC algorithm performed slightly worse with a mean MAD of $11 \%$. The two simplified algorithms varied in performance depending on whether 1992 or 1993 was used as the index year (mean MAD 12-26\% for Alternative \#1 10-15\% for Alternative \#2). The LS algorithm also was the best predictor with a mean MAD of $11 \%$ for the individual streams (Table 5). Alternative \#2 had nearly as good of a performance with mean MAD of 1 1-13\%, again depending on the selected index year. However, the performance of the different predictors is somewhat obscured by examination of the average performance across the entire season. Additional information on predictive performance can be acquired by examining the early and latter halves of the season.

Table 4: Comparison of mean absolute deviances (M AD) for selected stream
aggregates for the entire 1994 outmigration.

\begin{tabular}{|c|c|c|c|c|c|c|}
\hline \multirow{2}{*}{ Aggregate } & \multicolumn{2}{|c|}{ PIT Forecaster } & \multicolumn{2}{|c|}{ Alternative \#1 } & \multicolumn{2}{|c|}{ Alternative \#2 } \\
\hline & LS & SYNC & 1992 & 1993 & 1992 & 1993 \\
\hline Pahsimeroi River & 0.06 & 0.08 & 0.10 & 0.19 & 0.02 & 0.12 \\
\hline Salmon River Upper Middle FOrk & 0.07 & 0.14 & 0.18 & 0.41 & 0.13 & 0.11 \\
\hline Salmon River South Fork & 0.05 & 0.08 & 0.19 & 0.25 & 0.08 & 0.07 \\
\hline Upper Salmon River & 0.14 & 0.15 & 0.01 & 0.20 & 0.17 & 0.28 \\
\hline mean MAD & 0.08 & 0.11 & 0.12 & 0.26 & 0.10 & 0.15 \\
\hline median MAD & 0.06 & 0.11 & 0.14 & 0.22 & 0.11 & 0.12 \\
\hline range & $.05-.14$ & $.08-.15$ & $.01-.19$ & $.19-.41$ & $.02-.17$ & $.07-.28$ \\
\hline
\end{tabular}


Table 5: Comparison of mean absolute deviances (MAD) for selected single streams for the entire 1994 outmigration.

\begin{tabular}{lcccccc}
\hline \multirow{2}{*}{ Tagging Site } & \multicolumn{2}{c}{ PIT Forecaster } & \multicolumn{2}{c}{ Alternative \#l } & \multicolumn{2}{c}{ Alternative \#2 } \\
\cline { 2 - 7 } & LS & SYNC & 1992 & 1993 & 1992 & 1993 \\
\hline \hline Bear Valley Creek & 0.08 & 0.16 & 0.05 & 0.08 & 0.11 & 0.14 \\
Big Creek & 0.20 & 0.23 & 0.01 & 0.29 & 0.22 & 0.06 \\
Catherine Creek & 0.06 & 0.06 & 0.13 & 0.20 & 0.03 & 0.06 \\
Elk Creek & 0.08 & 0.14 & 0.19 & 0.21 & 0.19 & 0.19 \\
lmnaha River & 0.11 & 0.13 & 0.01 & 0.17 & 0.08 & 0.03 \\
Lostine River & 0.06 & 0.06 & 0.12 & 0.20 & 0.06 & 0.07 \\
Marsh Creek & 0.07 & 0.13 & 059 & 0.14 & 0.12 & 0.08 \\
Salmon River & 0.30 & 0.33 & 0.78 & 0.73 & 0.26 & 024 \\
Salmon River East Fork & 0.10 & 0.13 & 0.06 & 0.04 & 0.11 & 0.08 \\
Salmon River South Fork & 0.05 & 0.08 & 0.02 & 0.27 & 0.05 & 0.06 \\
Secesh River & 0.17 & 0.14 & 1.17 & 0.04 & 0.21 & 0.15 \\
Valley Creek & 0.06 & 0.14 & 026 & 0.18 & 0.08 & 0.11 \\
\hline \hline mean MAD & 0.11 & 0.14 & 028 & 0.21 & 0.13 & 0.11 \\
median MAD & 0.08 & 0.14 & 0.12 & 0.19 & 0.11 & 0.08 \\
range & $.05-.30$ & $.06-.33$ & $.01-1.17$ & $.04-.73$ & $.03-26$ & M-24 \\
\hline
\end{tabular}

Tables 6 and 7 examine the performances of the methods during the first half of the outmigration. For the aggregate streams (Table 6), Alternatives \#l and \#2 both outperform the methods of the PIT-Forecaster with mean MADs of $2-6 \%$ and 6- $11 \%$ respectively. Similarly, for the individual streams (Table 7), Alternatives \#l and \#2 were better than both LS and SYNC, regardless of the historical year used as the index year. The mean MAD for Alternative \#l was 4-5\%. The better performance of either alternative method can be attributed to the fact that there is little historical pattern to lock the LS or SYNC algorithms on at the start of the season. Historical recovery rates provide better priors for prediction early into the outmigration. 
Table 6: Comparison of mean absolute deviances for selected stream aggregates for the first half of the observed 1994 outmigration.

\begin{tabular}{lcccccc}
\hline \multirow{2}{*}{ Aggregate } & \multicolumn{2}{c}{ PIT Forecaster } & \multicolumn{2}{c}{ Alternative \#l } & \multicolumn{2}{c}{ Alternative \#2 } \\
\cline { 2 - 7 } & LS & Sync & 1992 & 1993 & 1992 & 1993 \\
\hline \hline Pahsimeroi River & 0.11 & 0.11 & 0.02 & 0.04 & 0.02 & 0.10 \\
Salmon River upper Middle Fork & 0.12 & 0.10 & 0.03 & 0.06 & 0.06 & 0.07 \\
Salmon River South Fork & 0.03 & 0.02 & 0.05 & 0.07 & 0.07 & 0.08 \\
Upper Salmon River & 0.17 & 0.18 & 0.00 & 0.06 & 0.11 & 0.19 \\
\hline \hline meanMAD & 0.11 & 0.10 & 0.02 & 0.06 & 0.06 & 0.11 \\
median MAD & 0.12 & 0.11 & 0.02 & 0.06 & 0.06 & 0.09 \\
range & $.03-.17$ & $.02-.18$ & $.00-.05$ & $.04-.07$ & $.02-.11$ & $.08-.19$ \\
\hline
\end{tabular}

Table 7: Comparison of mean absolute deviances for selected single streams for the first half of the observed 1994 outmigration.

\begin{tabular}{|c|c|c|c|c|c|c|}
\hline \multirow{2}{*}{ Tagging Site } & \multicolumn{2}{|c|}{ PIT Forecaster } & \multicolumn{2}{|c|}{ Alternative \#l } & \multicolumn{2}{|c|}{ Alternative \#2 } \\
\hline & LS & Sync & 1992 & 1993 & 1992 & 1993 \\
\hline Bear Valley Creek & 0.15 & 0.13 & 0.01 & 0.02 & 0.08 & 0.08 \\
\hline Big Creek & 0.14 & 0.13 & 0.00 & 0.06 & 0.10 & 0.03 \\
\hline Catherine Creek & 0.09 & 0.10 & 0.03 & 0.04 & 0.08 & 0.11 \\
\hline Elk Creek & 0.15 & 0.11 & 0.04 & 0.04 & 0.09 & 0.12 \\
\hline lmnaha River & 0.18 & 0.19 & 0.00 & 0.01 & 0.16 & 0.07 \\
\hline Lostine River & 0.14 & 0.11 & 0.03 & 0.05 & 0.07 & 0.09 \\
\hline Marsh Creek & 0.11 & 0.09 & 0.09 & 0.02 & 0.06 & 0.06 \\
\hline Salmon River & 0.21 & 0.20 & 0.12 & 0.11 & 0.10 & 0.10 \\
\hline Salmon River East Fork & 0.09 & 0.10 & 0.01 & 0.01 & 0.04 & 0.08 \\
\hline Salmon River South Fork & 0.04 & 0.04 & 0.01 & 0.07 & 0.04 & 0.08 \\
\hline Secesh River & 0.13 & 0.12 & 0.18 & 0.01 & 0.11 & 0.08 \\
\hline Valley Creek & 0.16 & 0.16 & 0.08 & 0.05 & 0.07 & 0.15 \\
\hline mean MAD & 0.13 & 0.12 & 0.05 & 0.04 & 0.08 & 0.09 \\
\hline median MAD & 0.14 & 0.12 & 0.03 & 0.04 & 0.08 & 0.08 \\
\hline range & $.04-.21$ & $.04-.20$ & $.00-.18$ & $.01-.11$ & $.04-.16$ & $.03-.15$ \\
\hline
\end{tabular}


Tables 8-9 summarize performances during the second half of the outmigration. The performance of the algorithms is reverse that observed during the first half of the season. The LS and SYNC methods performed better than Alternatives \#l and \#2. The LS method has the smallest mean MAD (8\%) and median MAD (6\%) of all methods for the aggregate streams. For individual streams, LS again had the smallest median MAD (6\%) and among the smallest mean MAD (11\%). The performance of the LS method improved as the season progressed while the error of the simplified methods increased. Appendix A presents plots of the progress of the predictions over the season for all streams and aggregates. These plots show that the LS and SYNC methods converged on the true outmigration patterns as the season progressed. The simplified alternatives lack this property, accounting for their poor performance in the latter half of the season.

Table 8: Comparison of mean absolute deviances (MAD) for selected stream aggregates for the last half of observed 1994 outmigration.

\begin{tabular}{lcccccc}
\hline \multirow{2}{*}{ Aggregate } & \multicolumn{2}{c}{ PIT-Forecaster } & \multicolumn{2}{c}{ Alternative \# } & \multicolumn{2}{c}{ Alternative \#2 } \\
\cline { 2 - 7 } & LS & Sync & $\mathbf{1 9 9 2}$ & $\mathbf{1 9 9 3}$ & $\mathbf{1 9 9 2}$ & 1993 \\
\hline \hline Pahsimeroi River & $\mathbf{0 . 0 5}$ & $\mathbf{0 . 0 7}$ & $\mathbf{0 . 1 2}$ & $\mathbf{0 2 2}$ & $\mathbf{0 . 0 3}$ & $\mathbf{0 . 1 2}$ \\
Salmon River Upper Middle Fork & 0.06 & 0.15 & 022 & 0.50 & 0.14 & 0.13 \\
Salmon River South Fork & 0.06 & $\mathbf{0 . 1 0}$ & $\mathbf{0 . 2 4}$ & $\mathbf{0 3 2}$ & $\mathbf{0 . 0 9}$ & $\mathbf{0 . 0 6}$ \\
Upper Salmon River & $\mathbf{0 . 1 3}$ & $\mathbf{0 . 1 5}$ & $\mathbf{0 . 0 1}$ & $\mathbf{0 2 4}$ & $\mathbf{0 . 1 9}$ & $\mathbf{0 . 3 0}$ \\
\hline \hline mean MAD & $\mathbf{0 . 0 8}$ & $\mathbf{0 . 1 2}$ & $\mathbf{0 . 1 5}$ & $\mathbf{0 . 3 2}$ & $\mathbf{0 . 1 1}$ & $\mathbf{0 . 1 5}$ \\
median MAD & $\mathbf{0 . 0 6}$ & $\mathbf{0 . 1 2}$ & $\mathbf{0 . 1 7}$ & $\mathbf{0 2 8}$ & $\mathbf{0 . 1 2}$ & $\mathbf{0 . 1 2}$ \\
range & $\mathbf{0 5 - . 1 3}$ &. $\mathbf{0 7 - . 1 5}$ & $.01-.24$ &. $\mathbf{2 2 - . 5 0}$ & $\mathbf{. 0 3 - .} \mathbf{1 9}$ & $\mathbf{. 0 6 - . 3 0}$ \\
\hline
\end{tabular}


Table 9: Comparison of mean absolute deviances (MAD) for selected single streams for the last half of the observed 1994 outmigration.

\begin{tabular}{lcccccc}
\hline \multirow{2}{*}{ Tagging Site } & \multicolumn{2}{c}{ PIT Forecaster } & \multicolumn{2}{c}{ Alternative \#l } & \multicolumn{2}{c}{ Alternative \#2 } \\
\cline { 2 - 7 } & LS & Sync & 1992 & 1993 & 1992 & 1993 \\
\hline \hline Bear Valley Creek & 0.06 & 0.17 & 0.07 & 0.11 & 0.12 & 0.16 \\
Big Creek & 0.21 & 0.25 & 0.02 & 0.36 & 025 & 0.07 \\
catherine Creek & 0.05 & 0.05 & 0.16 & 0.25 & 0.02 & 0.04 \\
Elk Creek & 0.07 & 0.15 & 024 & 026 & 021 & 0.21 \\
Imnaha River & 0.10 & 0.11 & 0.01 & 023 & 0.06 & 0.02 \\
Lostine River & 0.04 & 0.05 & 0.15 & 0.25 & 0.06 & 0.07 \\
Marsh Creek & 0.06 & 0.13 & 0.74 & 0.18 & 0.13 & 0.08 \\
salmon River & 0.31 & 0.35 & 0.97 & 0.90 & 0.31 & 0.28 \\
Salmon River East Fork & 0.11 & 0.14 & 0.08 & 0.05 & 0.13 & 0.08 \\
Salmon River South Fork & 0.05 & 0.10 & 0.03 & 0.34 & 0.05 & 0.06 \\
Secesh River & 0.17 & 0.14 & 1.31 & 0.05 & 022 & 0.16 \\
Valley Creek & 0.05 & 0.14 & 0.32 & 022 & 0.08 & 0.10 \\
\hline \hline mean MAD & 0.11 & 0.15 & 0.34 & 027 & 0.14 & 0.11 \\
median MAD & 0.06 & 0.14 & 0.16 & 024 & 0.12 & 0.08 \\
range & $.04-.31 .05-.35$ & $.01-1.31$ & $.05-.90$ & $.02-.31$ & $.02-.28$ \\
\hline & & & & & & \\
\hline
\end{tabular}

\section{Discussion}

The results from the 1994 season are encouraging and suggest improvements that can be made to the PIT Forecaster program. The LS method had an average MAD of only $8 \%$ over the entire 1994 observed season. Although not the best method for the start of the season, it improved markedly by the end of the season. Alternative \#l's performance in the first half of the season recommends its incorporation into the PIT Forecaster to improve the performance of the program. The predictions by the two methods will be weighted through the season, giving more weight to predictions made by Alternative \#l at the beginning and less as the season progresses, where the LS method proved to be more accurate.

The second change for 1995 will be the removal of the SYNC method from the program. Its original inclusion into the PIT Forecaster was as a time/resource-saving method which would give comparable results without the computational intensity of the LS method. As present computer resources have been quite adequate, the removal of the less accurate SYNC method will 
remove conflicting recommendations from the program.

In this analysis, the streams that were included in an aggregate were fixed. A third change will allow the user to determine the individual streams to be included into a composite for outmigration prediction. This enables the user to tailor the predictions to specific areas of interest. Furthermore, rather than predicting an average outmigration for the streams within an aggregate, the new method will weight predictions on the expected numbers of PIT-tagged salmon outmigrating from their respective streams. 


\section{Appendix A}

\section{Performance Plots for the 1994 Outmigration Season}

\section{PIT F orecaster Plots}




\section{PIT Forecaster: Pahsimeroi}

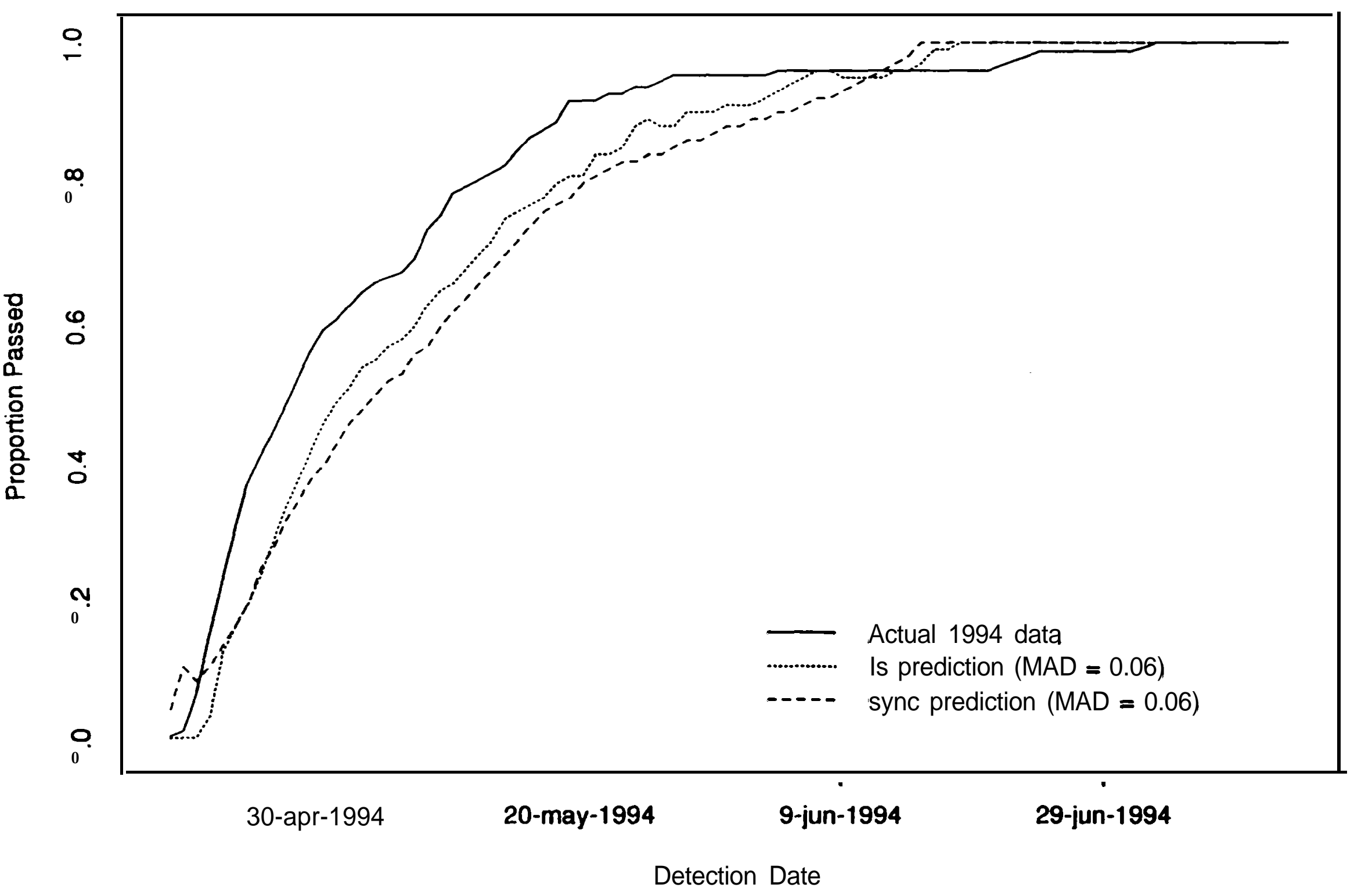




\section{PIT Forecaster: Upper Salmon}

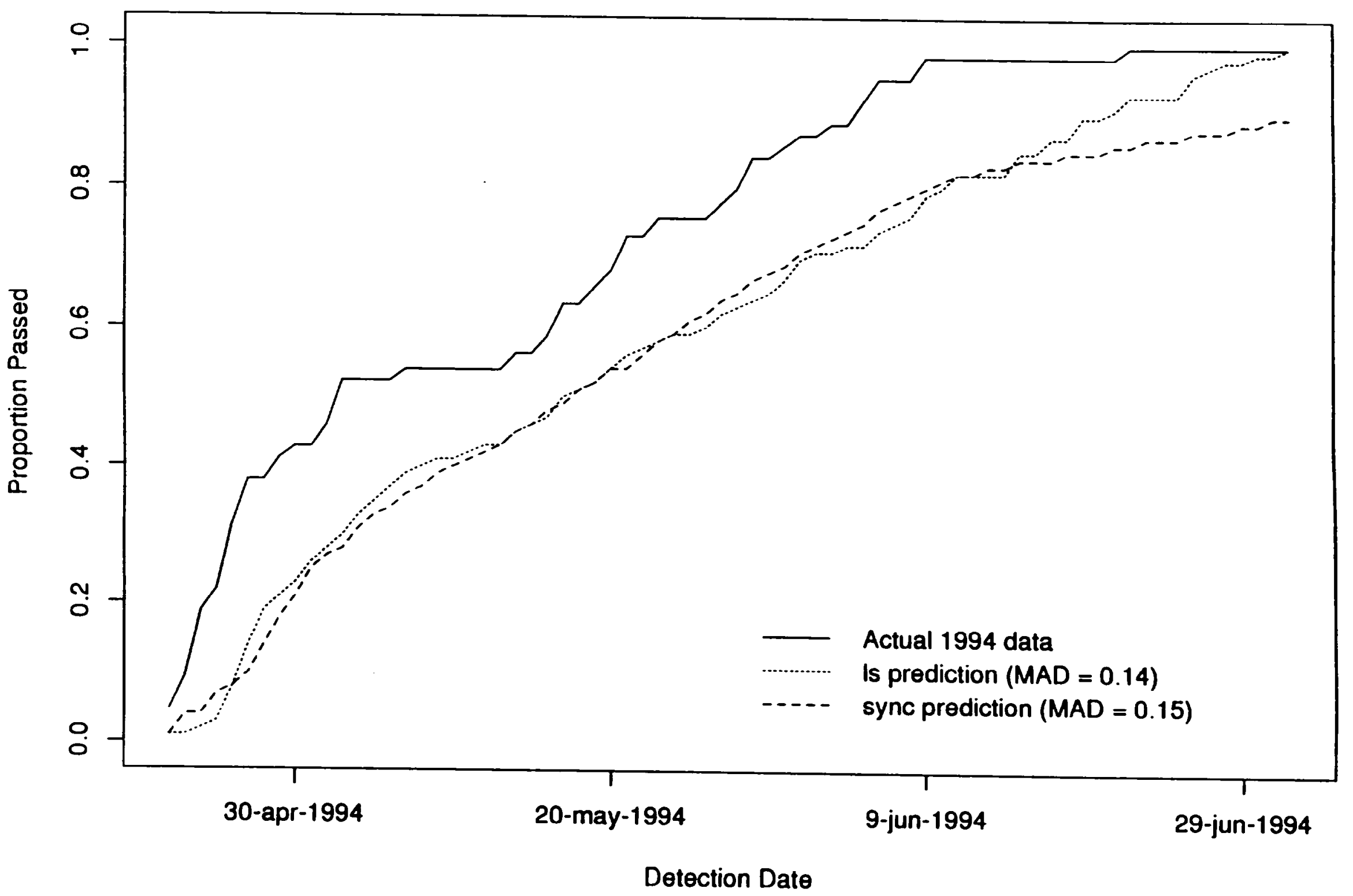




\section{PIT Forecaster: South Fork Salmon}

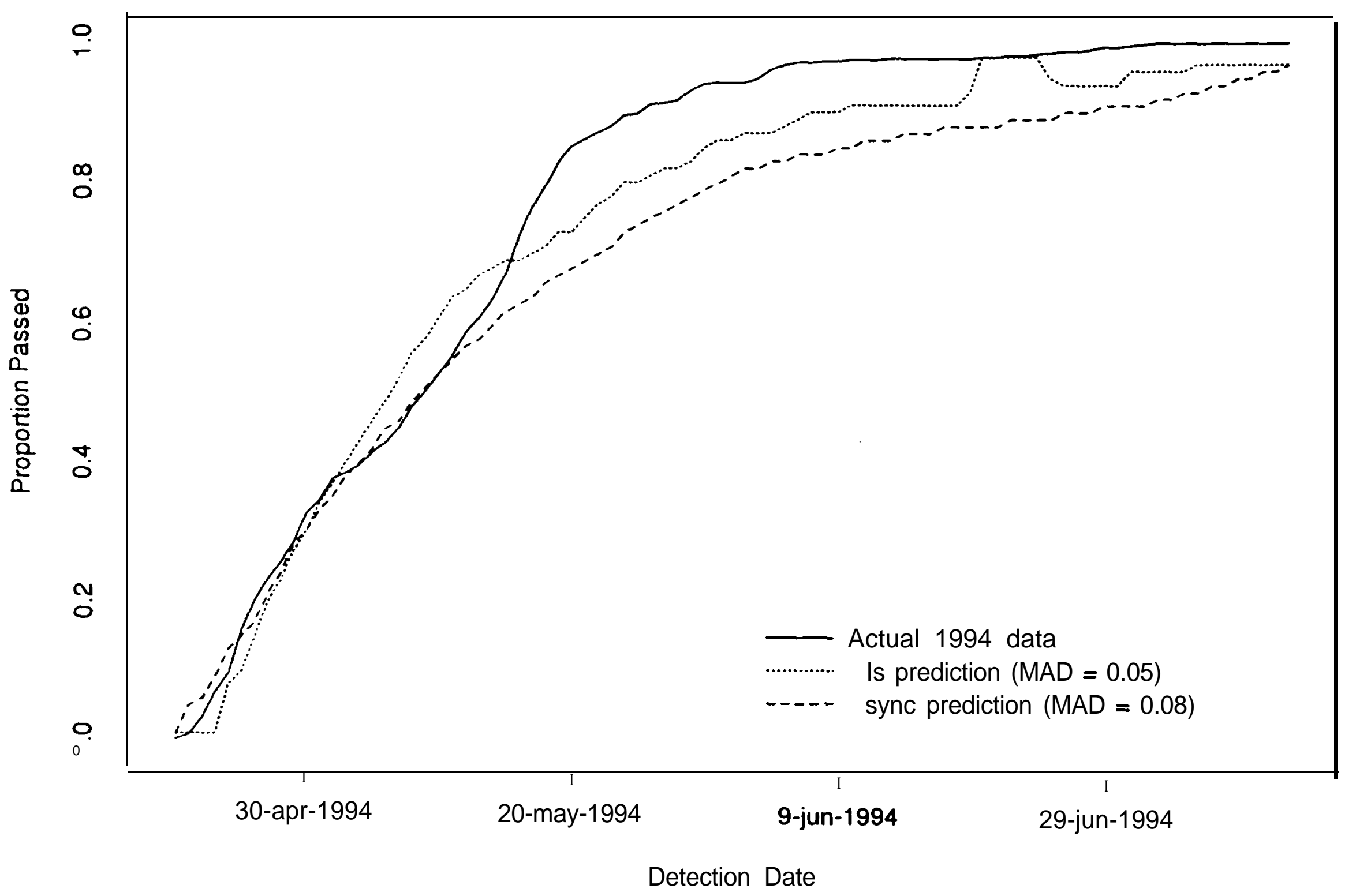




\section{PIT Forecaster: Upper Middle Fork Salmon}

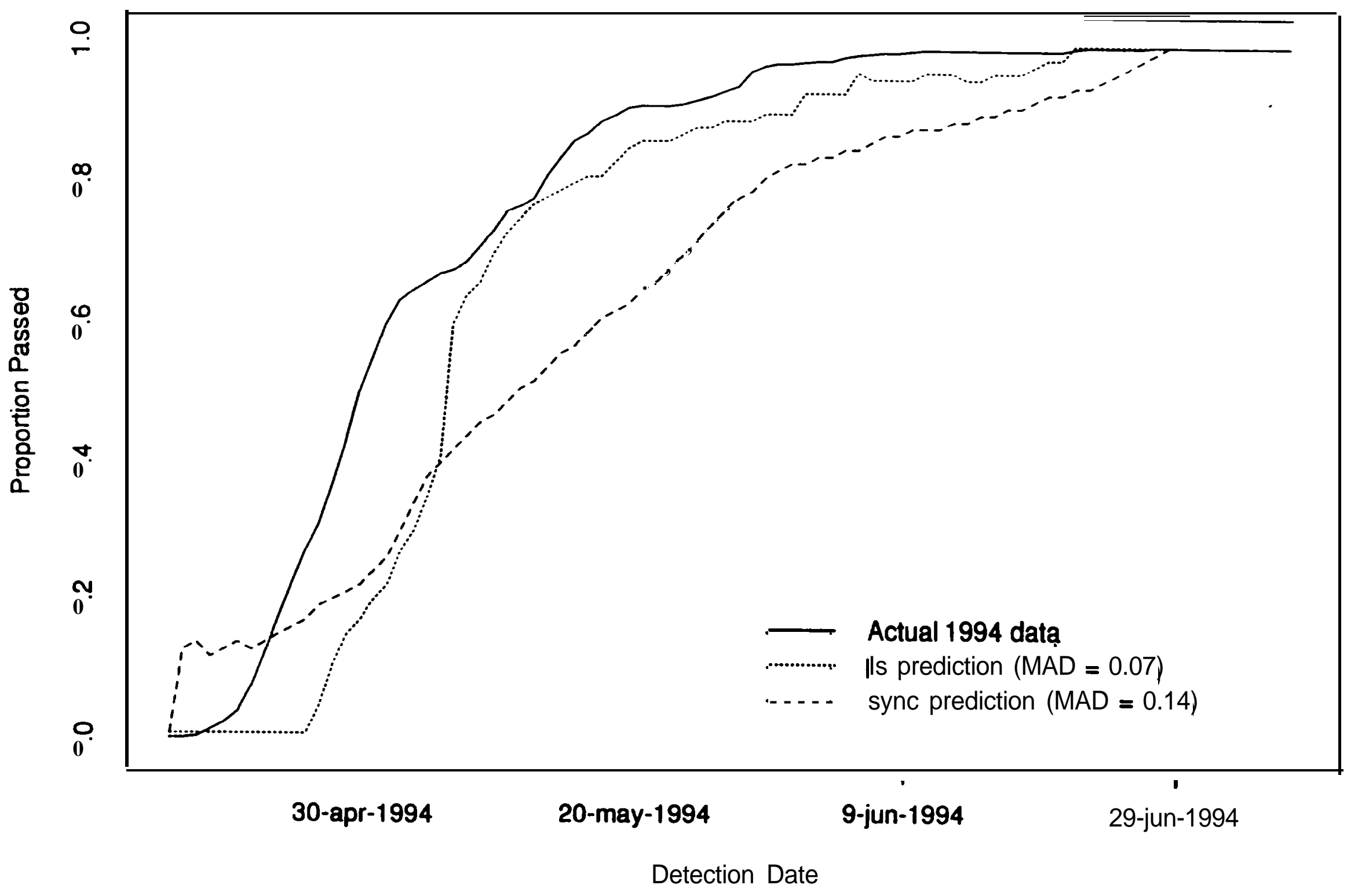




\section{PIT Forecaster: Bear Valley Creek}

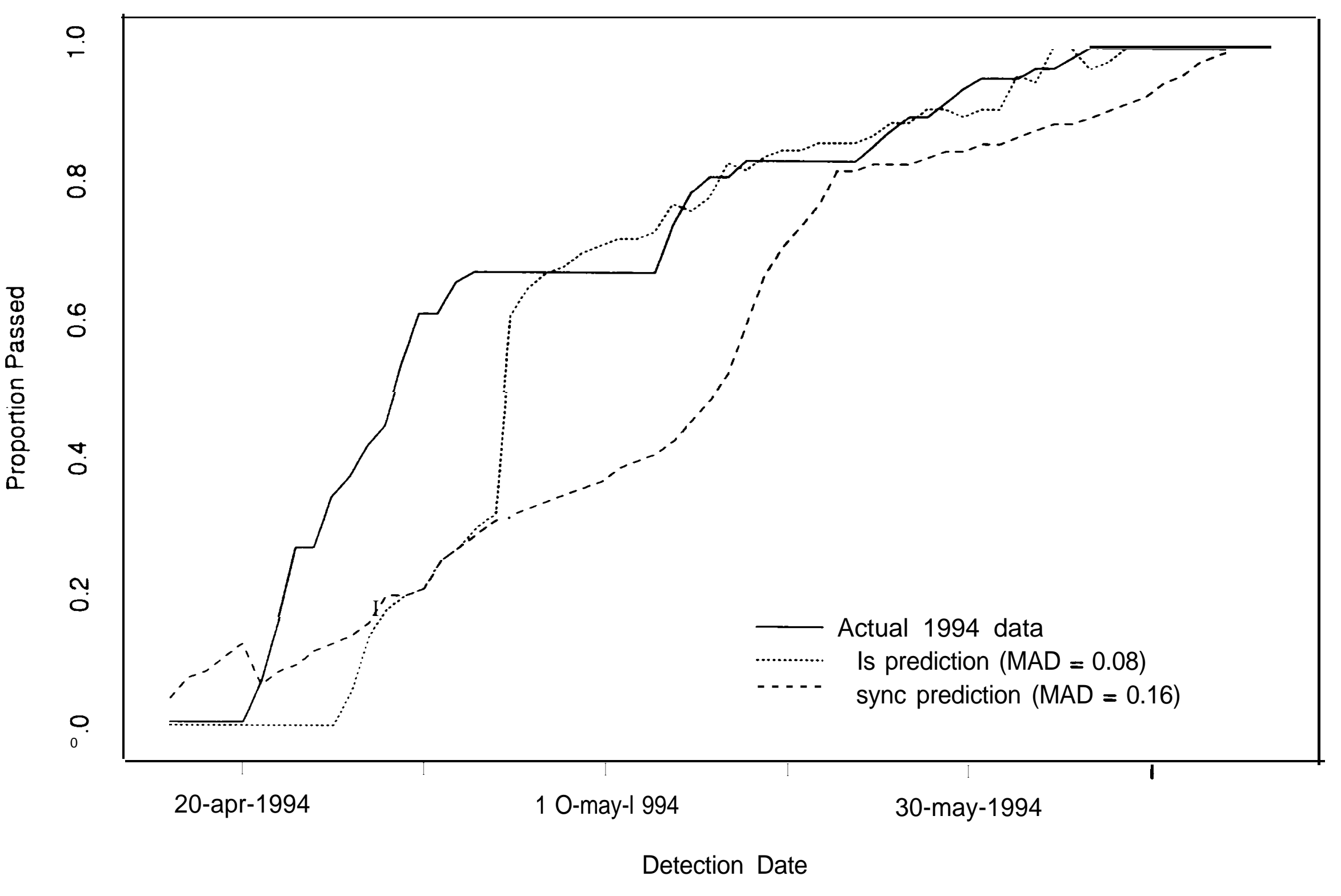




\section{PIT Forecaster: Big Creek}

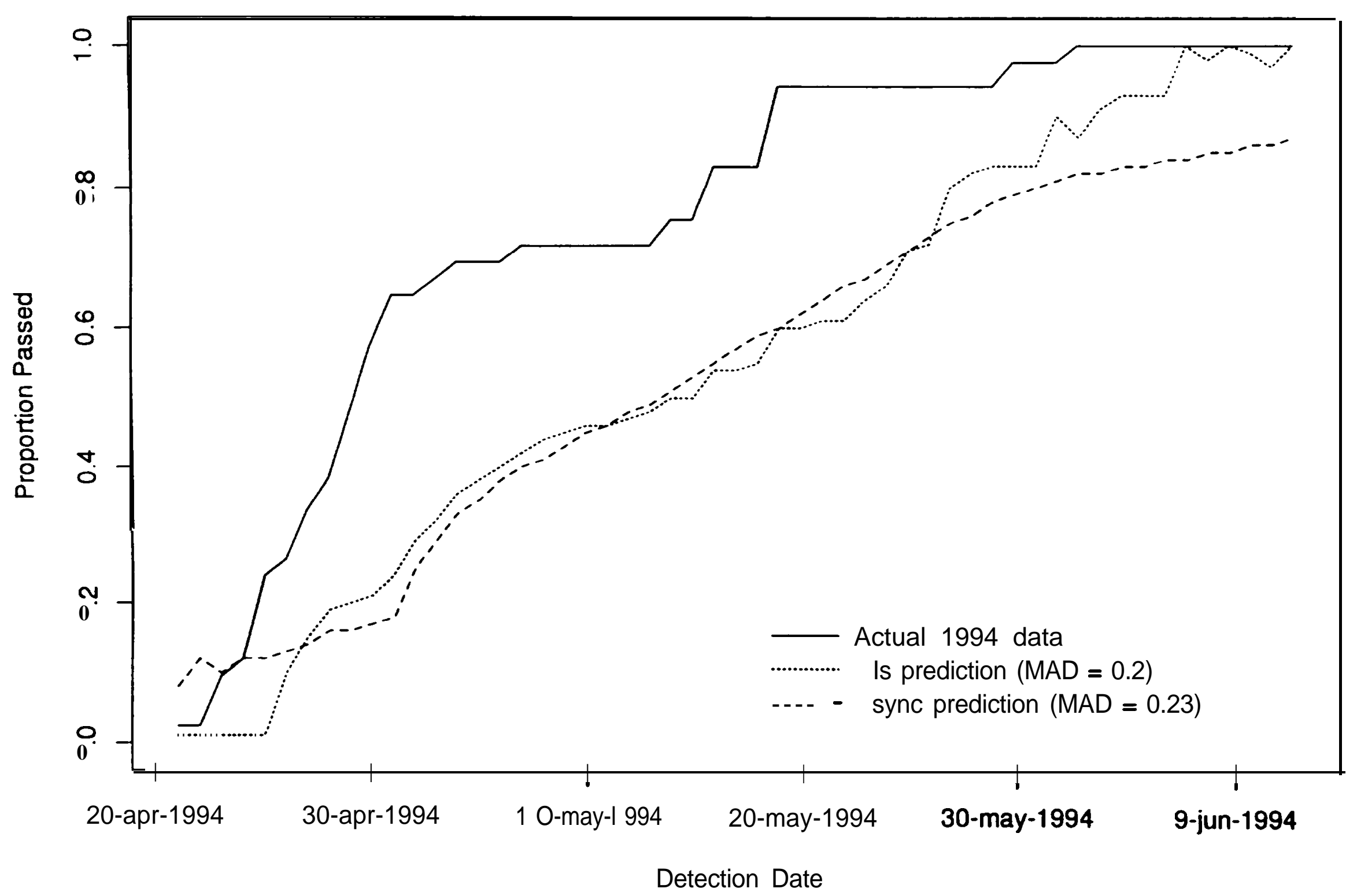




\section{PIT Forecaster: Catherine Creek}

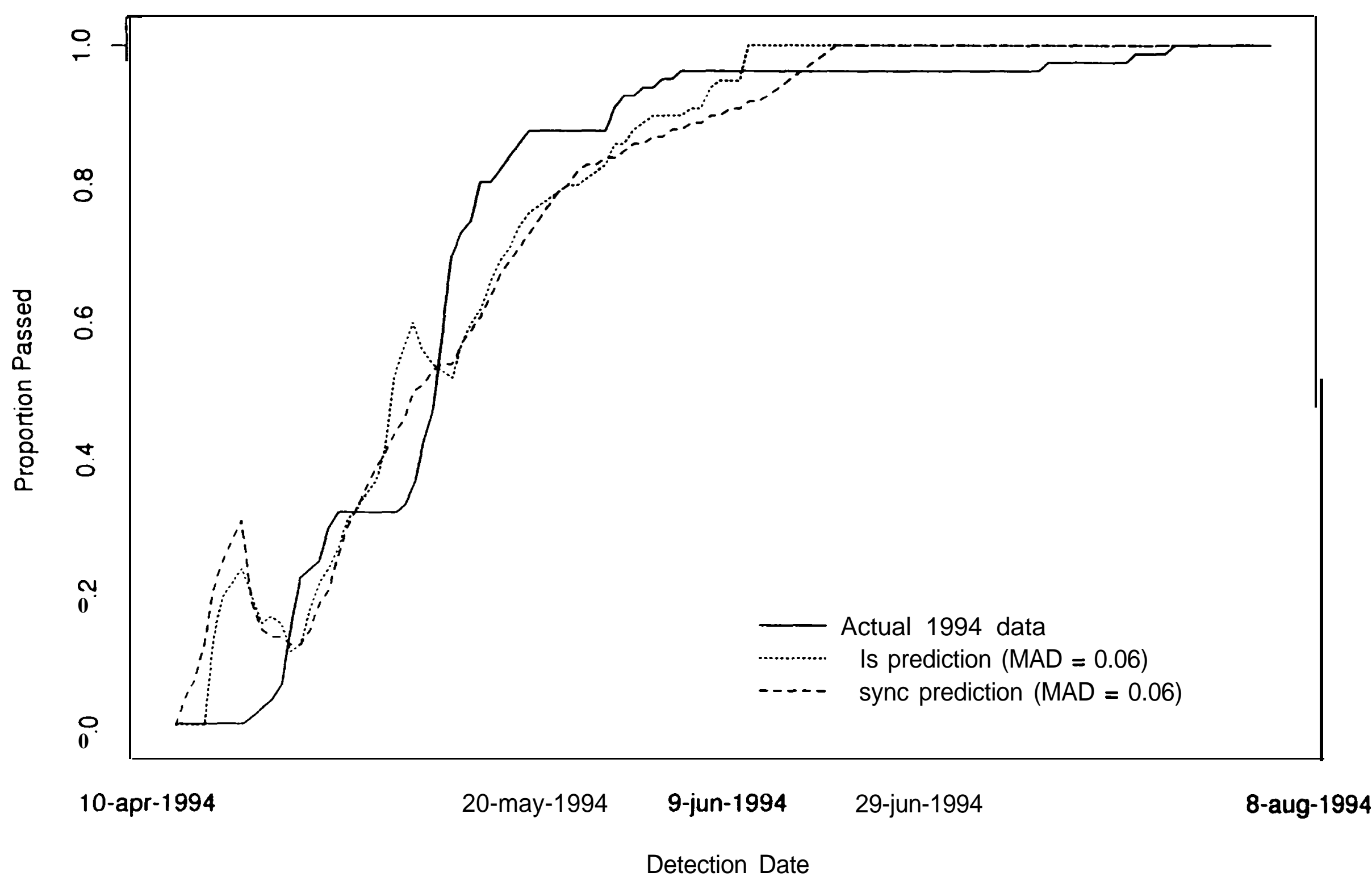




\section{PIT Forecaster: Elk Creek}

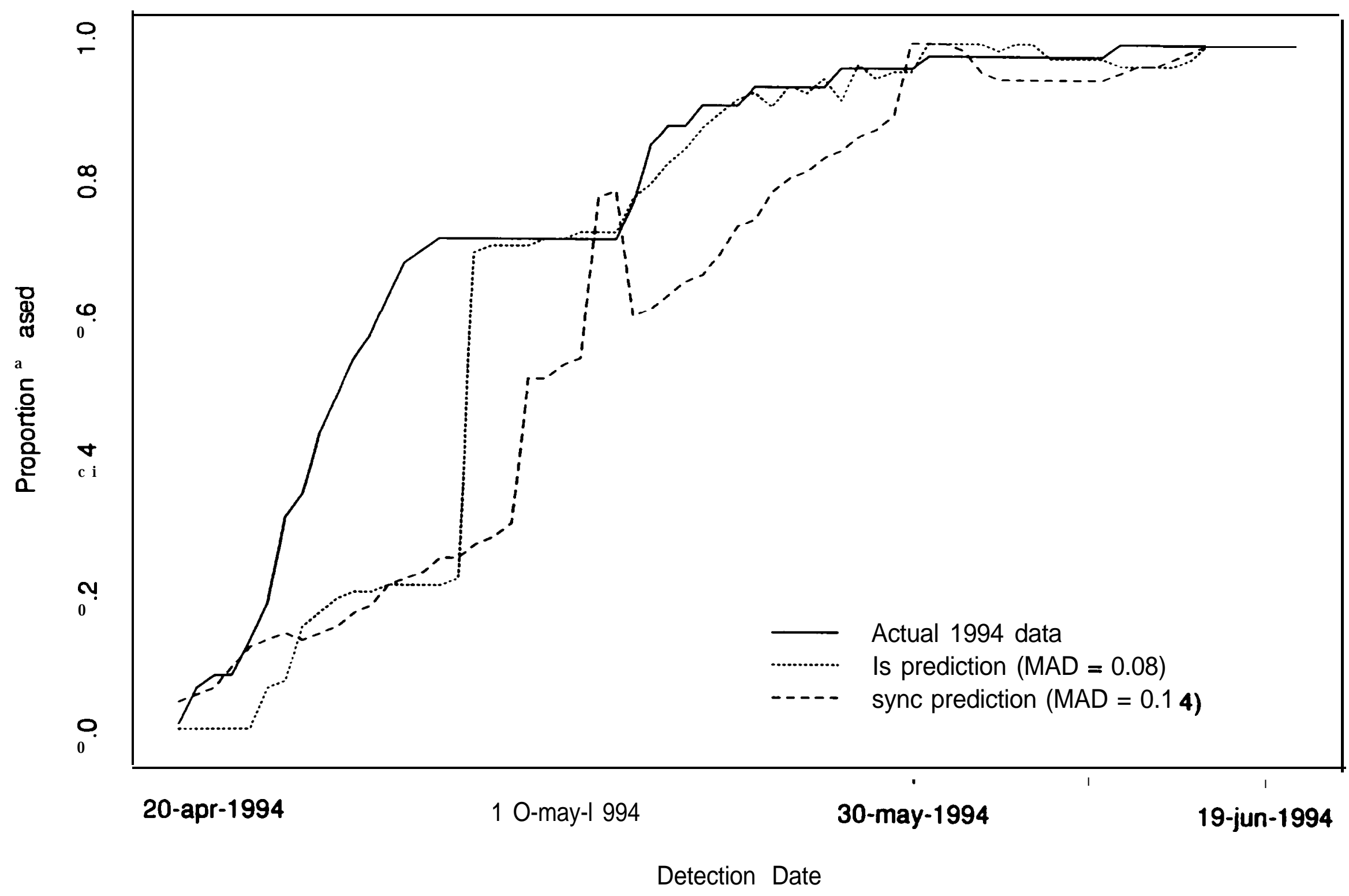




\section{PIT Forecaster: Imnaha River}

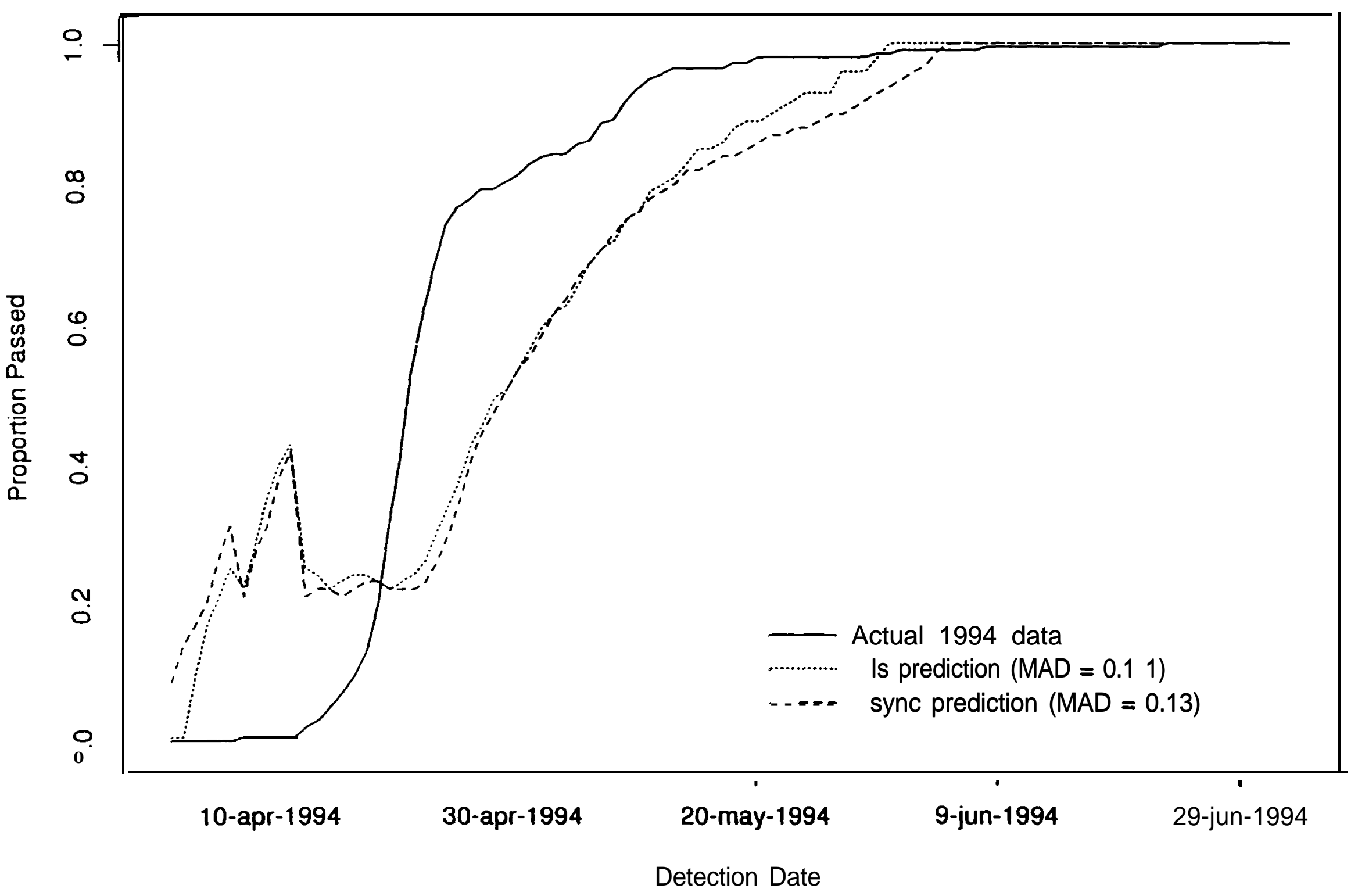




\section{PIT Forecaster: Lostine River}

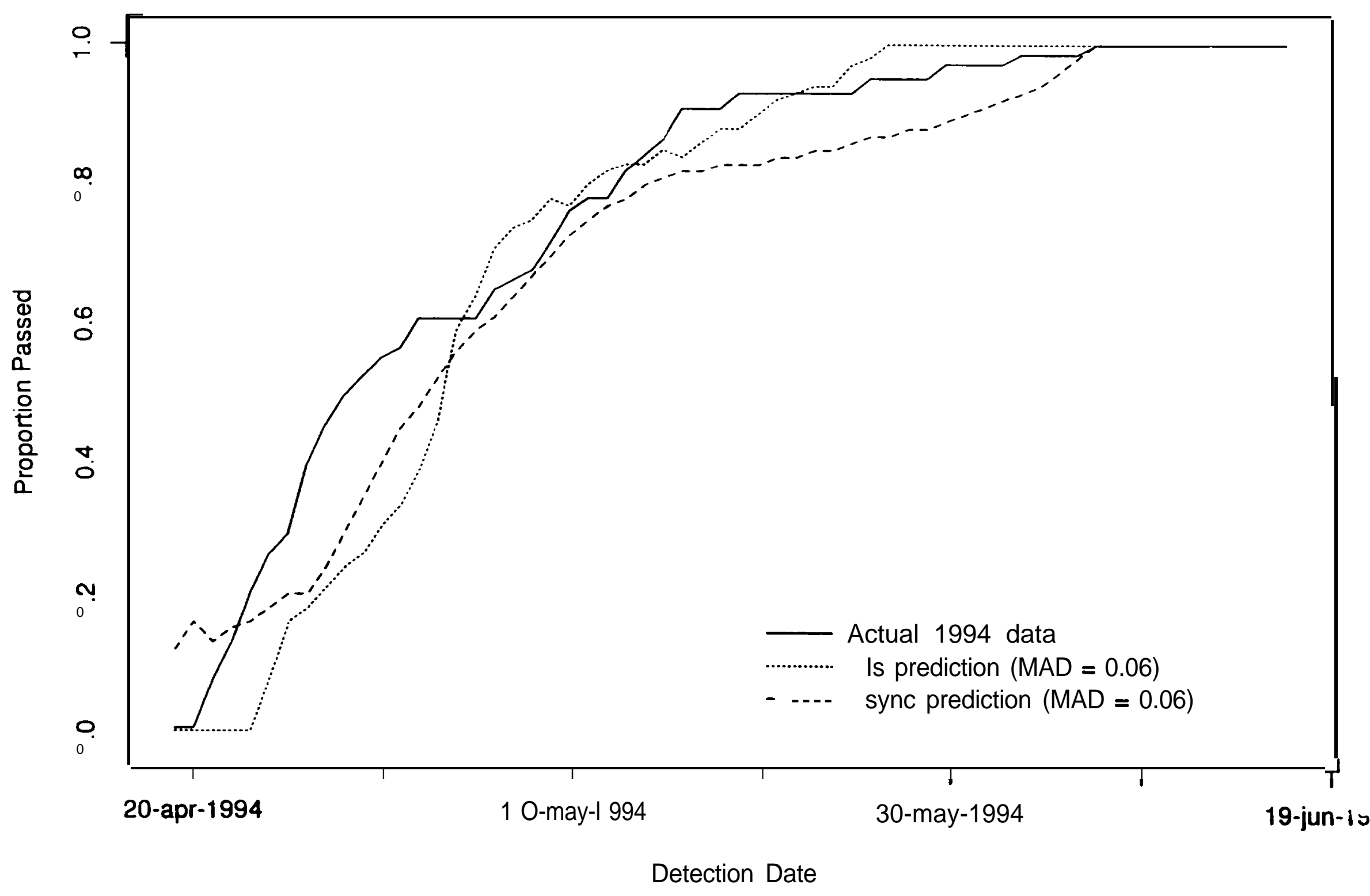




\section{PIT Forecaster: Marsh Creek}

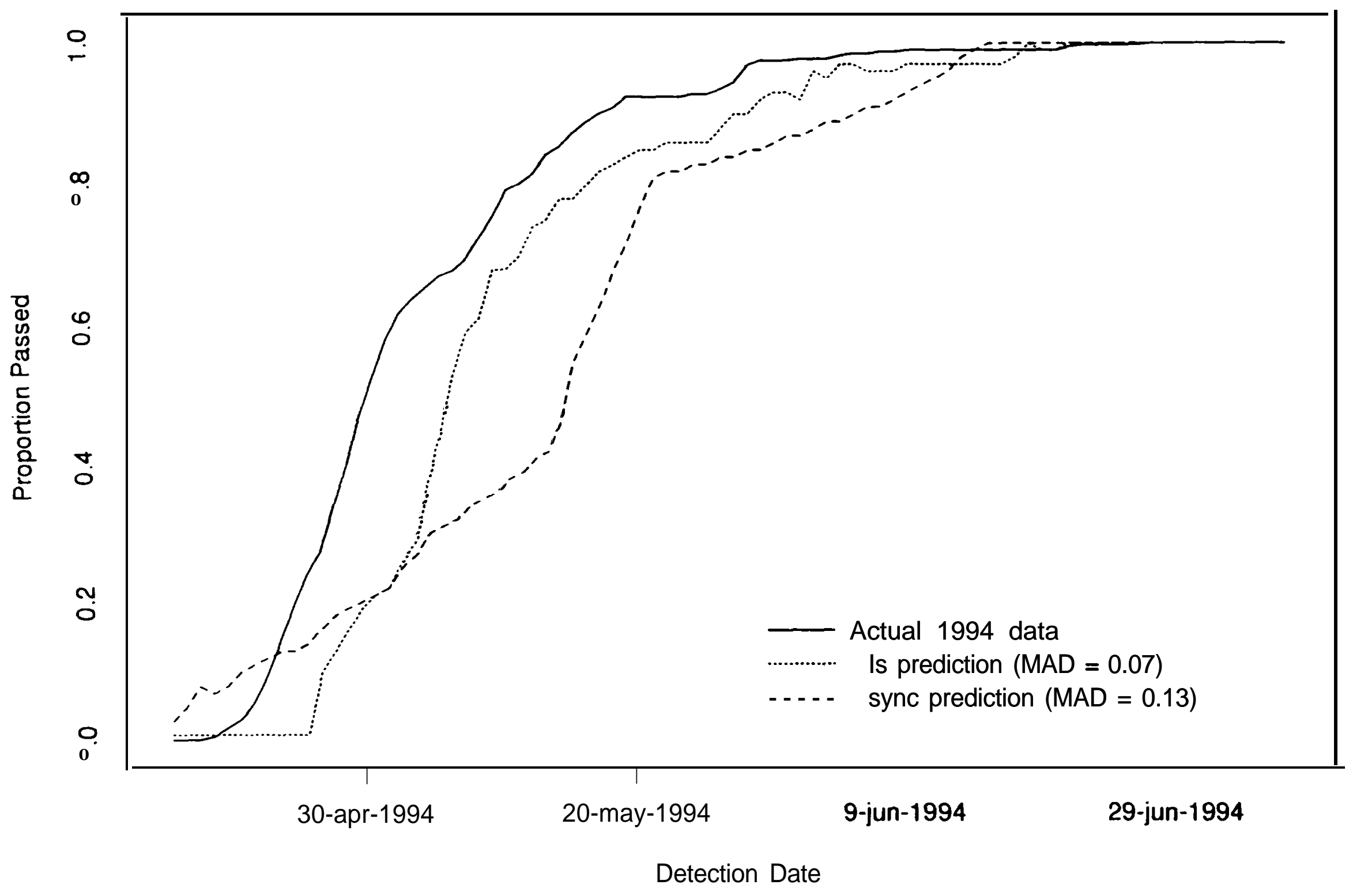




\section{PIT Forecaster: Salmon River}

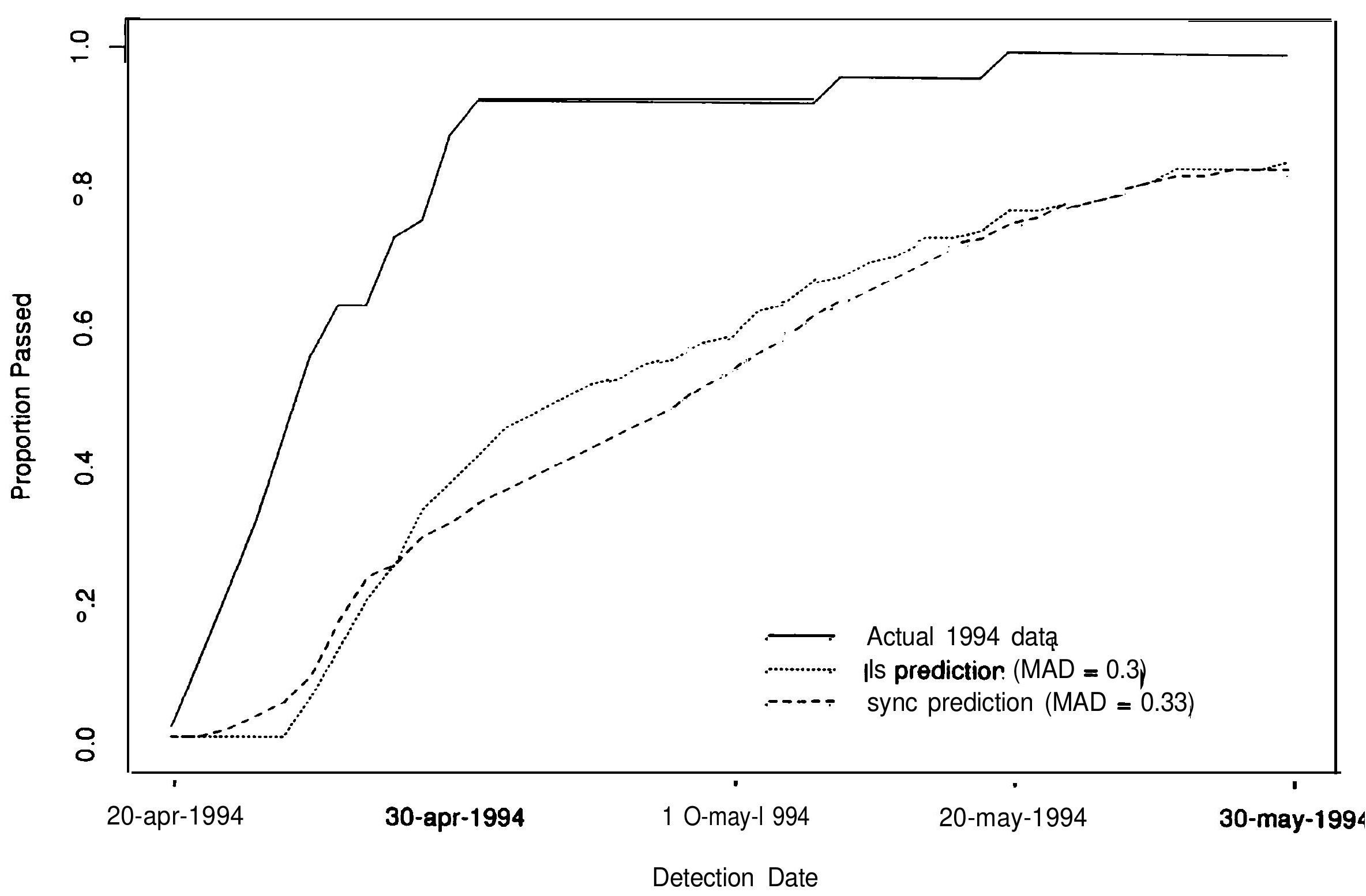




\section{PIT Forecaster: Salmon River East Fork}

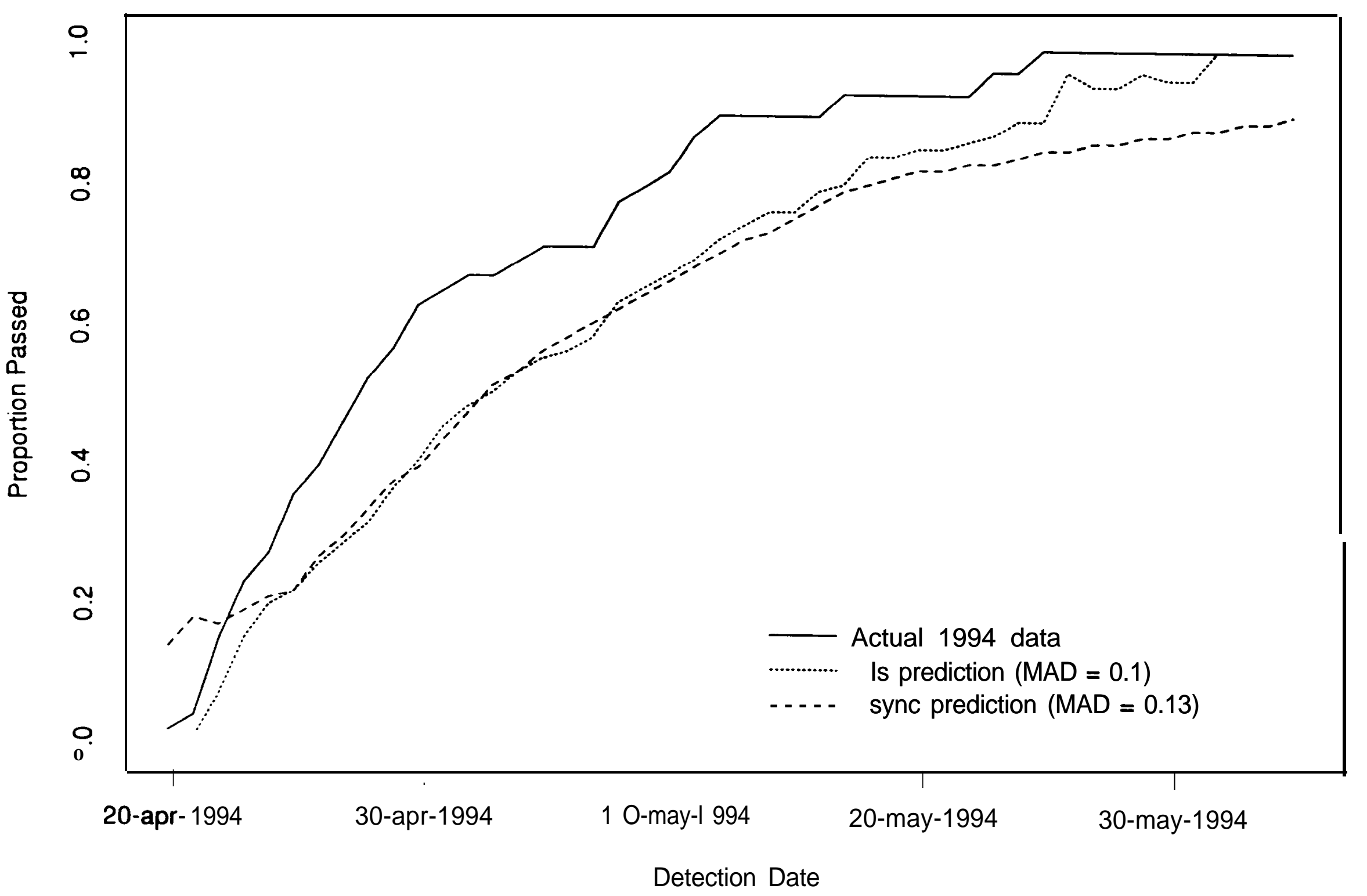




\section{PIT Forecaster: Salmon River South Fork}

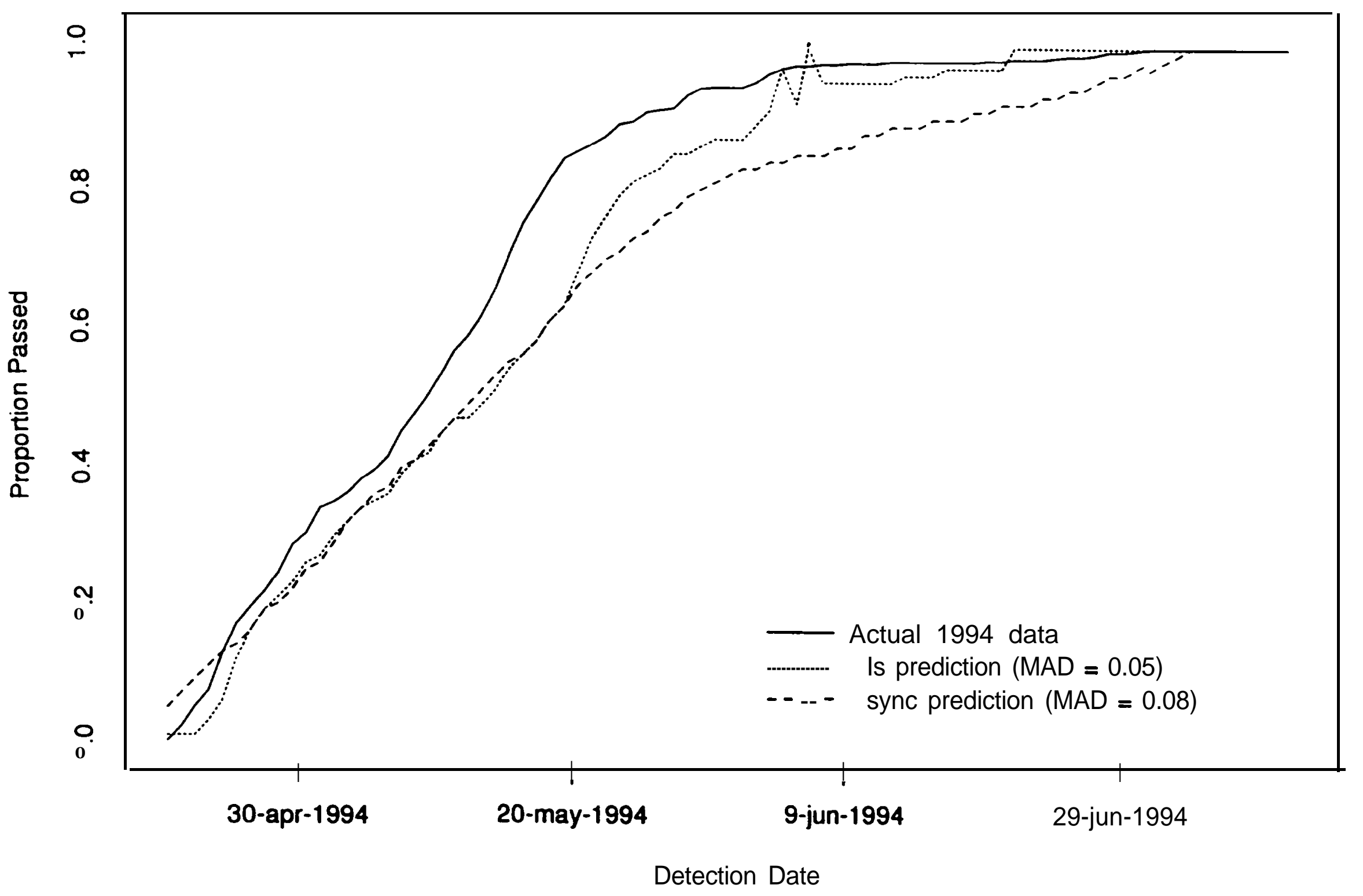




\section{PIT Forecaster: Secesh River}

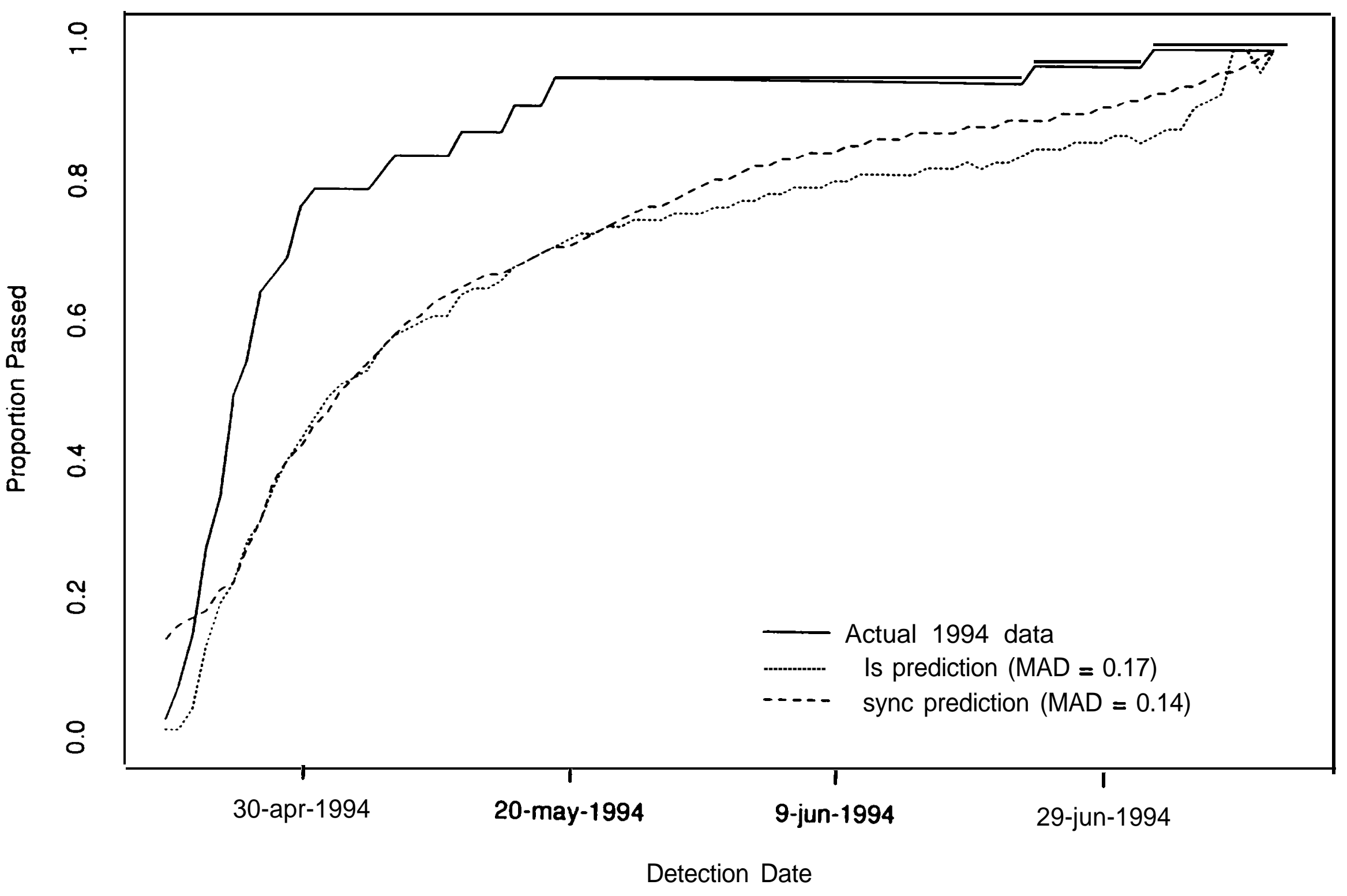




\section{PIT Forecaster: Valley Creek}

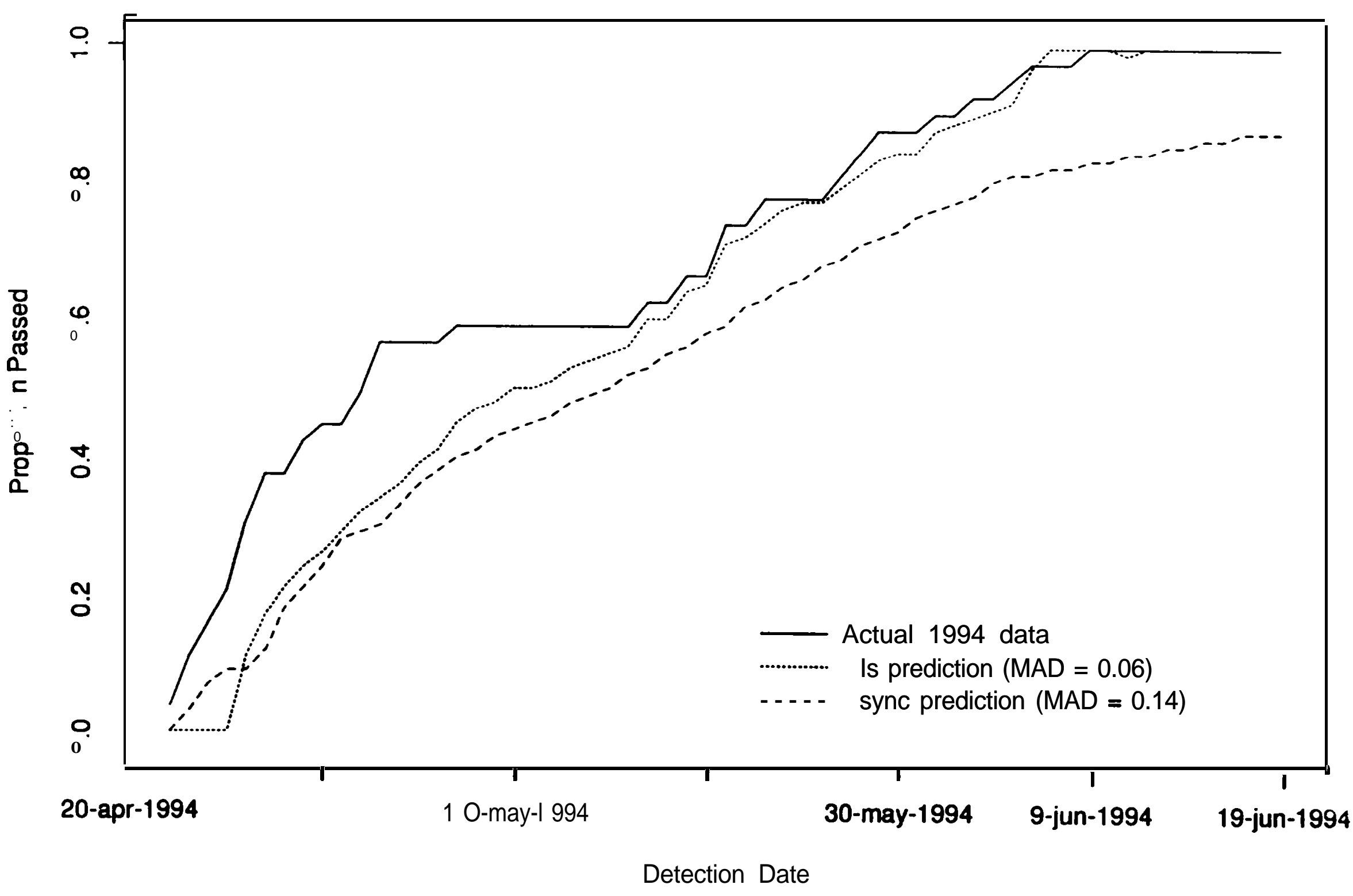


Alternative M ethod \#1 Plots 


\section{Alternative Method \#1: Pahsimeroi}

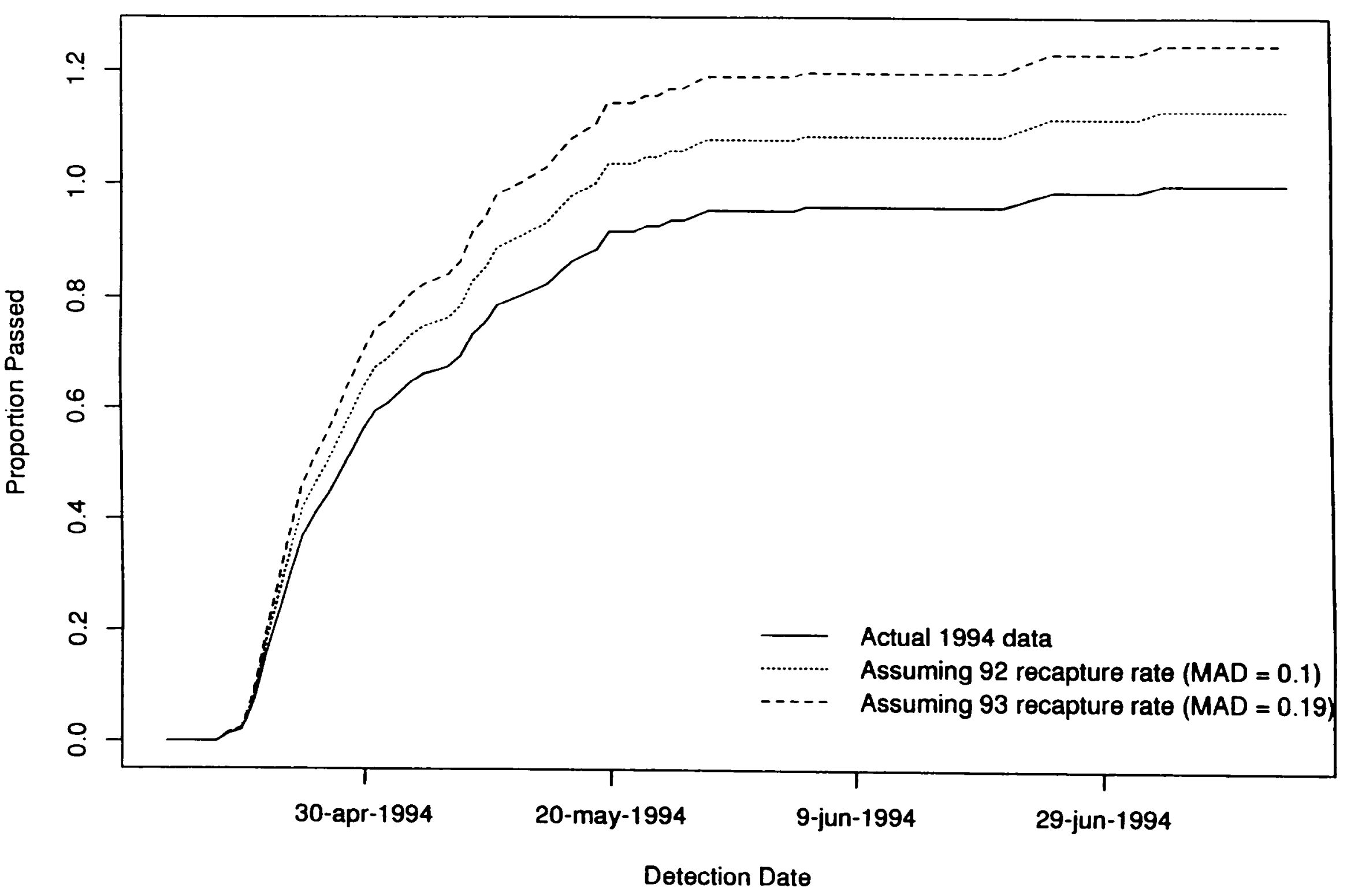




\section{Alternative Method \#1: Upper Salmon}

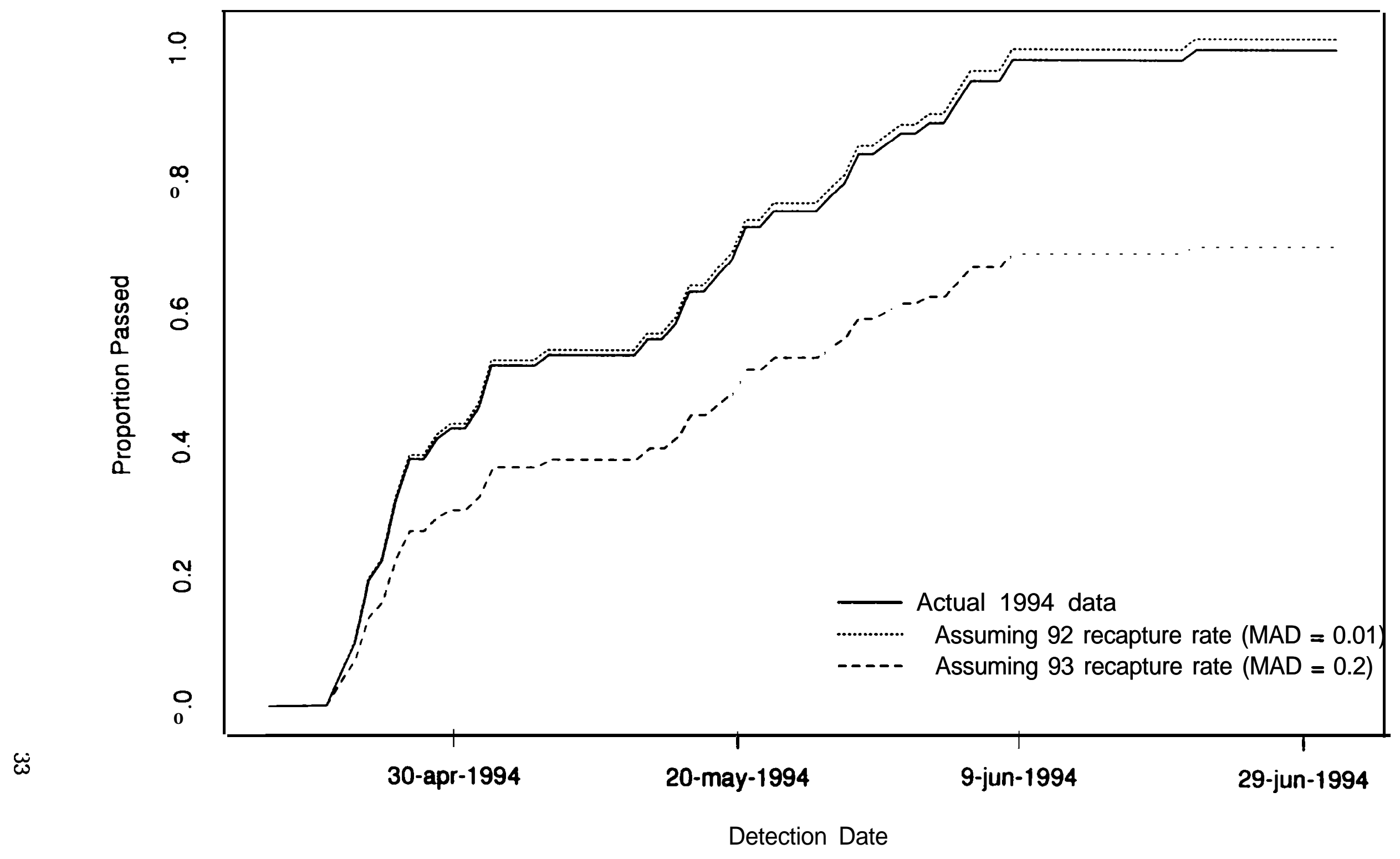




\section{Alternative Method \#1: South Fork Salmon}

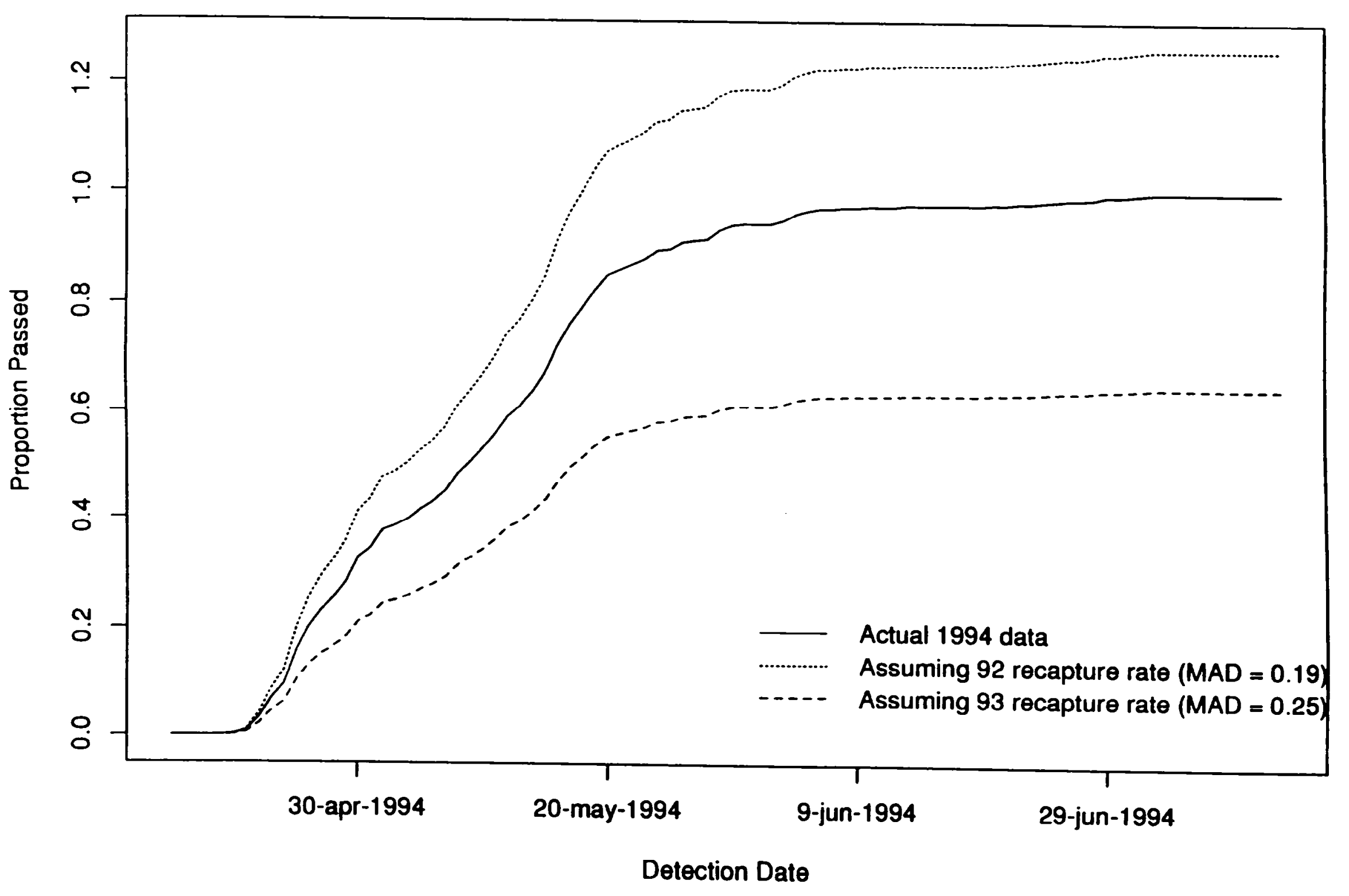




\section{Alternative Method \#1: Upper Middle Fork Salmon}

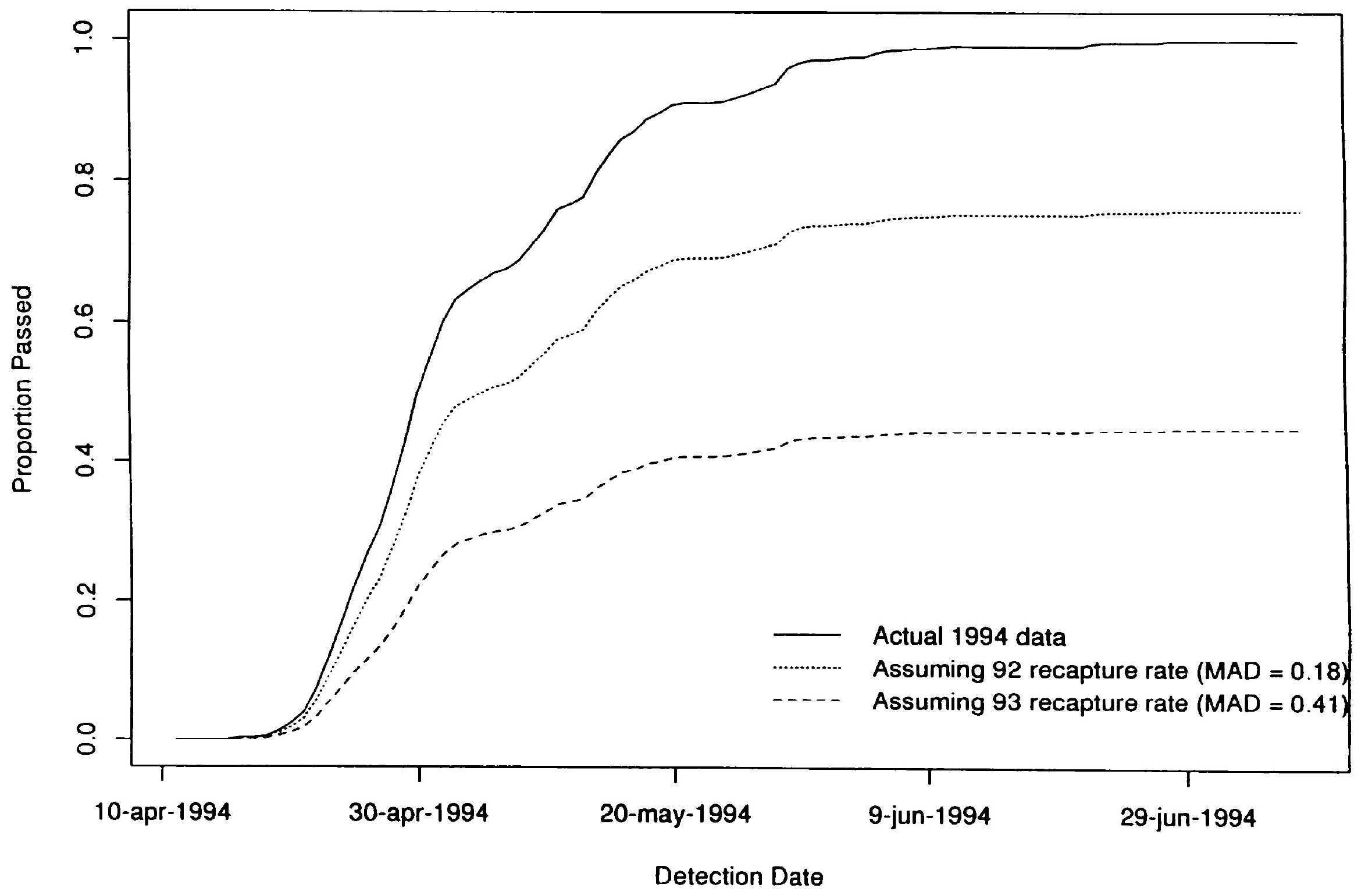




\section{Alternative Method \#1: Bear Valley Creek}

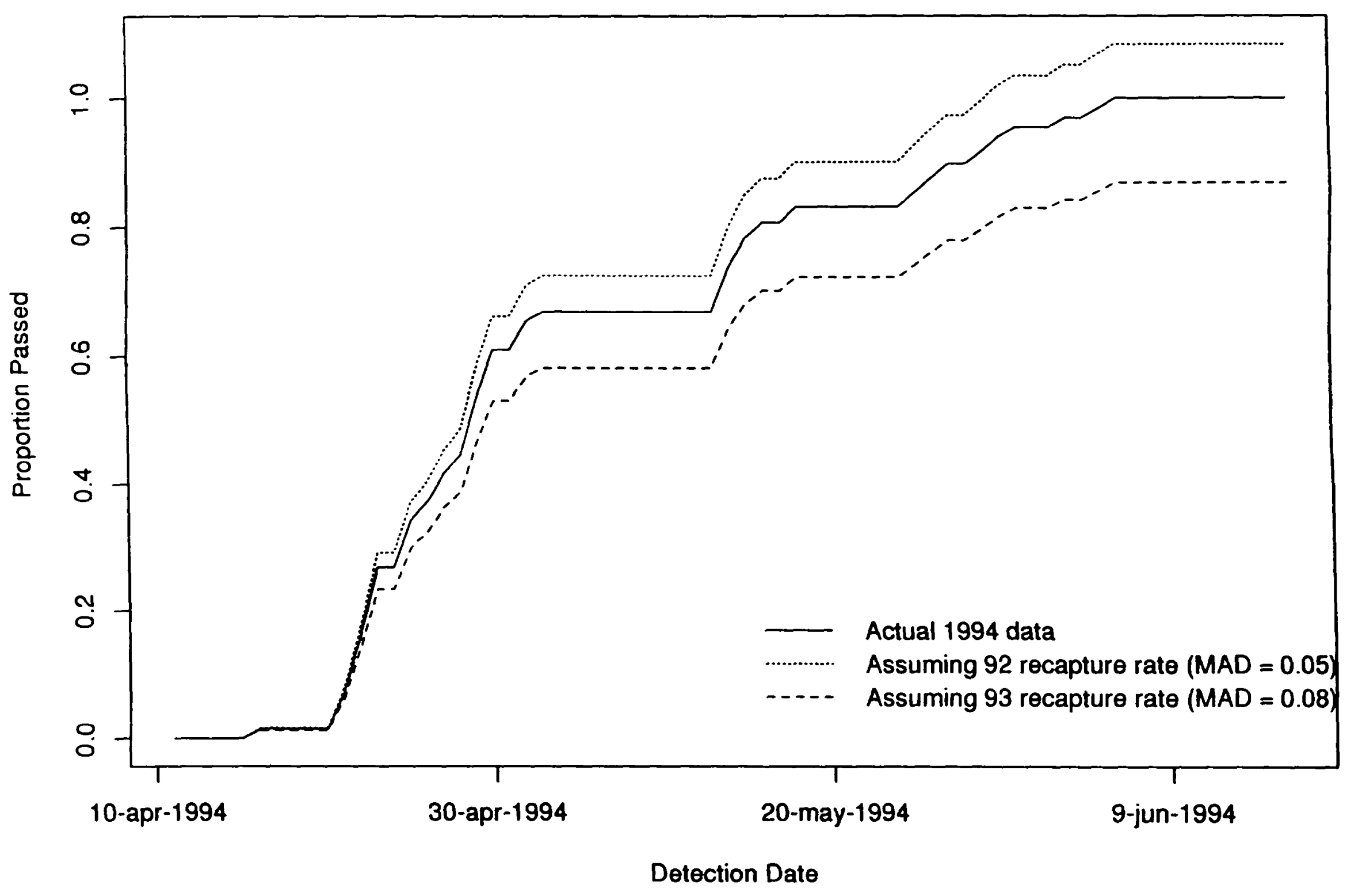




\section{Alternative Method \#1: Big Creek}

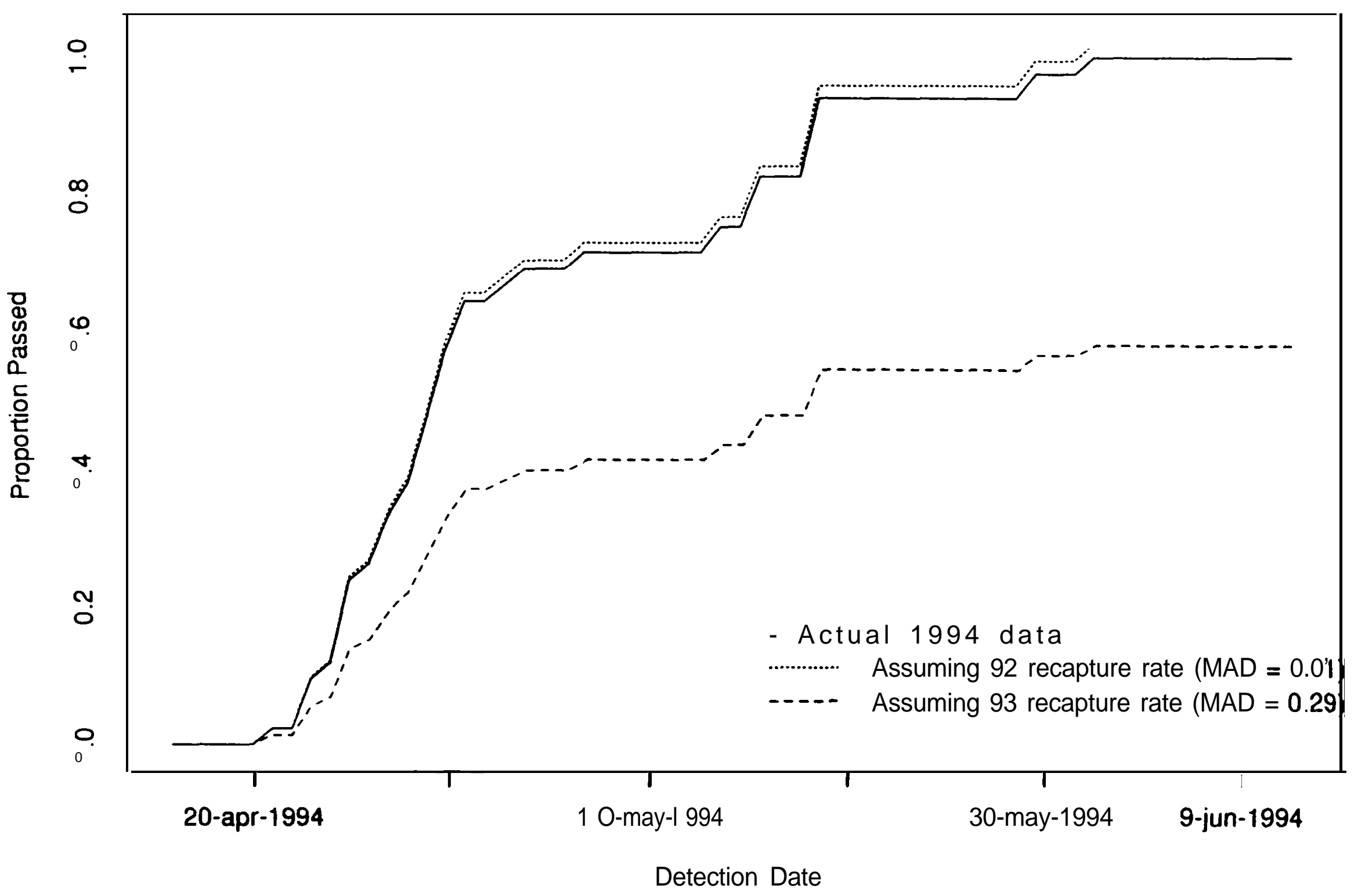




\section{Alternative Method \#1: Catherine Creek}

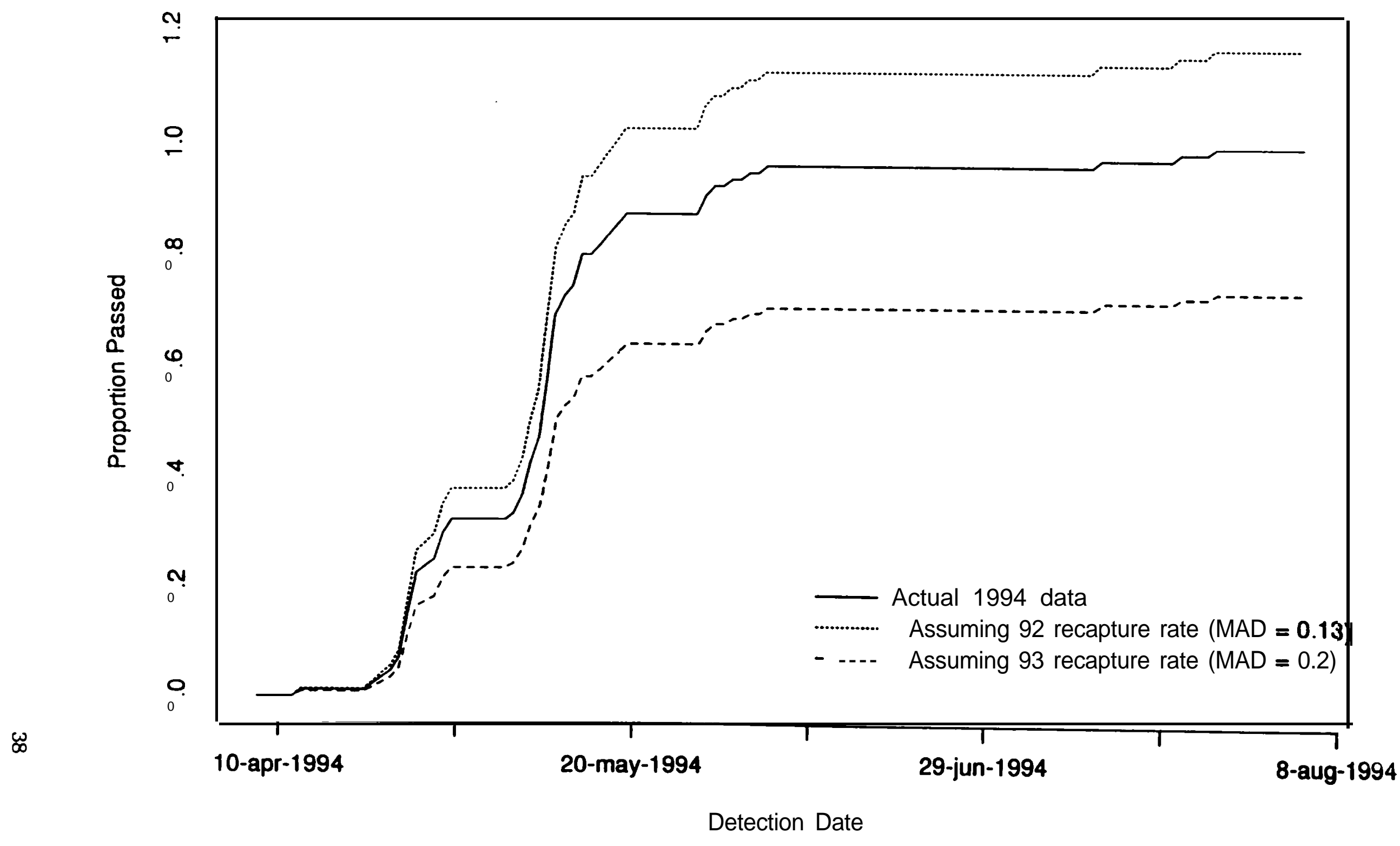




\section{Alternative Method \#1: Elk Creek}

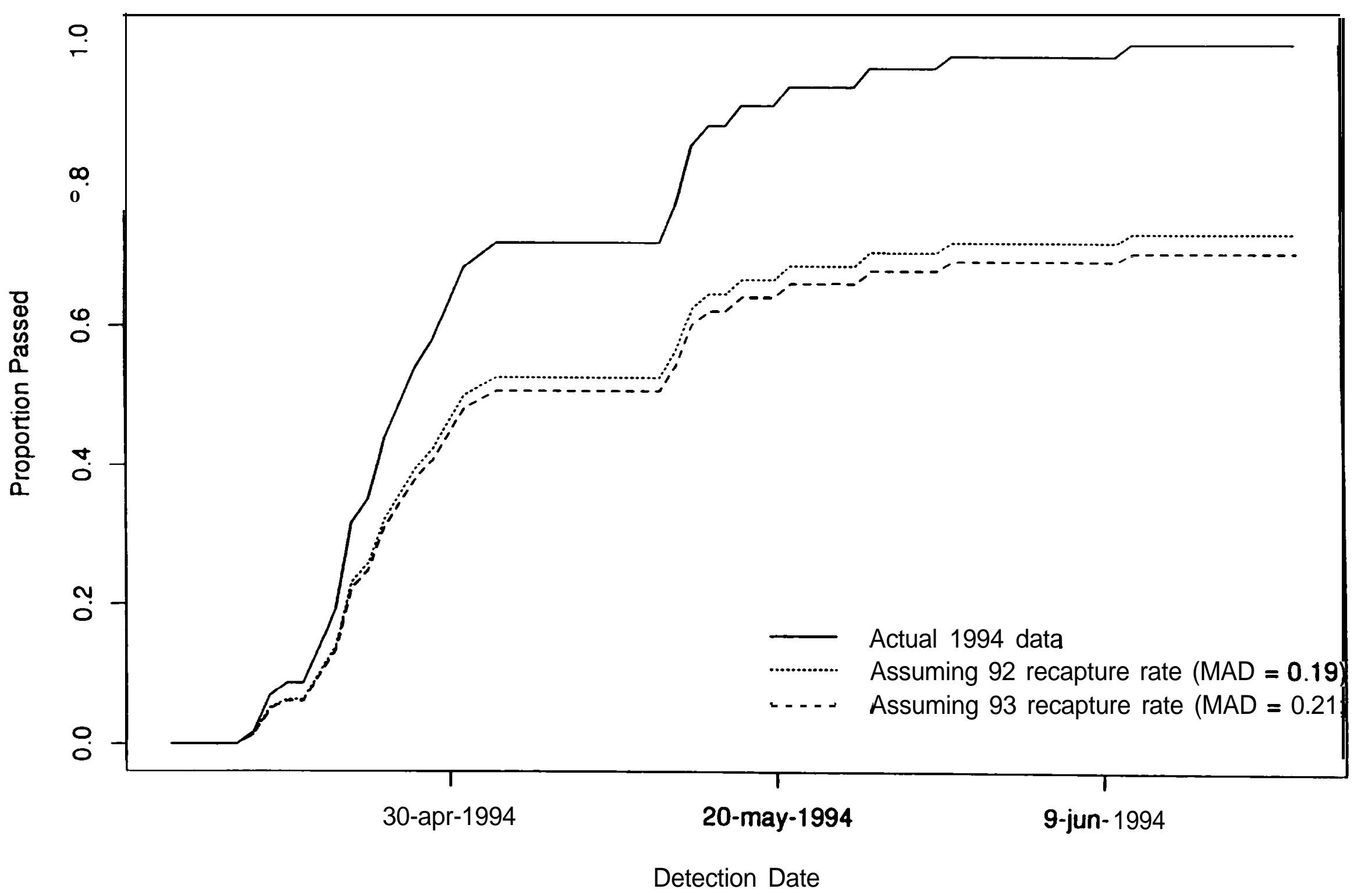




\section{Alternative Method \#1: Imnaha River}

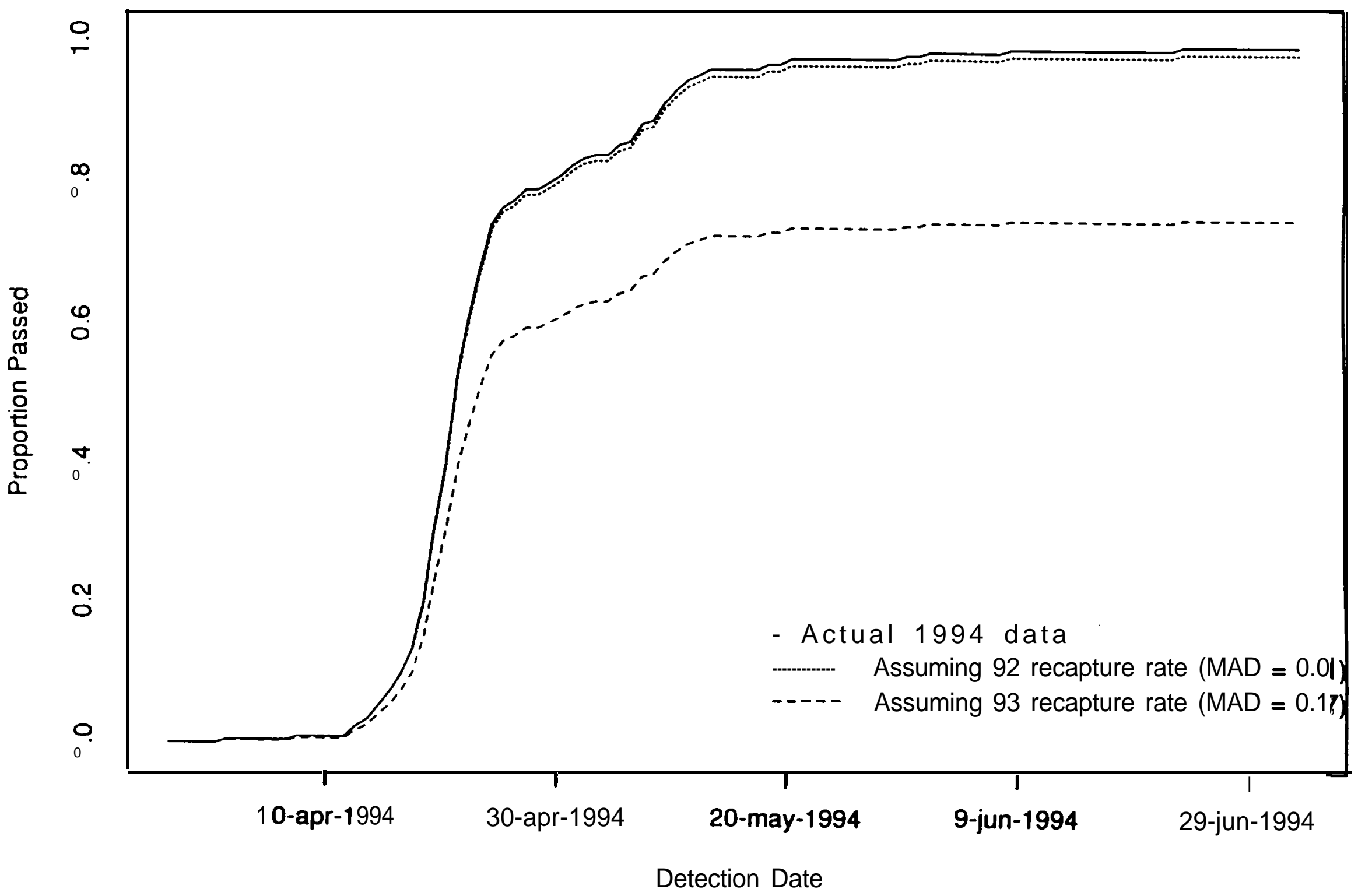




\section{Alternative Method \#1: Lostine River}

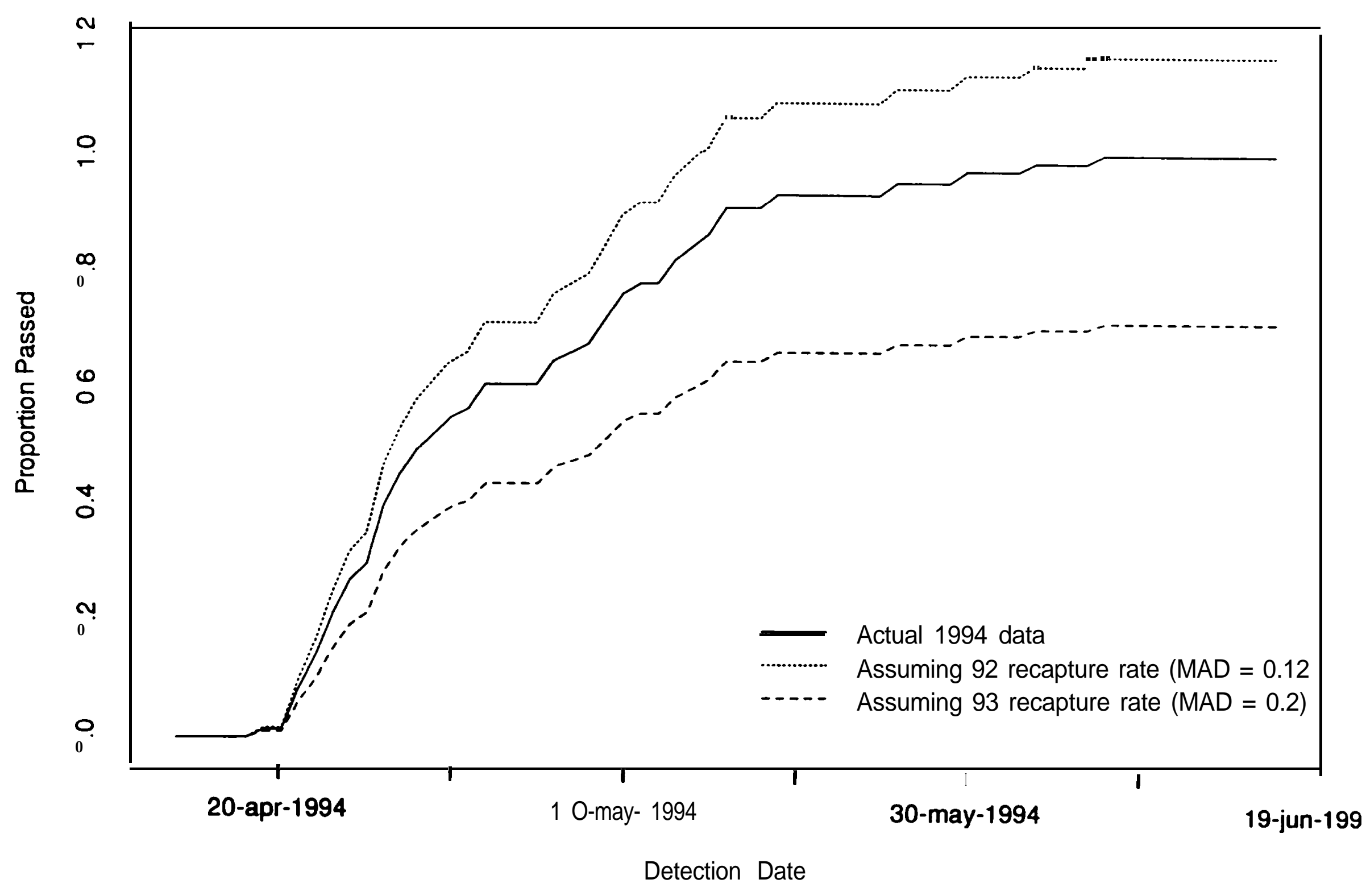




\section{Alternative Method \#1: Marsh Creek}

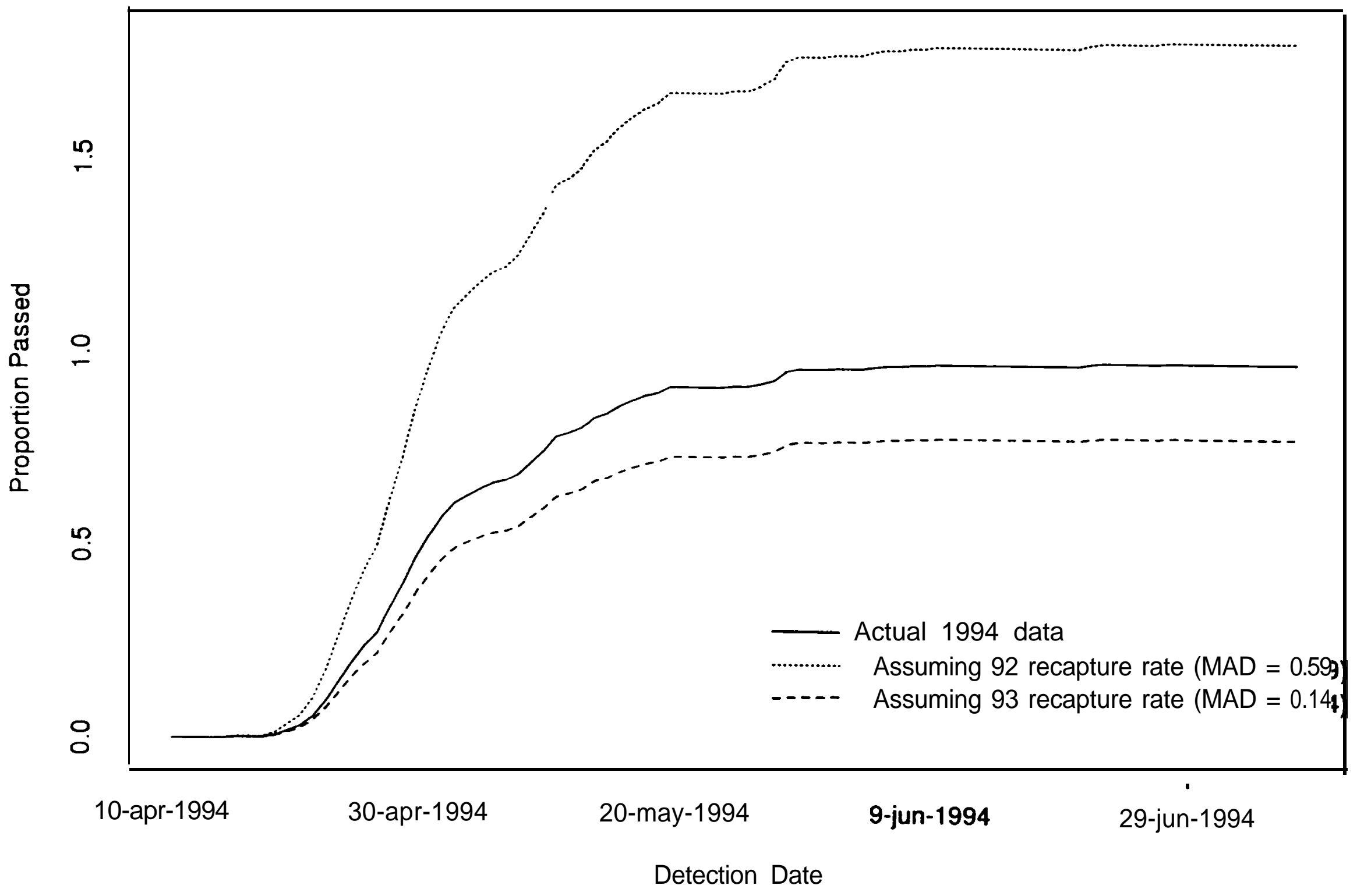




\section{Alternative Method \#1: Salmon River}

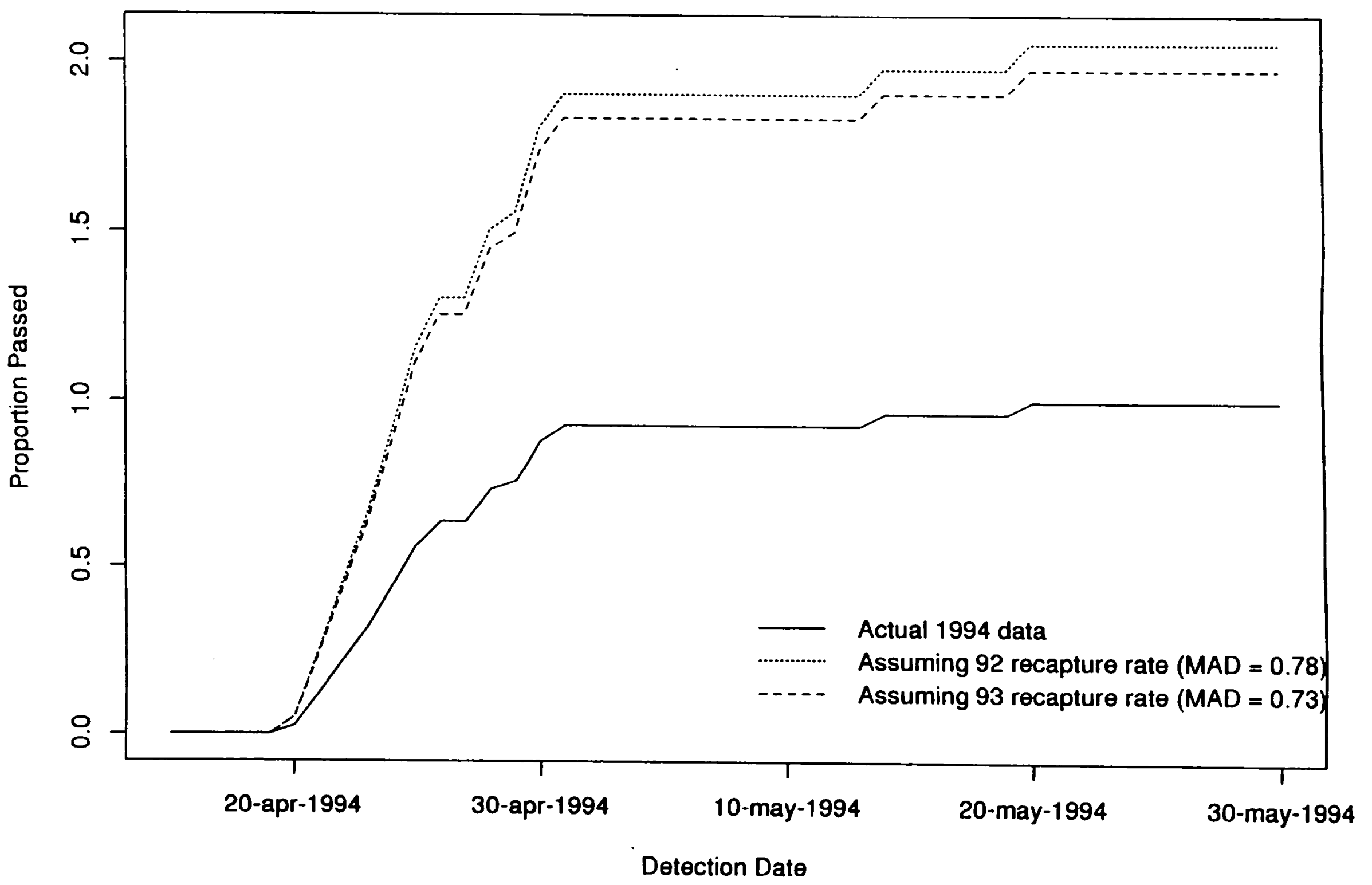




\section{Alternative Method \#1: Salmon River East Fork}

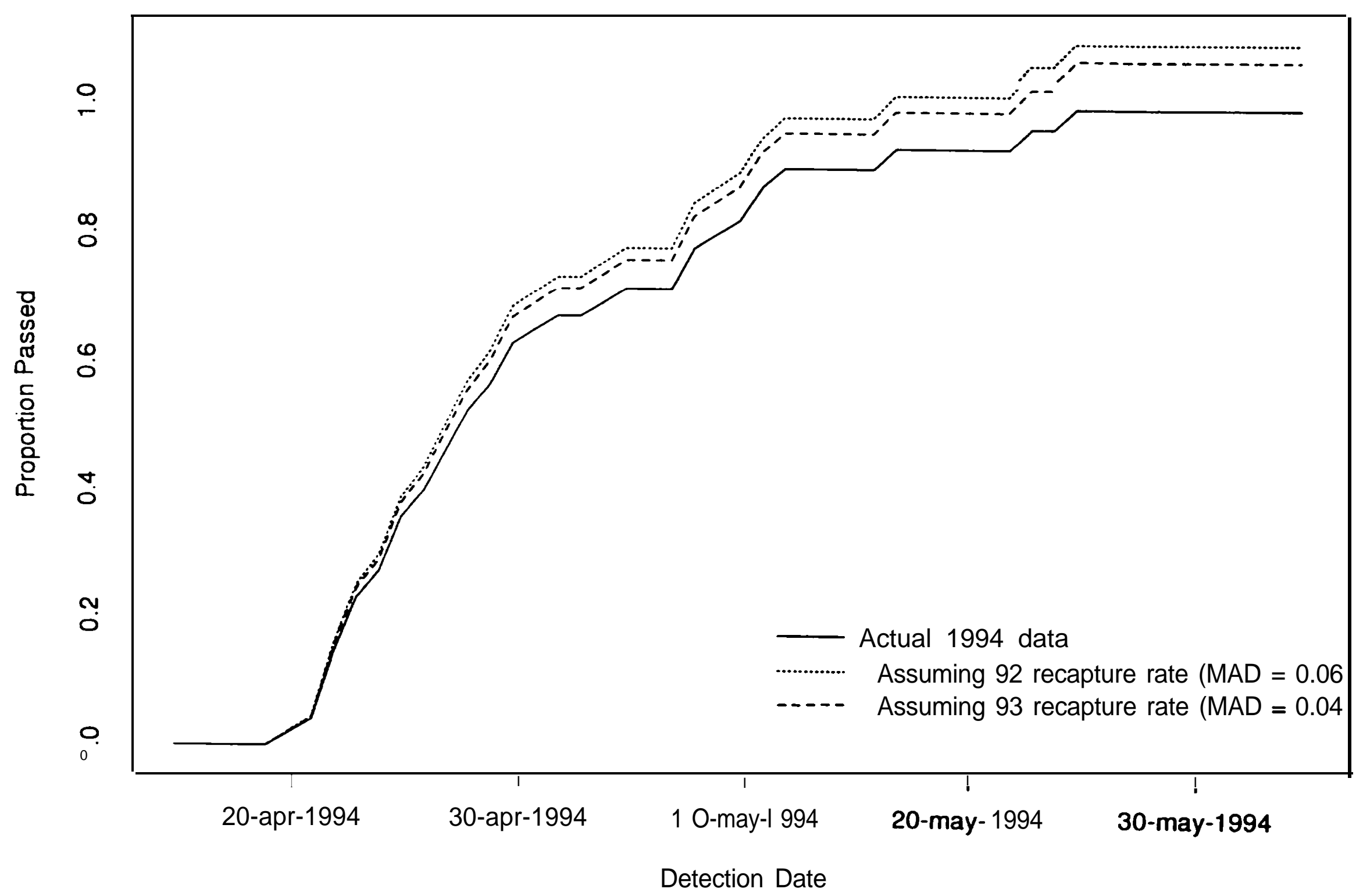




\section{Alternative Method \#1 : Salmon River South Fork}

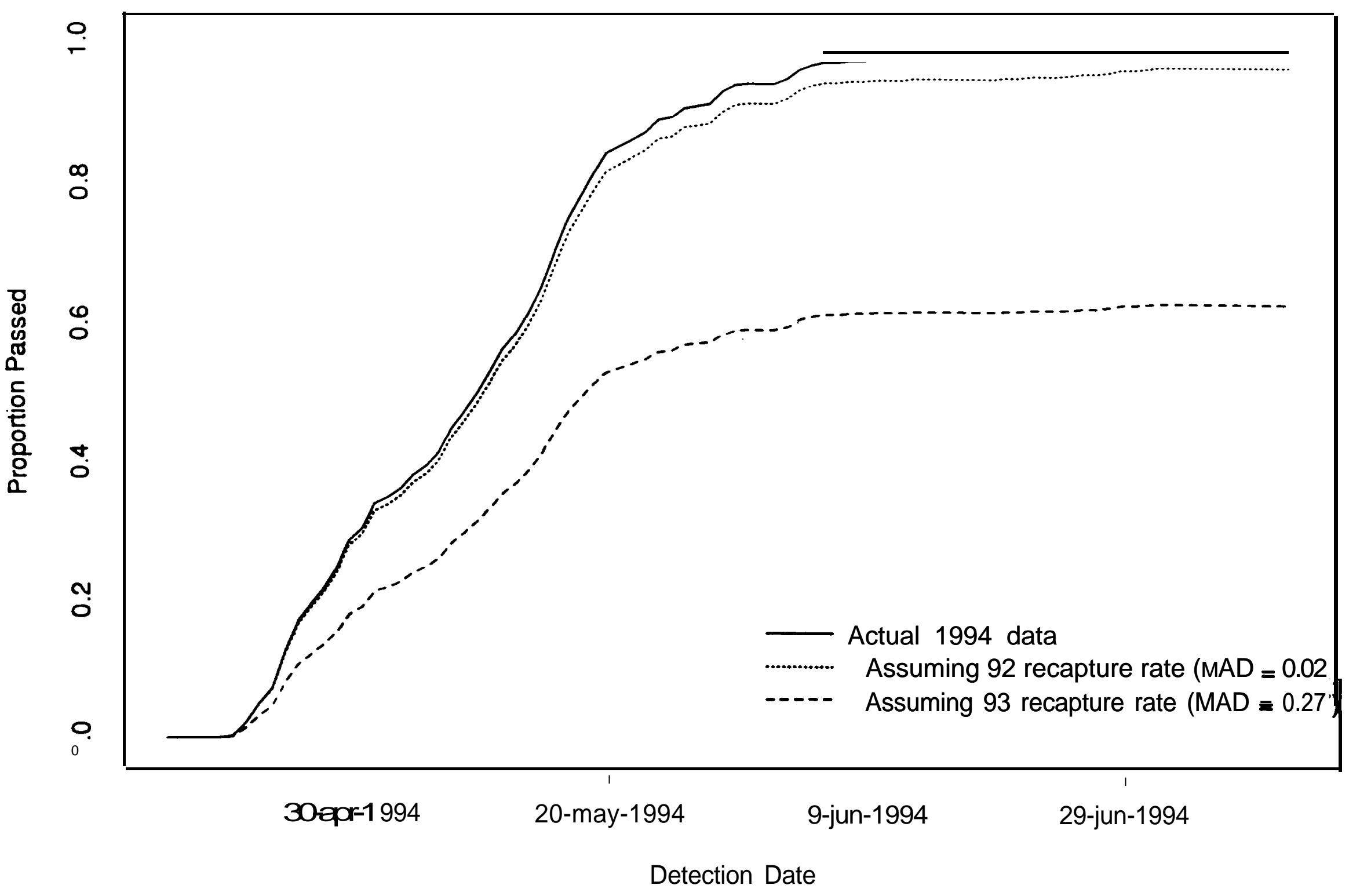


Alternative Method \#1: Secesh River

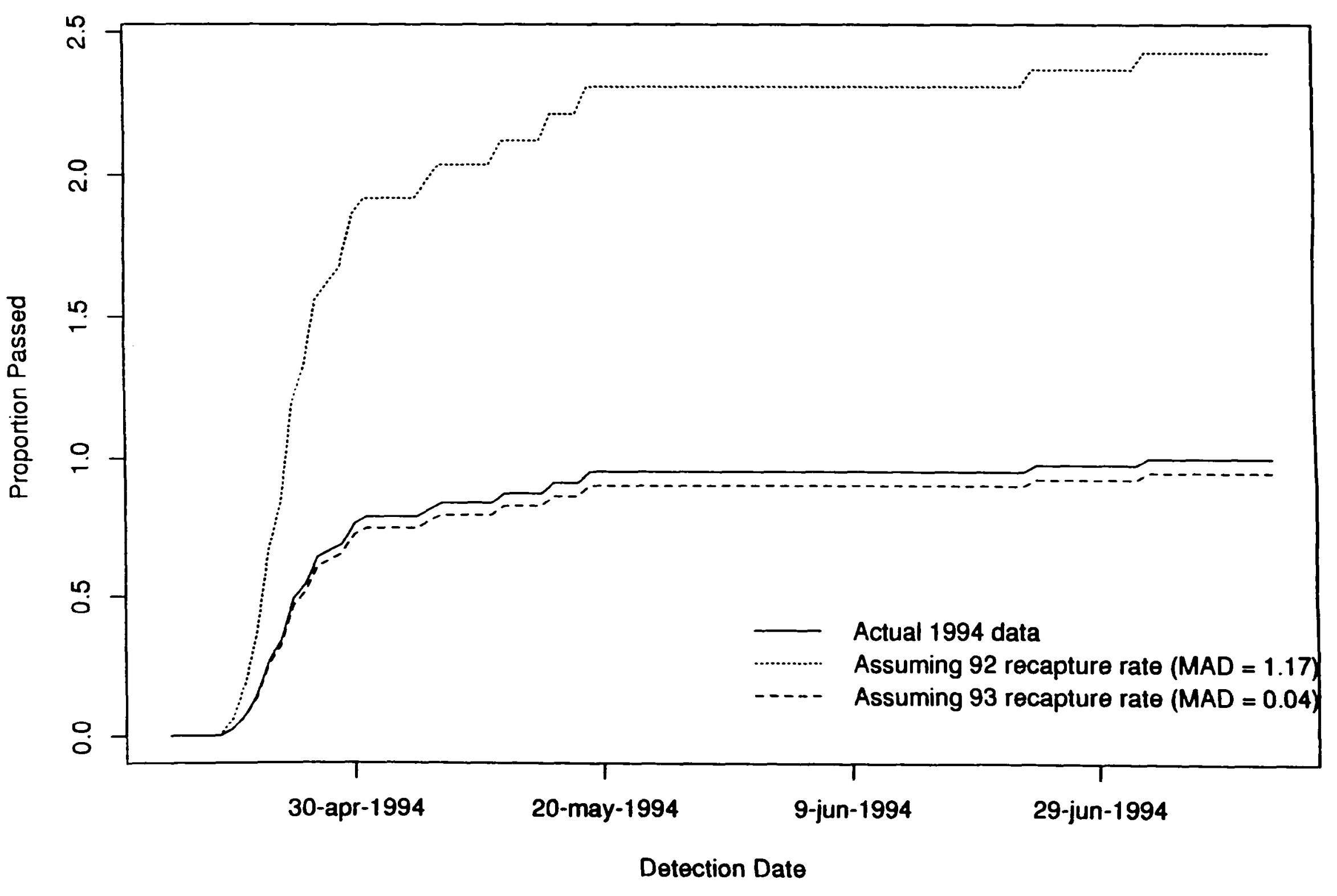




\section{Alternative Method \#1: Valley Creek}

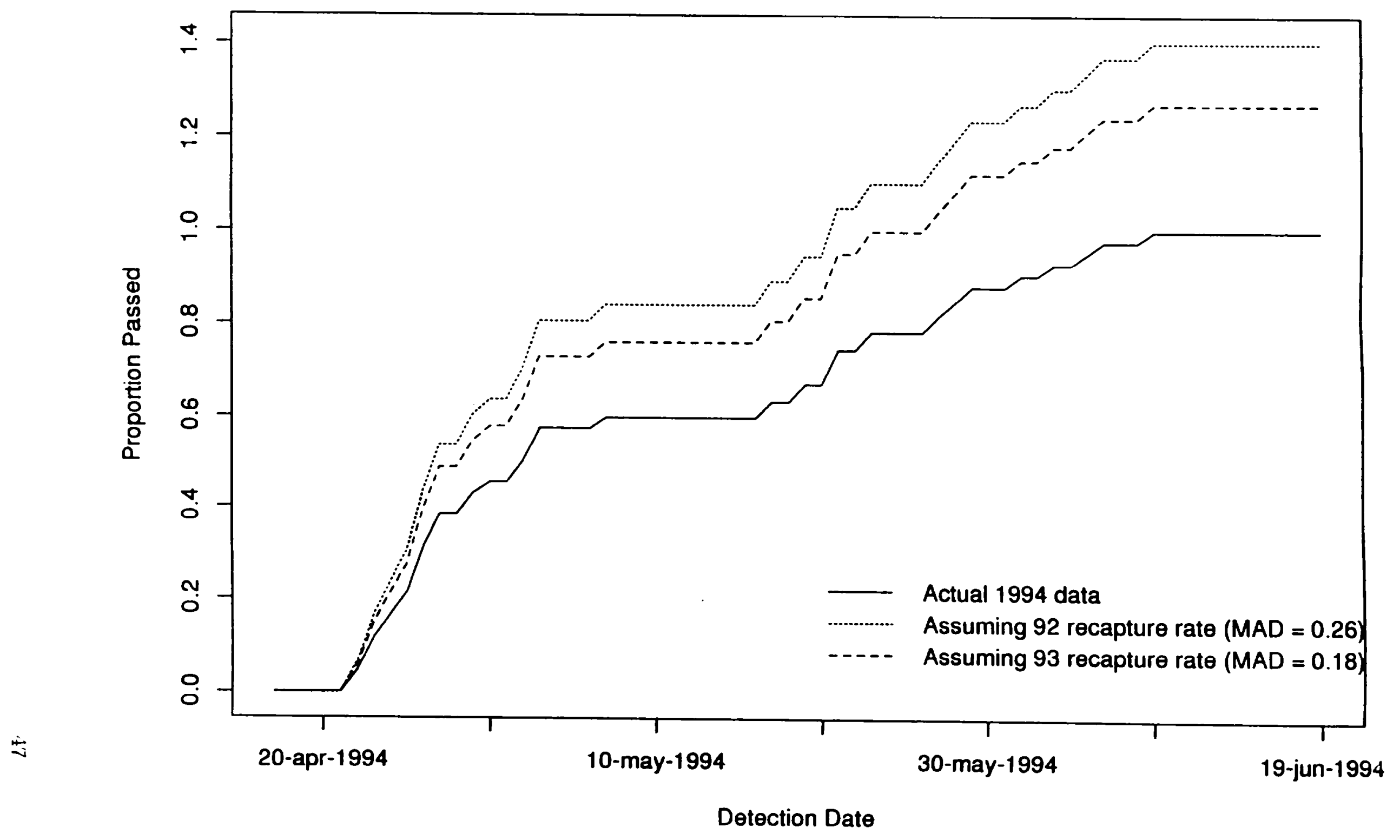




\section{Alternative M ethod \#2 Plots}




\section{Alternative Method \#2: Pahsimeroi}

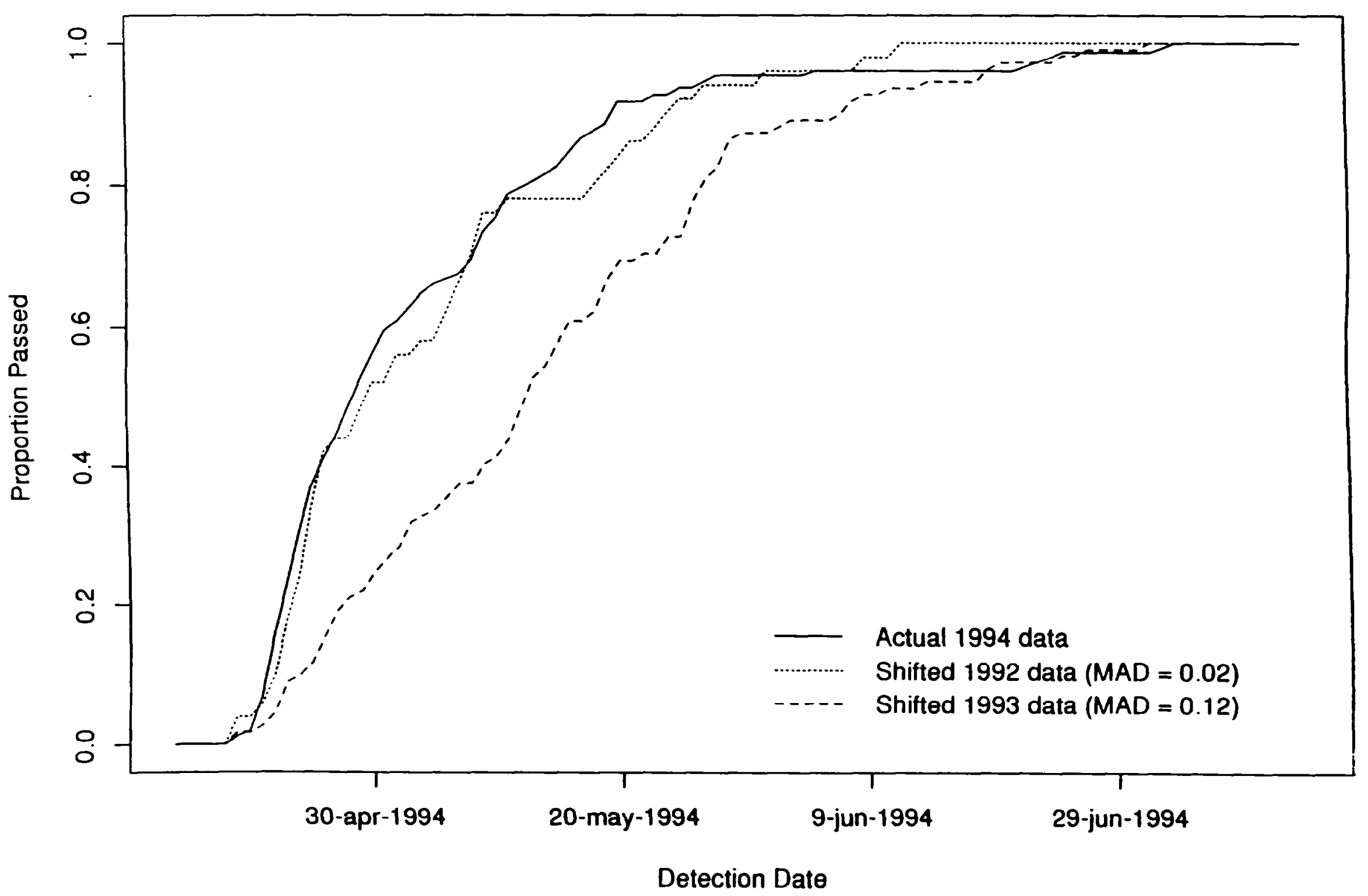




\section{Alternative Method \#2: Upper Salmon}

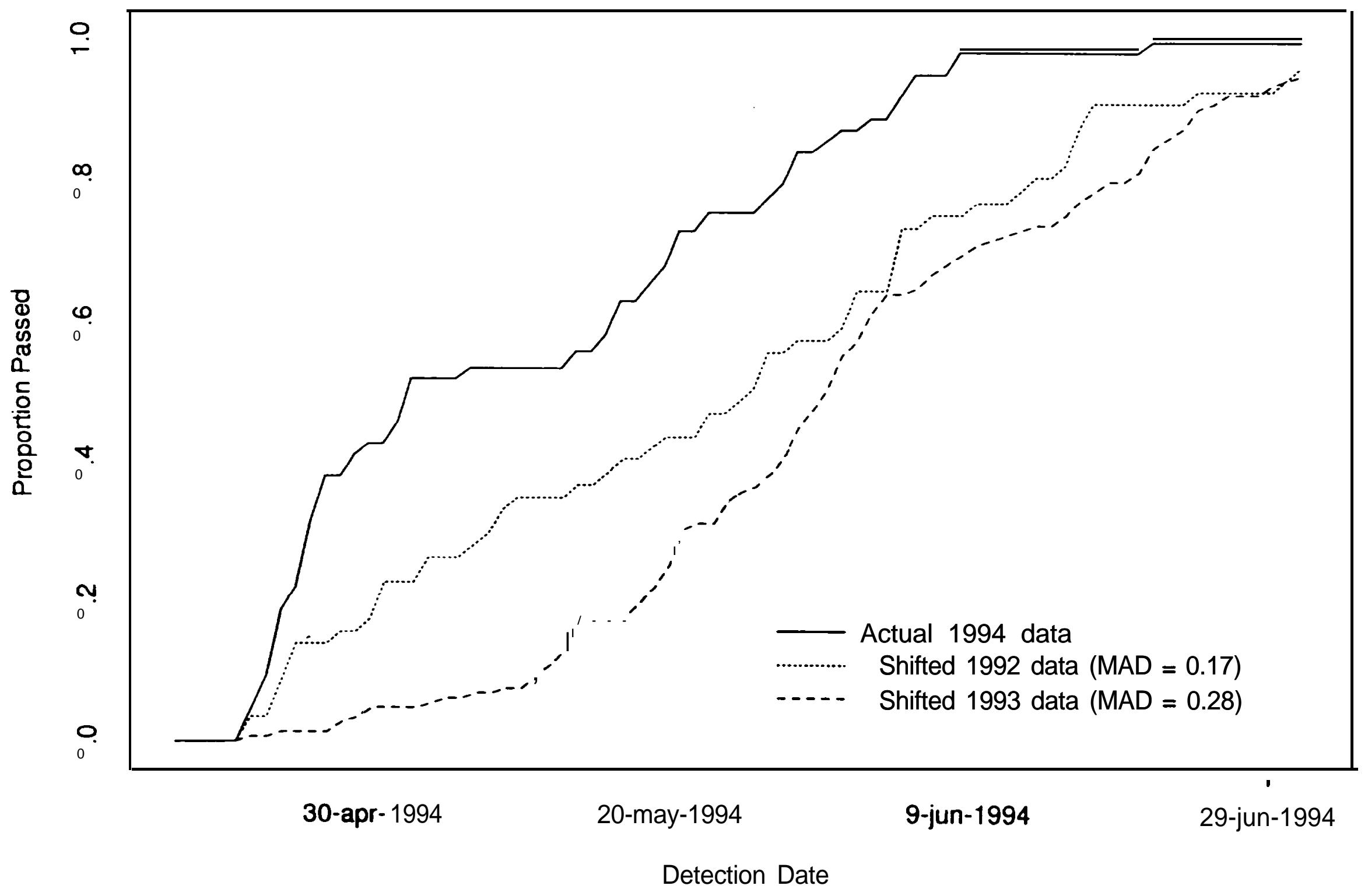




\section{Alternative Method \#2: South Fork Salmon}

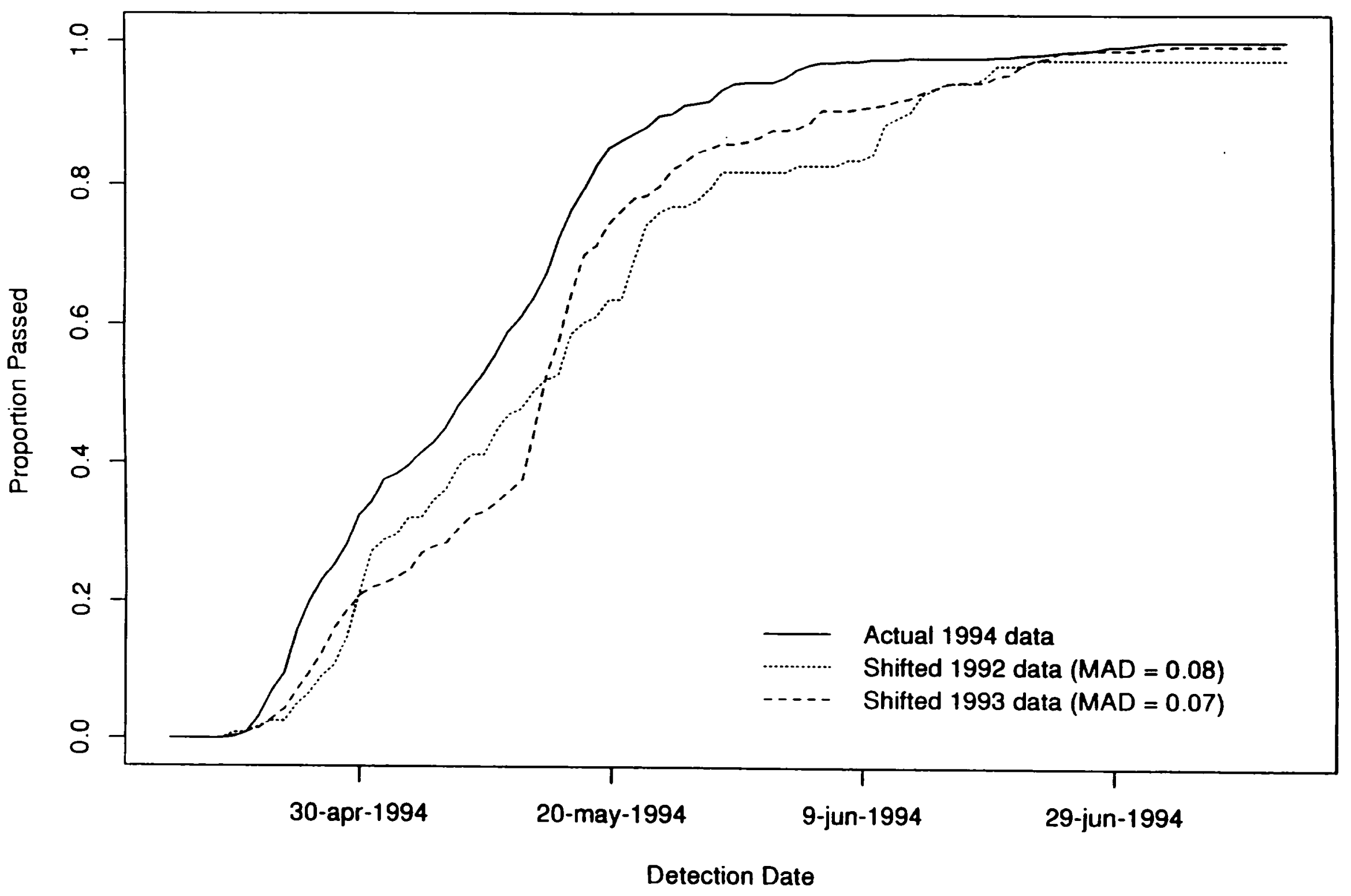


Alternative Method \#2: Upper Middle Fork Salmon

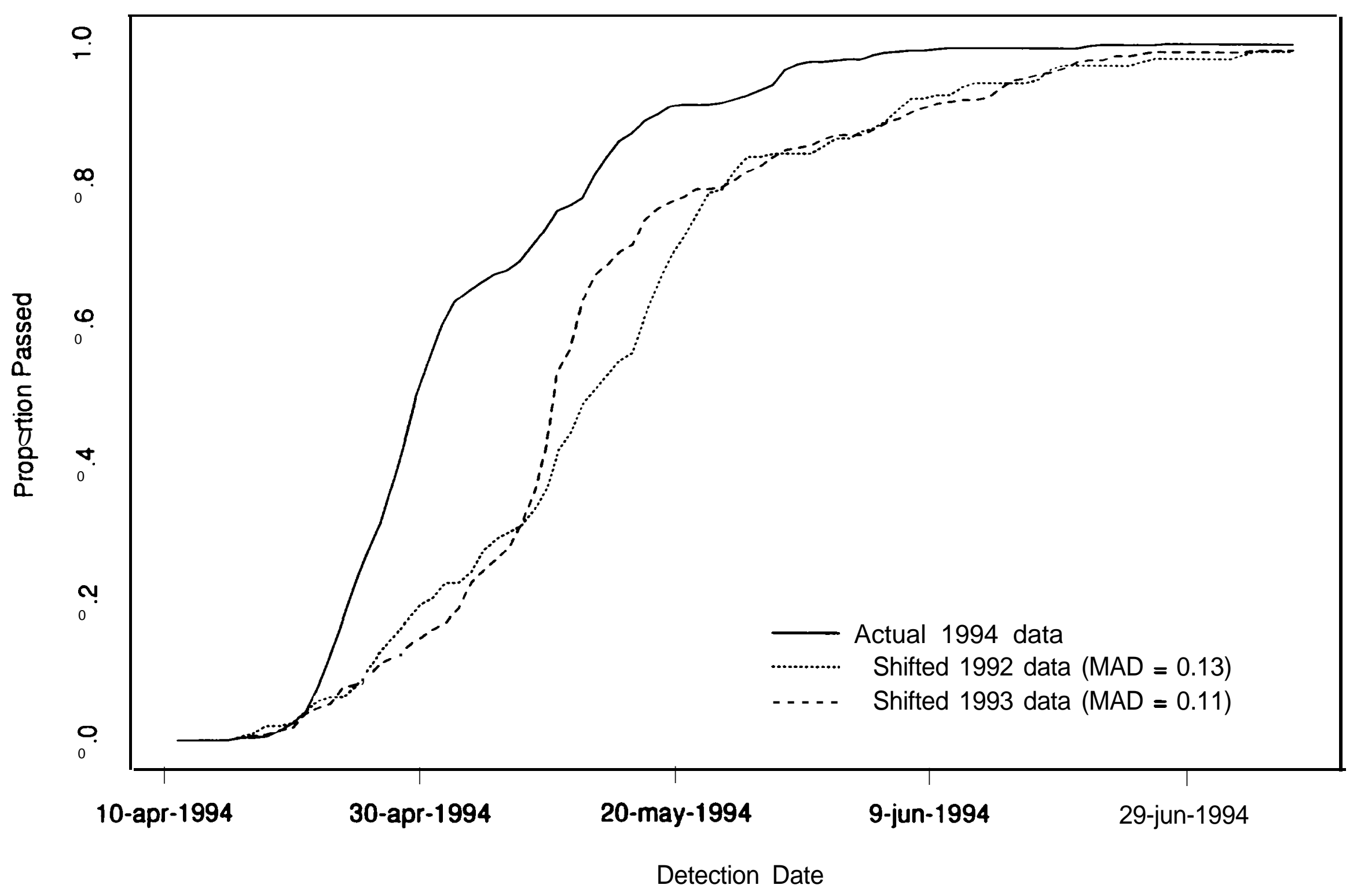




\section{Alternative Method \#2: Bear Valley Creek}

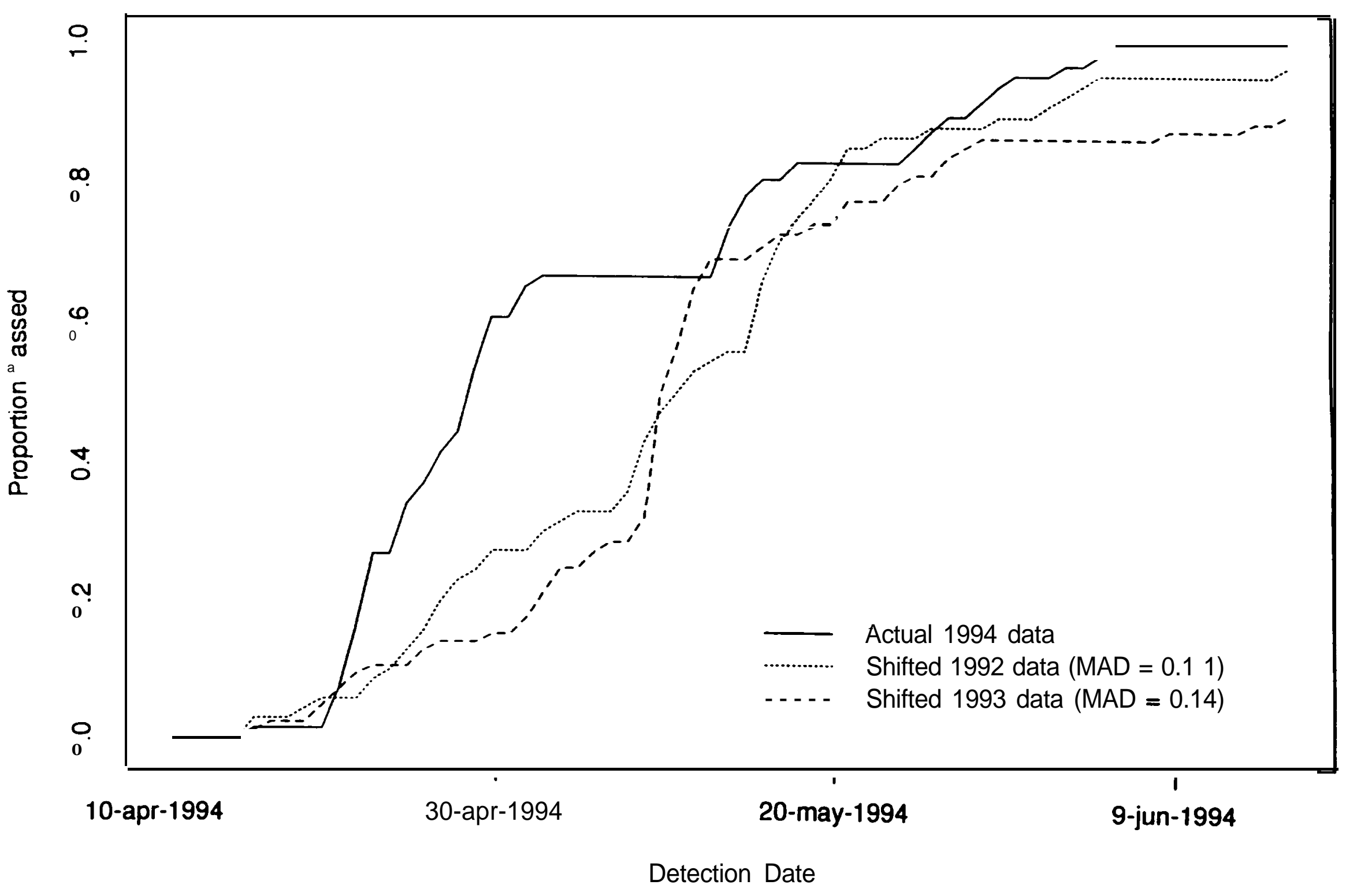




\section{Alternative. Method \#2: Big Creek}

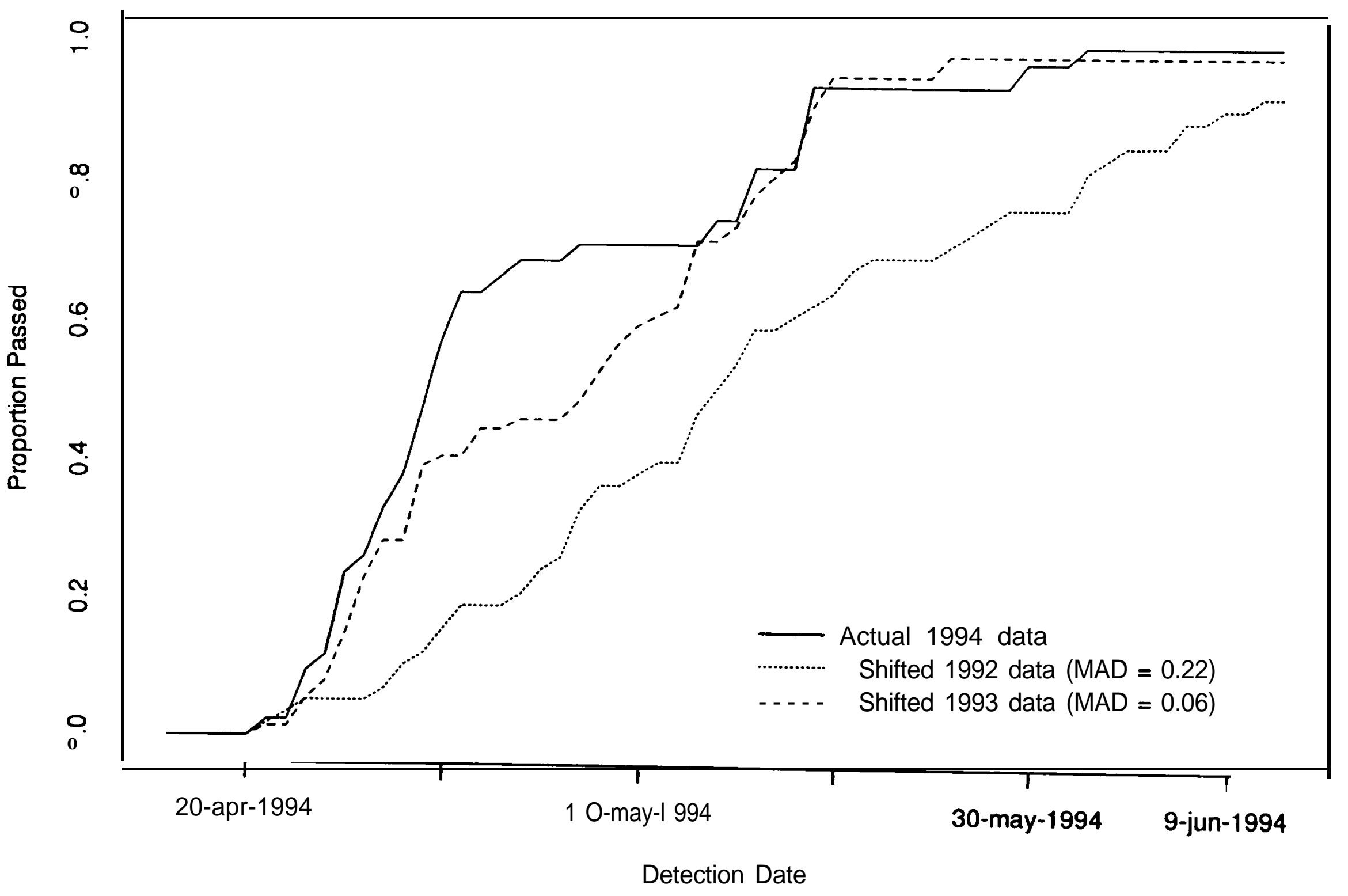




\section{Alternative Method \#2: Catherine Creek}

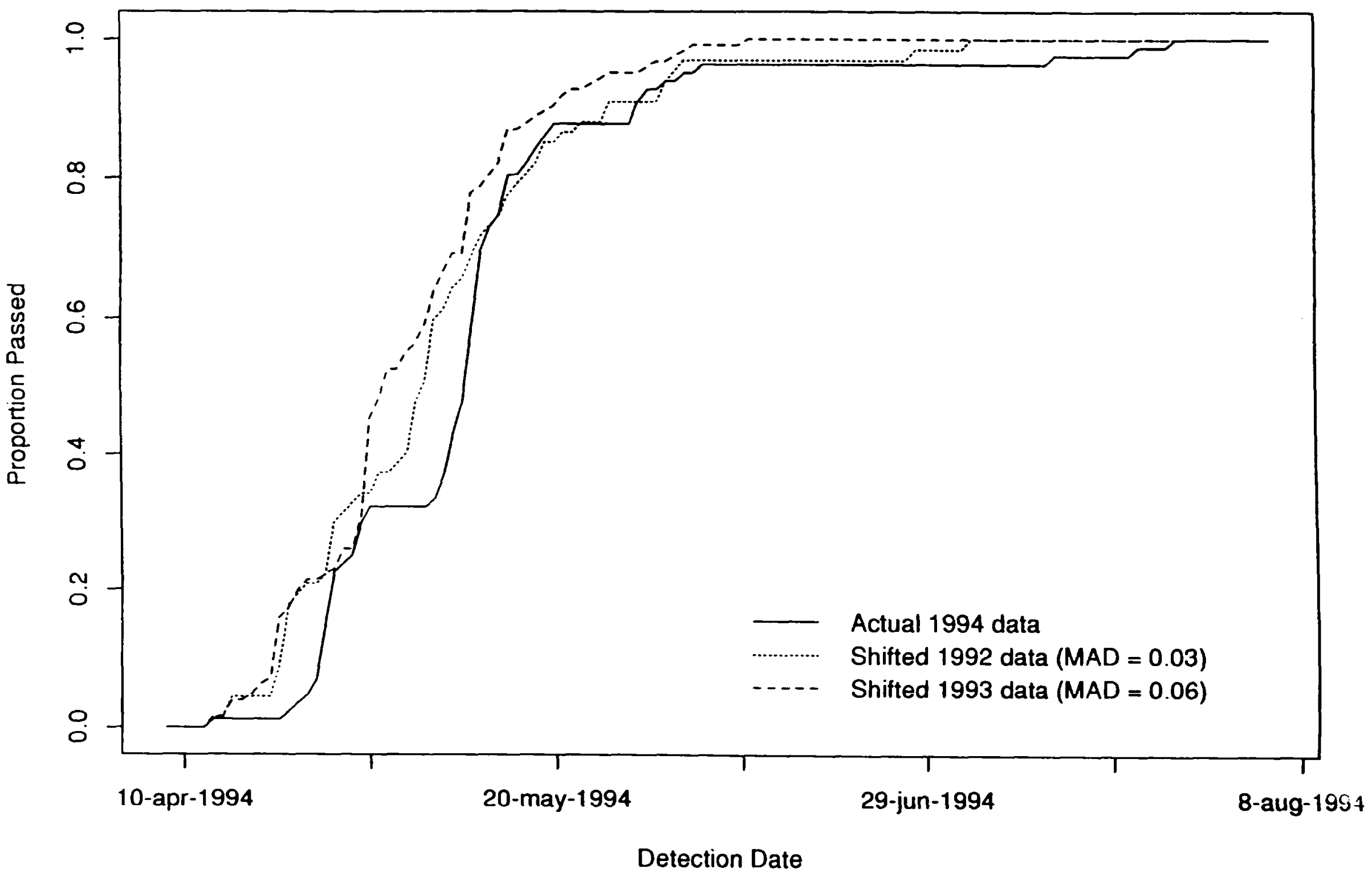




\section{Alternative Method \#2: Elk Creek}

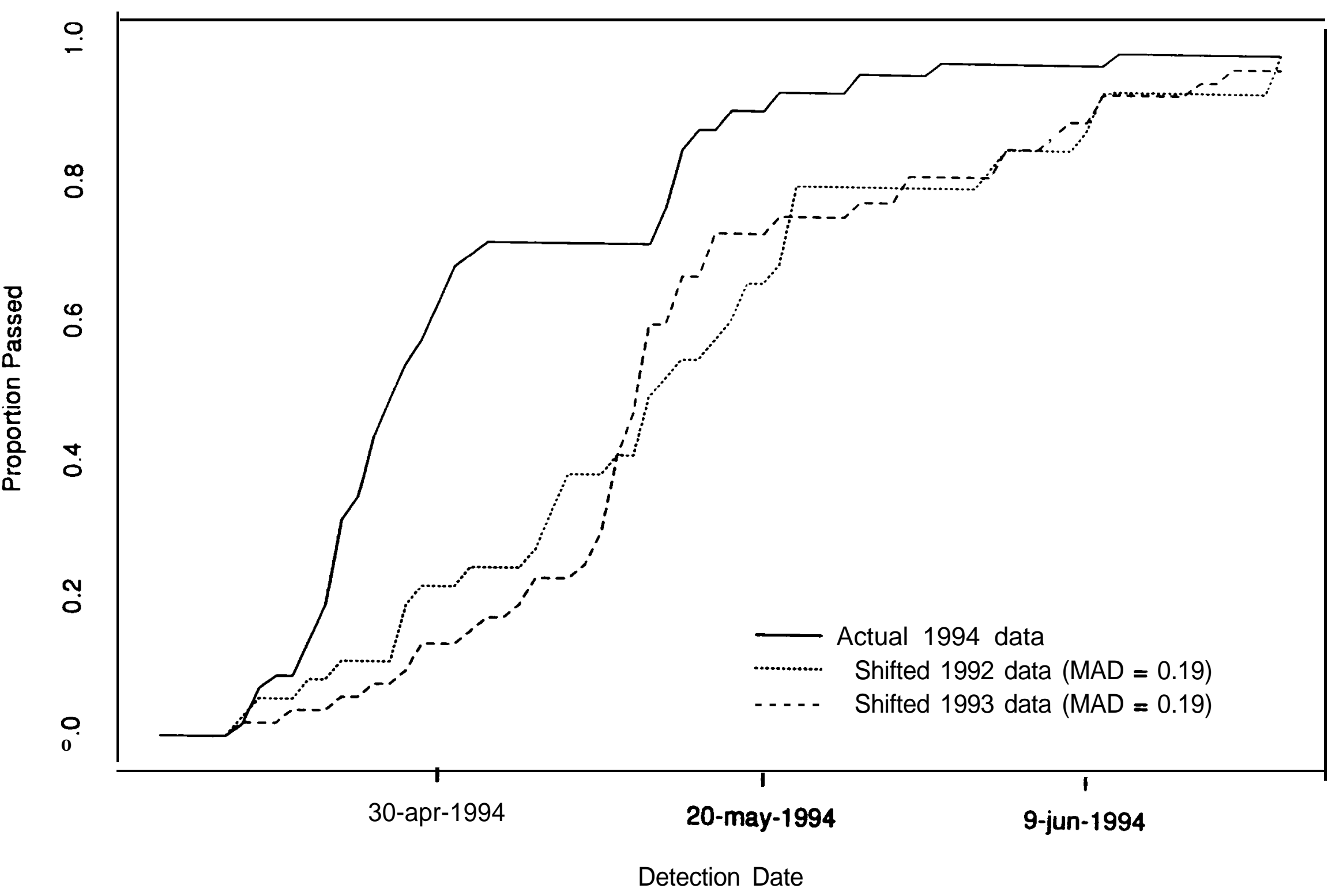




\section{Alternative Method \#2: Imnaha River}

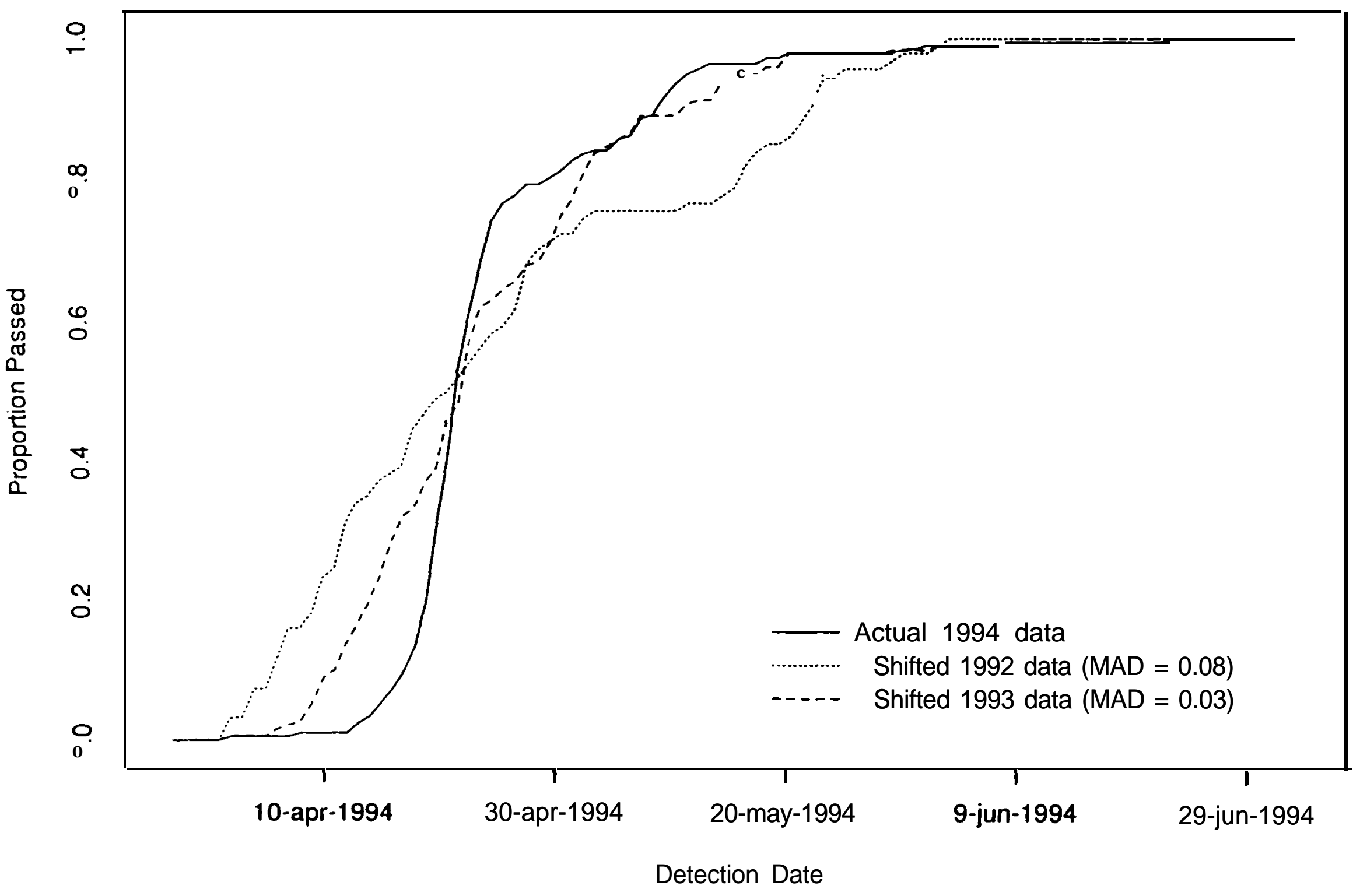




\section{Alternative Method \#2: Lostine River}

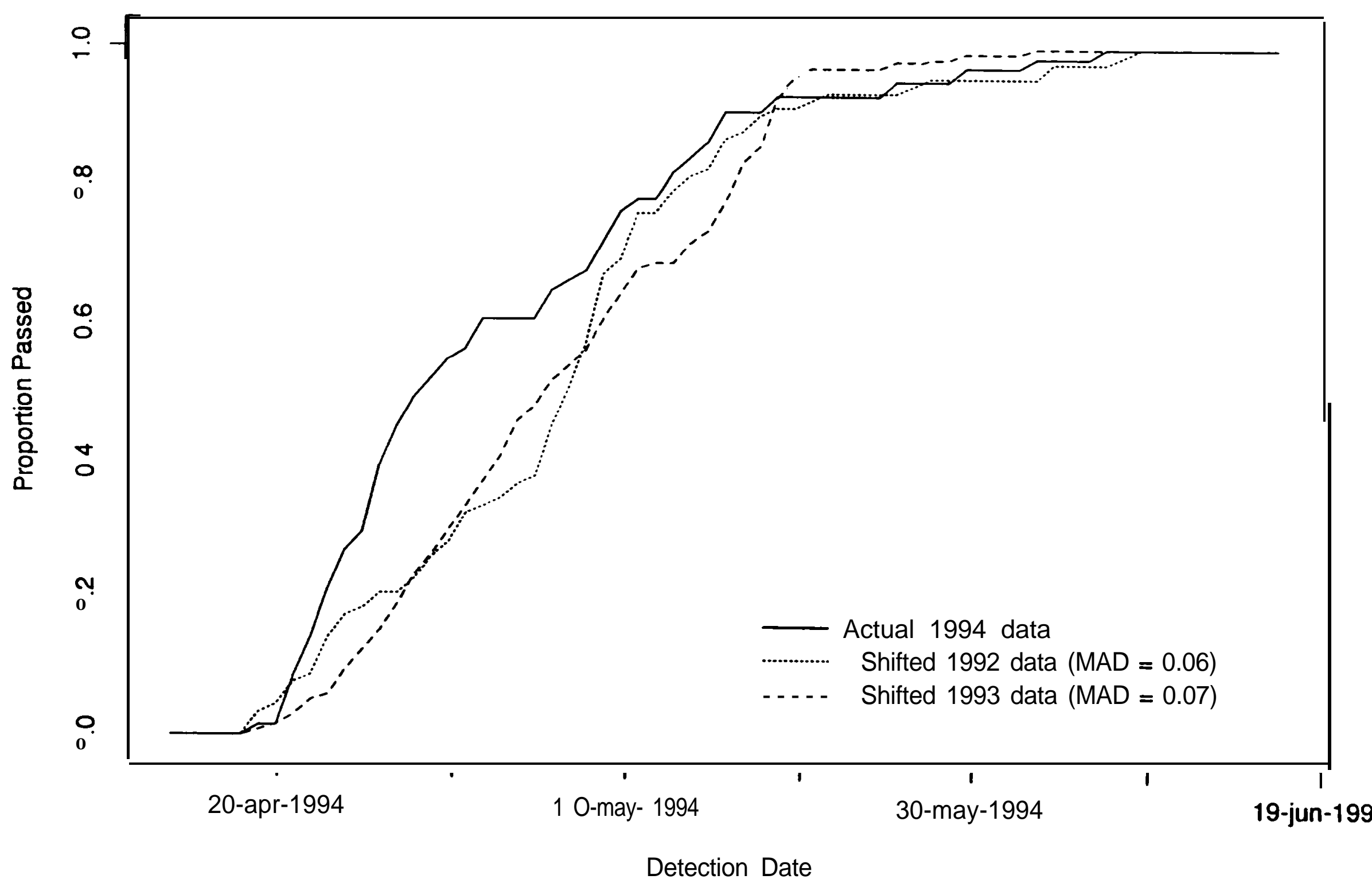




\section{Alternative Method \#2: Marsh Creek}

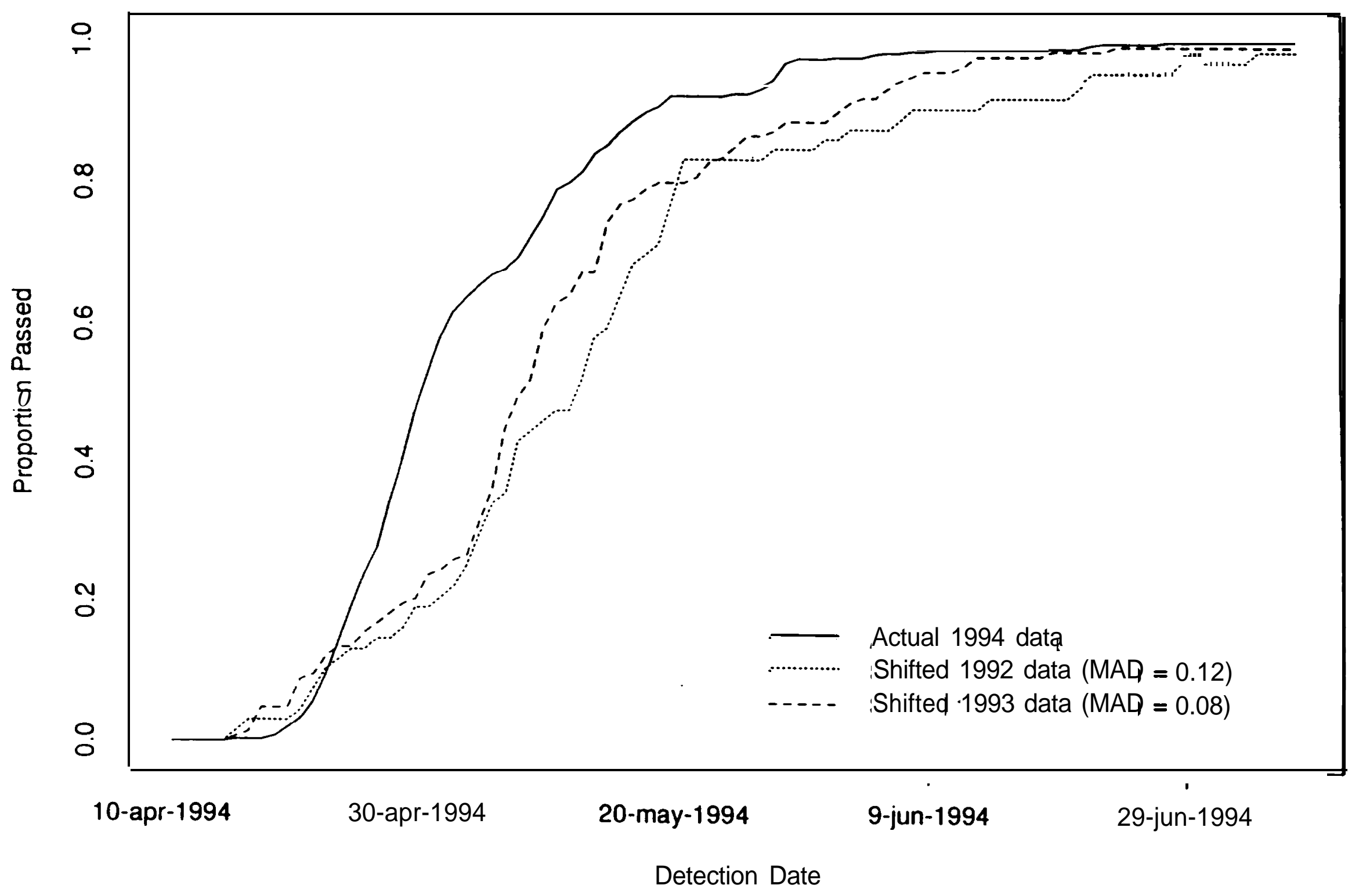




\section{Alternative Method \#2: Salmon River}

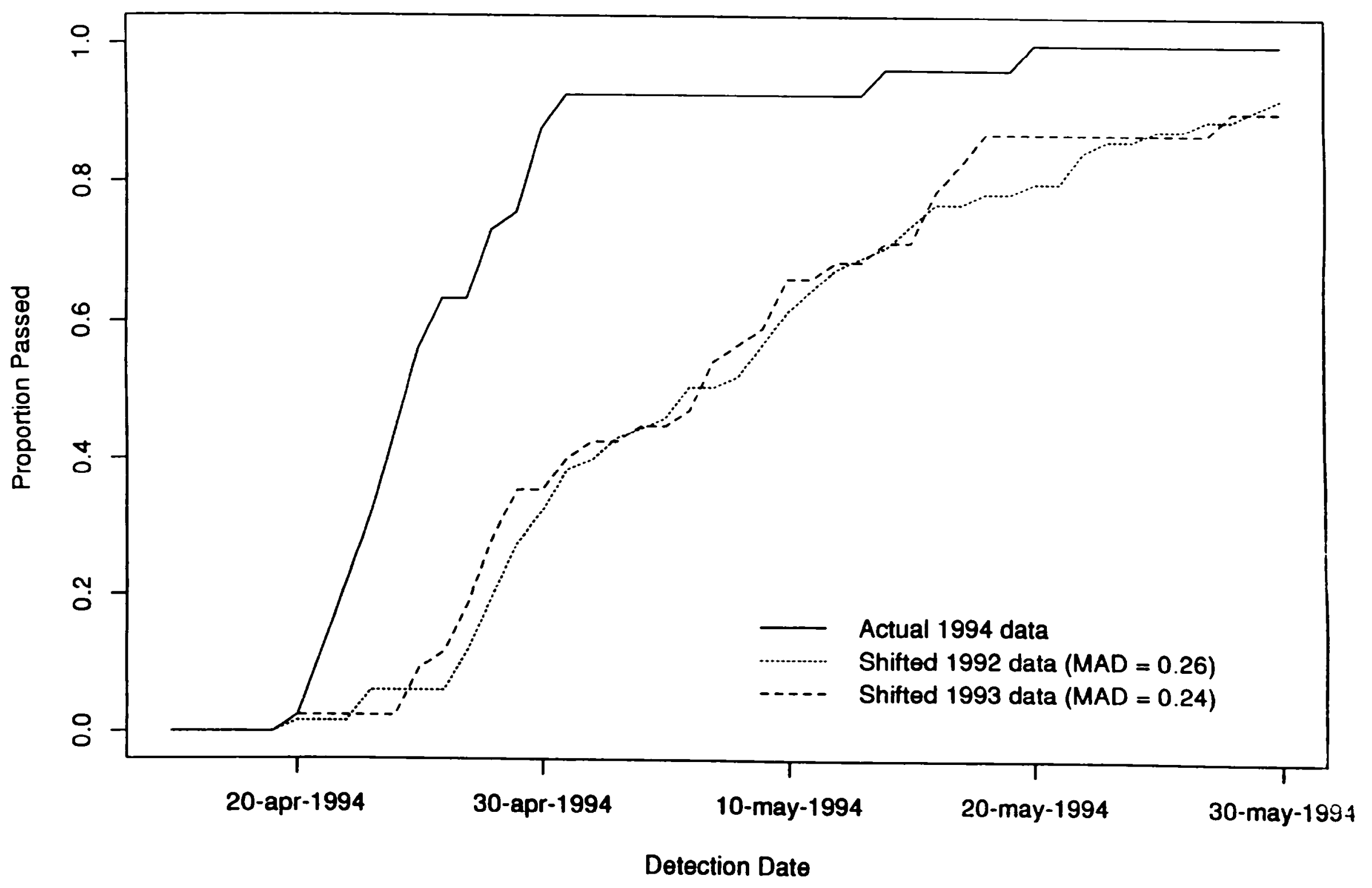




\section{Alternative Method \#2: Salmon River East Fork}

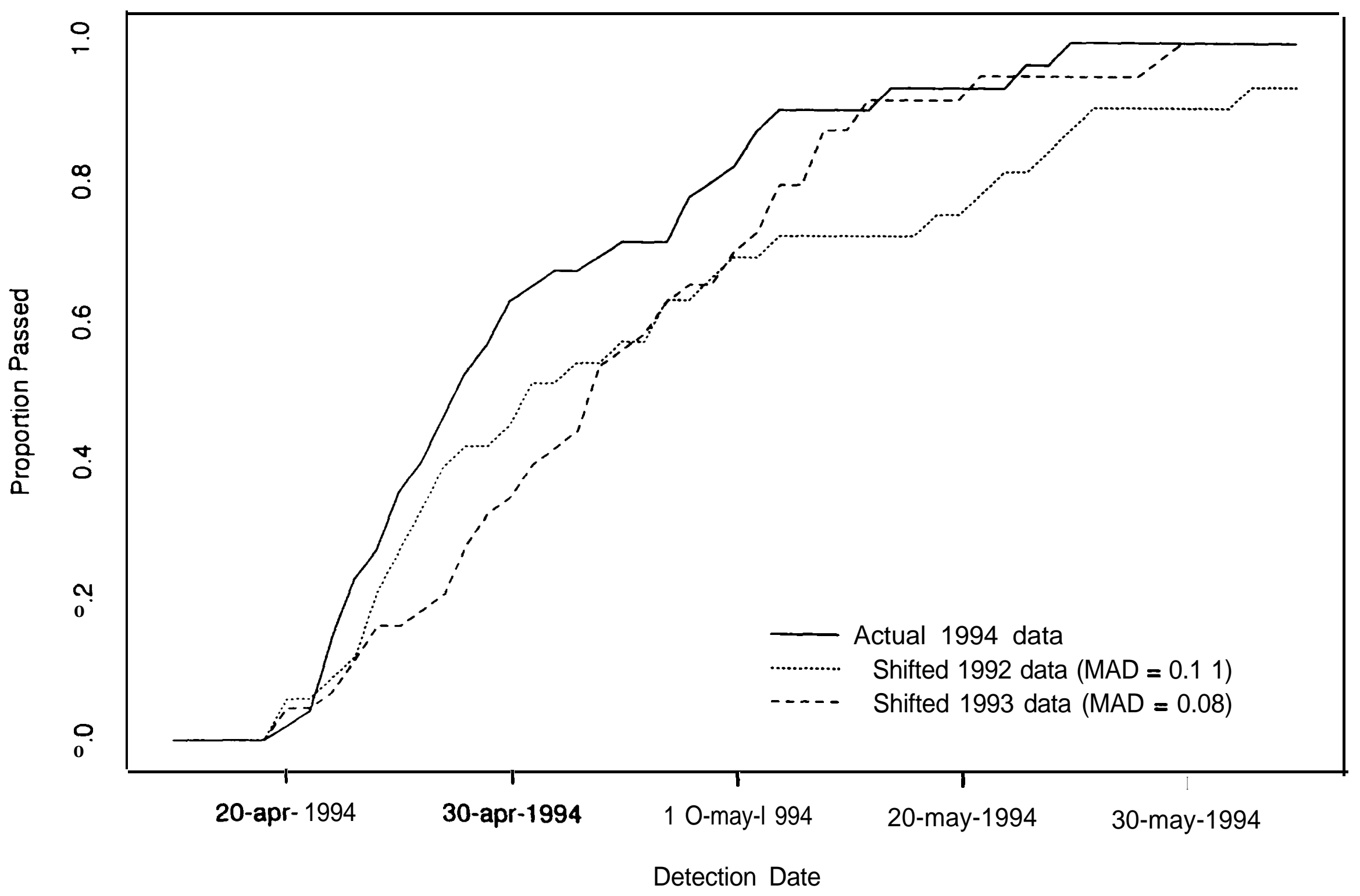




\section{Alternative Method \#2: Salmon River South Fork}

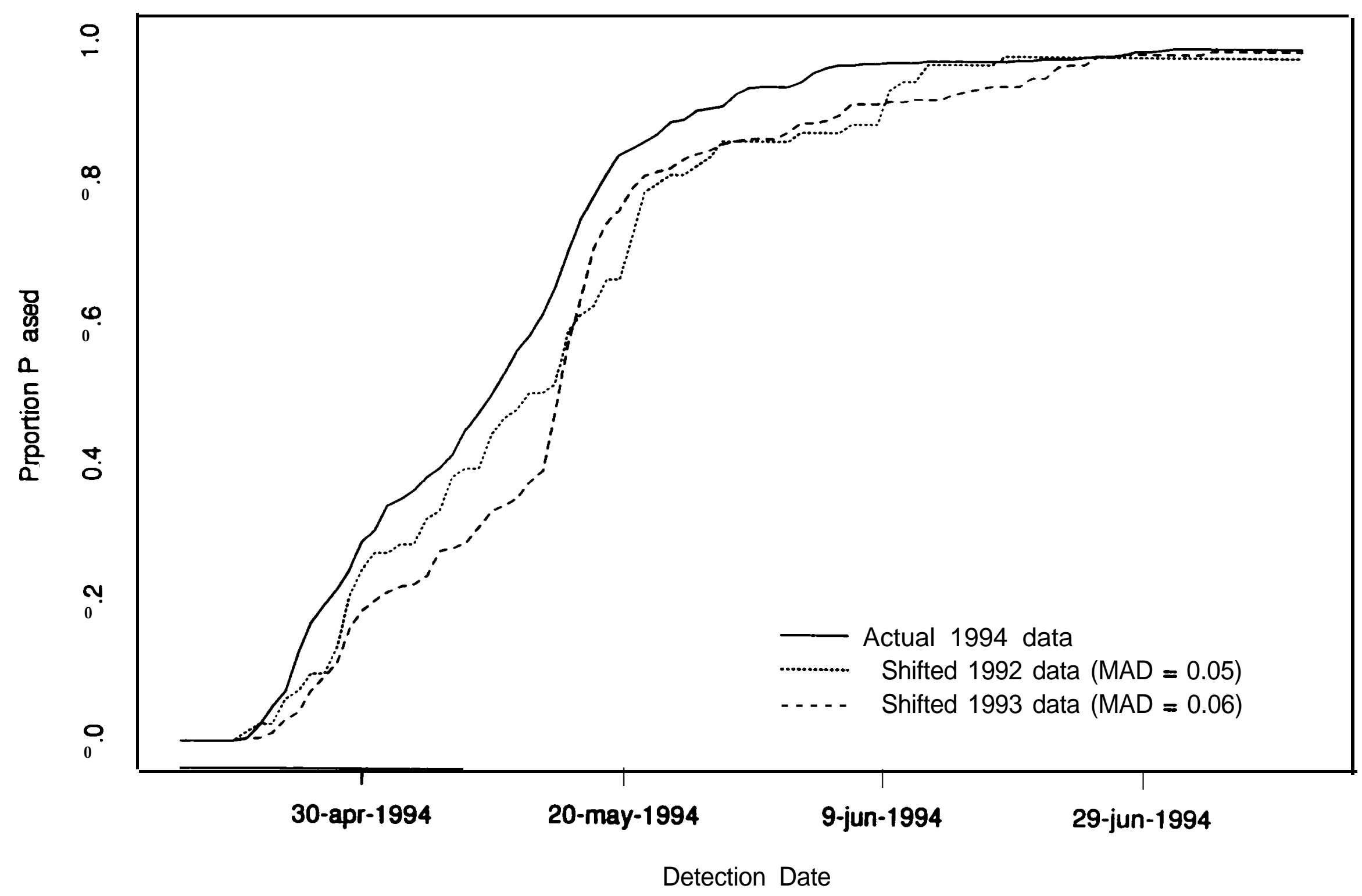




\section{Alternative Method \#2: Secesh River}

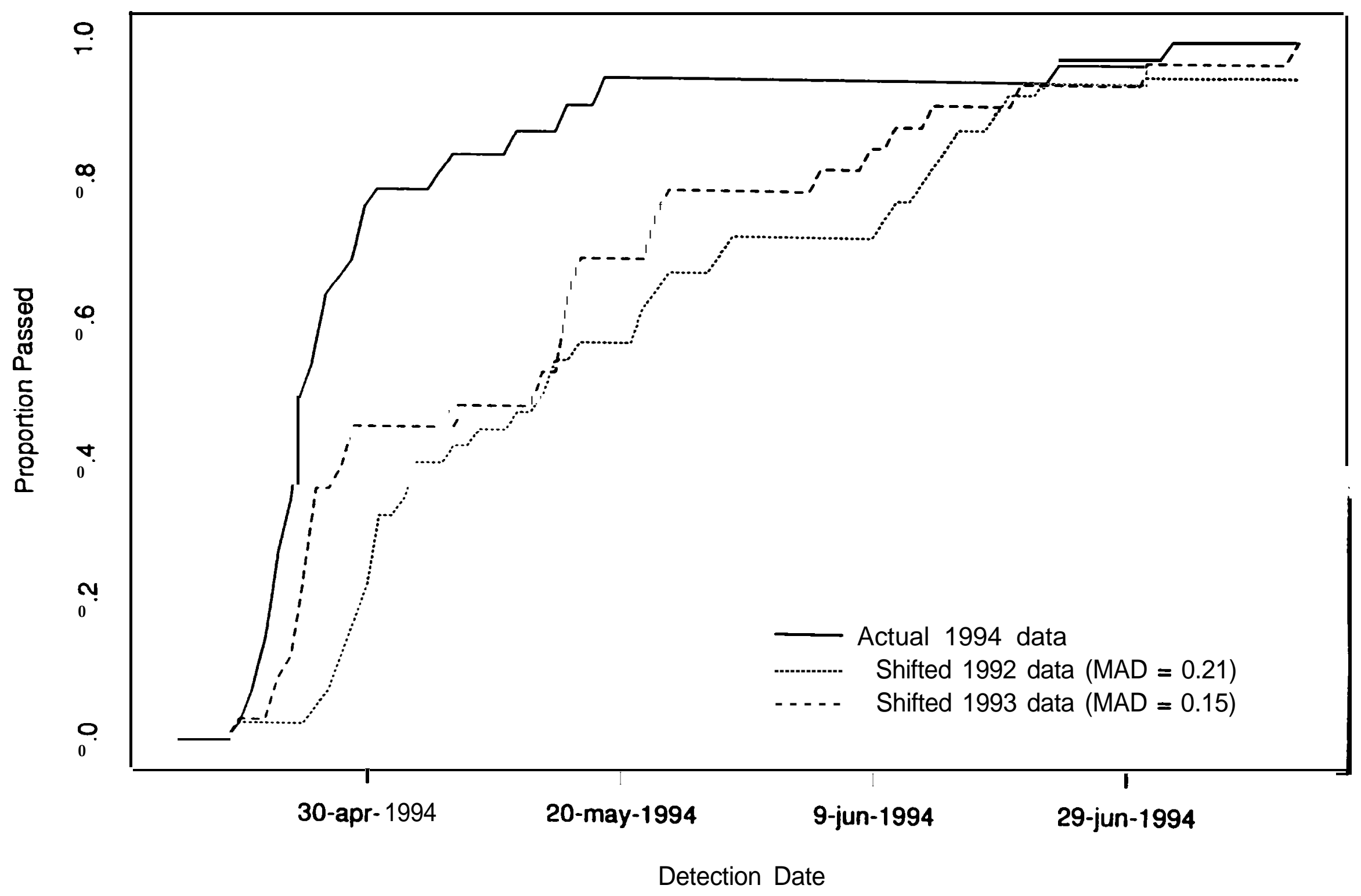




\section{Alternative Method \#2: Valley Creek}

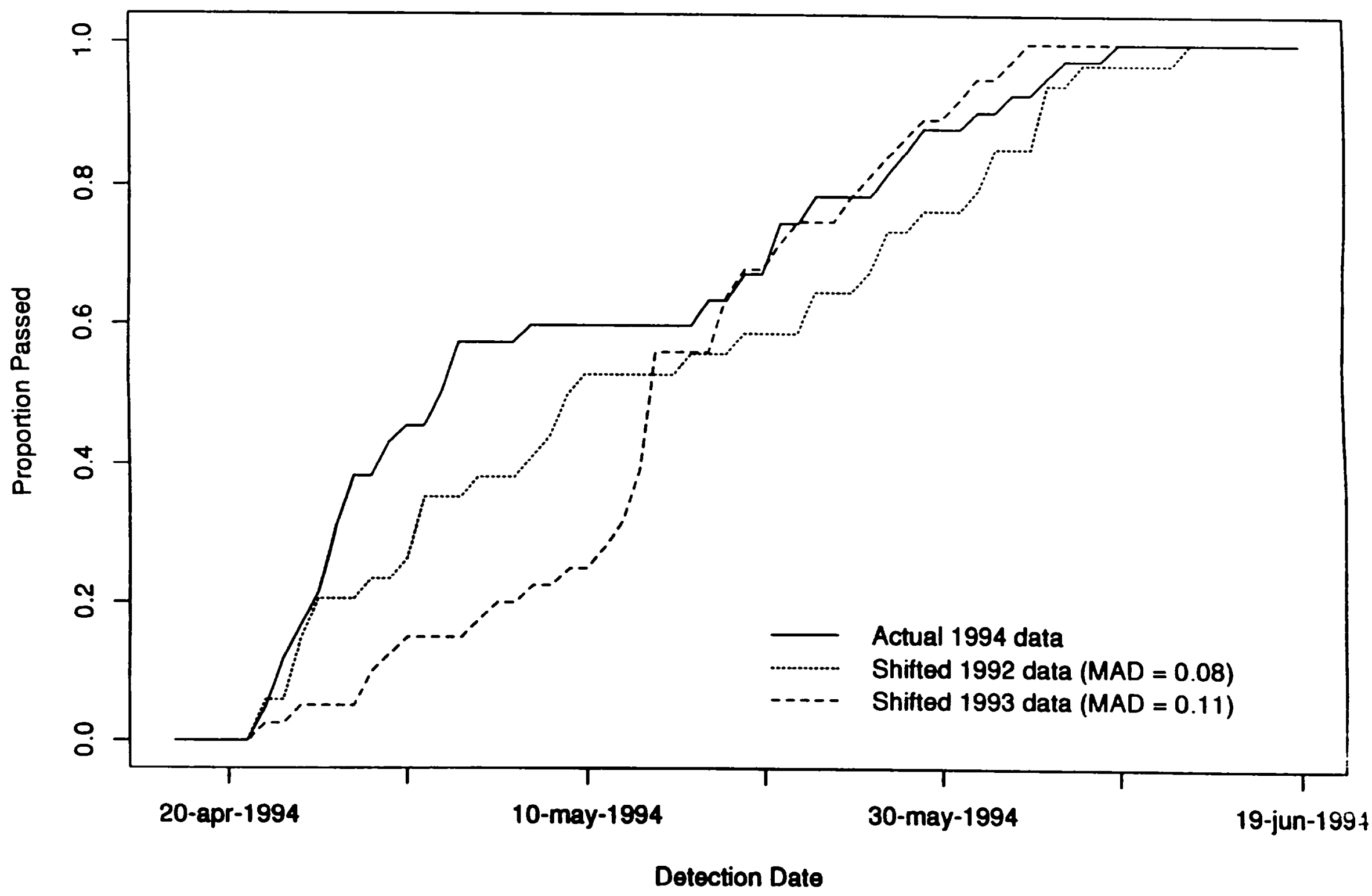




\title{
Appendix B
}

\author{
Instructions on the Use of the Forecasting Software
}




\section{Realtime}

RUNS:

The Realtime PIT Forecaster has two operating modes: windows or batch. To run under windows, type "rt" at system prompt:

$\% \mathrm{rt}$

The realtime base frame will come up. See following sections for a full description of the various frames.

To run in batch mode, type "t-t -batch -option"*, where option is either "LS" or "Sync":

$\%$ rt -batch -LS or

$\% \mathrm{rt}$-batch -Sync

This will results in predictions for all tagsites and tagsite aggregates currently included in the realtime database. The results will be written to a file. either rt.ls.out or rt.sync.out. See section "Batch Output'*.

DATA:

Realtime uses two types of datafiles, flow data files and files with detections of pit tagged fish. We get the detection files from PITAGIS, and the flow files from the Army Corps of Engineers.

The PITAGIS files will have a .csv on the end (comma separated variables) and the ACOE flow files will be of the form rp92xxxx.txt where $\operatorname{xxxx}$ is the month and day (i.e. 0424).

These files are parsed and sorted to become the Realtime data files (.flow and .obs) which are kept in the "data" directory.

New data files can be placed in the "newdata" directory. Realtime will automatically read any .txt of csv file from the "newdata" directory, parse the files and then append them to the existing data files, if the files are of the proper format. Once a new data file has been read. a "done" is added to the end of it to let Realtime now the file has already been read. 


\section{Batch Output}

PIT FORECASTER: forecast summary

Wed Apr 27 14:35:01 1994

\begin{tabular}{|c|c|c|c|c|c|c|c|c|}
\hline Tag Site & $\begin{array}{l}\text { Days } \\
\text { into } \\
\text { Run }\end{array}$ & $\begin{array}{l}\text { Fish } \\
\text { so } \\
\text { Far }\end{array}$ & $\begin{array}{l}\text { Ave } \\
\text { Hist } \\
\text { Perc }\end{array}$ & $\begin{array}{l}\text { Pred } \\
\text { Perc }\end{array}$ & MAD & $\begin{array}{c}\text { Days } \\
\text { till } \\
75 \%\end{array}$ & $\begin{array}{c}\text { Days } \\
\text { till } \\
85 \%\end{array}$ & $\begin{array}{l}\text { Days } \\
\text { till } \\
95 \%\end{array}$ \\
\hline UPPER SALMON & 5 & 12 & 15 & 12 & 6.00 & 37 & 43 & 54 \\
\hline PAHS IMEROI & 8 & 45 & 35 & 31 & 13.67 & 17 & 24 & 39 \\
\hline UPPER MIDDLE FORK SALMON & 11 & 96 & 21 & 16 & 11.00 & 22 & 32 & 45 \\
\hline SOUTH FORK SALMON & 7 & 47 & 37 & 24 & 2.00 & 23 & 41 & 56 \\
\hline SALMON R & 7 & 18 & 25 & 23 & 15.00 & 18 & 24 & 38 \\
\hline VALLEY C & 7 & 20 & 20 & 16 & 8.40 & 32 & 37 & 44 \\
\hline BEAR VALLEY C & 11 & 18 & 20 & 2 & 0.00 & 32 & 43 & 55 \\
\hline ELK C & 9 & 18 & 17 & 11 & 4.67 & 25 & 36 & 49 \\
\hline MARSH C & 11 & 59 & 20 & 15 & 11.50 & 23 & 29 & 45 \\
\hline $\mathrm{BIG} \mathrm{C}$ & 6 & 5 & 14 & 17 & 14.00 & 25 & 32 & 42 \\
\hline SALMON RE FK & 7 & 13 & 38 & 37 & 5.67 & 15 & 20 & 34 \\
\hline SALMON R S FK & 6 & 3 & 23 & 17 & 7.25 & 29 & 38 & 51 \\
\hline SECESH R & 7 & 14 & 43 & 35 & 5.60 & 25 & 40 & 60 \\
\hline IMNAHA R & 25 & 136 & 47 & 43 & 12.25 & 10 & 18 & 29 \\
\hline LOSTINE $\mathrm{R}$ & 19 & 22 & 22 & 28 . & .3310 & 10 & 15 & 24 \\
\hline CATHERINE C & 4 & 6 & 14 & 23 & 5.33 & 19 & 25 & 37 \\
\hline
\end{tabular}

Tag Site:

Days into Run:

Fish so Far:

Ave Hist Perc:

Pred Perc:

MAD

Days till $75 \%$

Days till $85 \%$

Days till $95 \%$
The first four are aggregates. the rest are individual tag sites.

The number of days since the first detection.

The number of fish detected this year.

The average percent passed over historical years on this date.

The predicted percentile.

Mean Absolute Deviation over historical years at this percentile.

The number of days till we are at the 75 th percentile.

The number of days till we are at the 85 th percentile.

The number of days till we are at the 95th percentile. 


\section{Tagsites Frame}

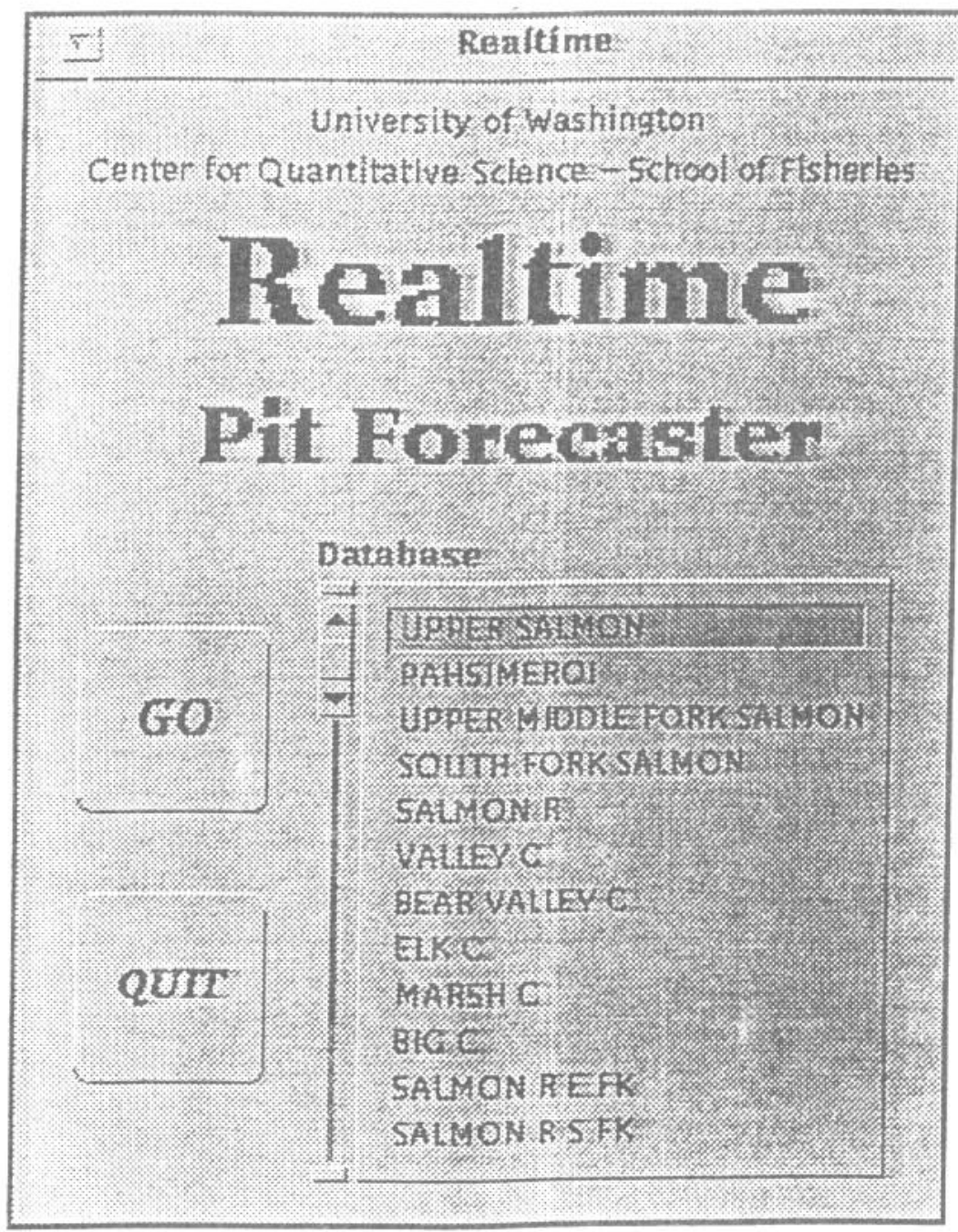

Type "rt" at system prompt and the Realtime base frame comes up. 


\section{Tagsites Erame}

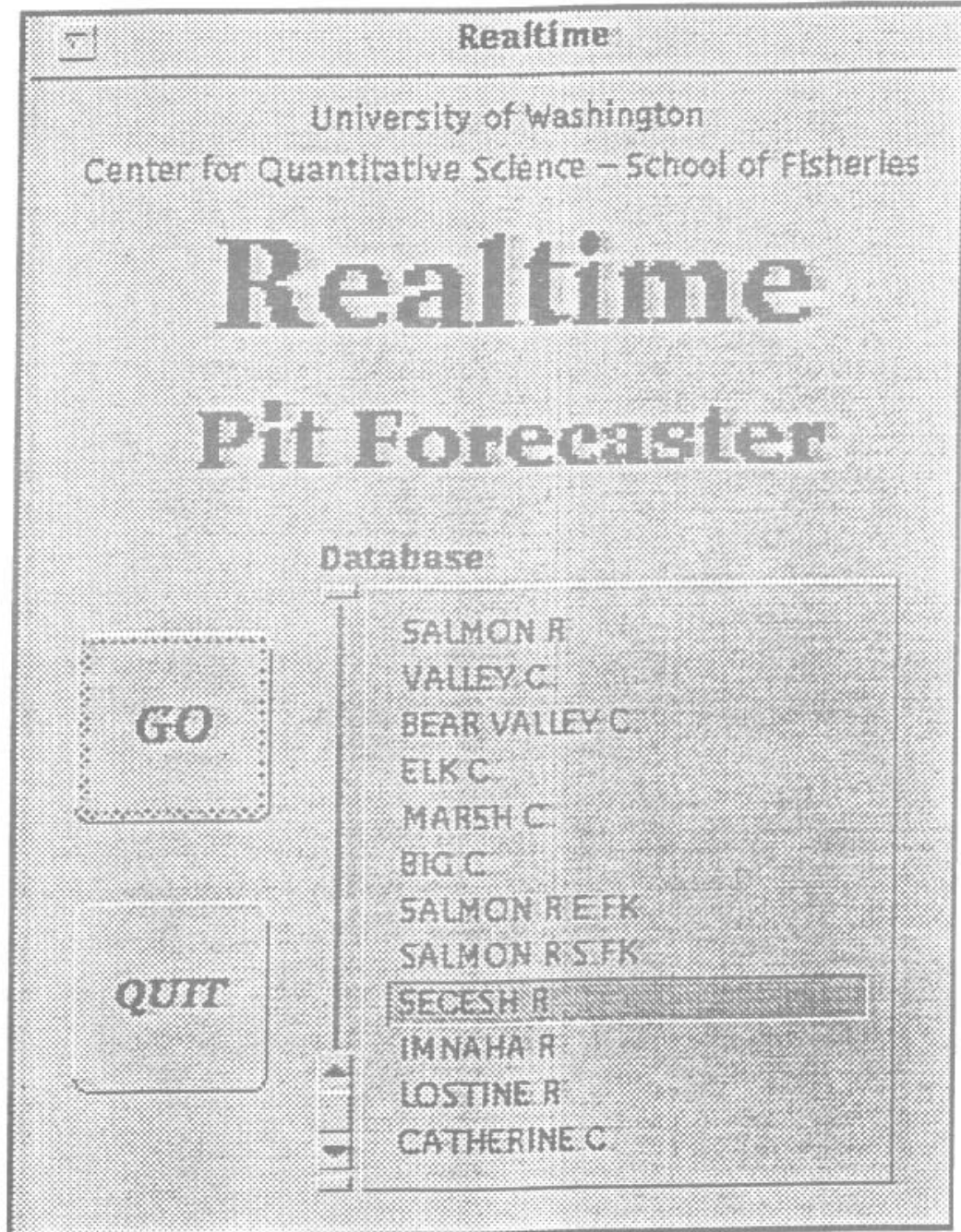

Select database by pointing to named databases with the mouse and clicking the left mouse button. Use scroll bar to see database names that are out of view. To deselect a database, either click again on the name with mouse, or select another database.

These database names are the PIT Tag Information System names for either individual tag sites or in some cases, aggregations of multiple tag sites. The first four names in the menu are aggregates: UPPER SALMON, PAHSIMEROI, UPPER MIDDLE FORK SALMON, and SOUTH FORK SALMON. The rest are individual tag sites.

After you have selected your database, click once on "GO" with the mouse button. This brings up the river frame. 


\section{River Frame}

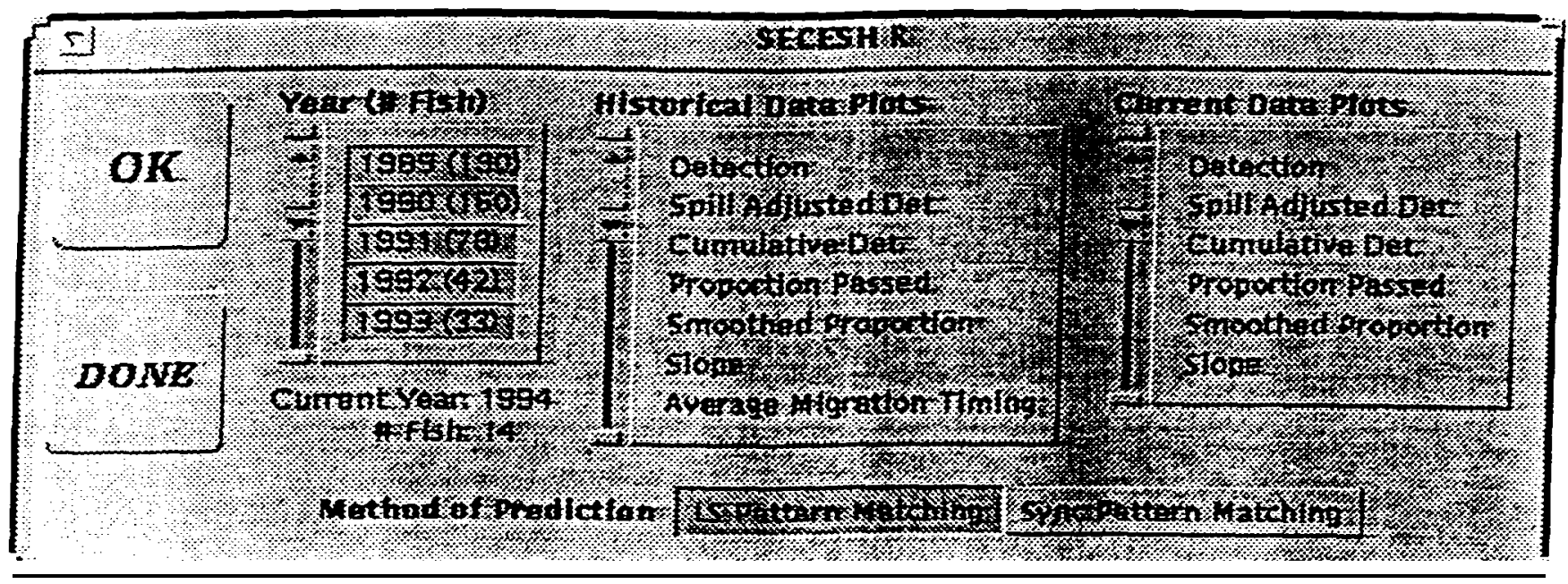

In the river frame you can look at the data, both "Historical" and "Current". select which historic years the prediction will be based on, and choose which method of prediction should be used. 


\section{River Frame}

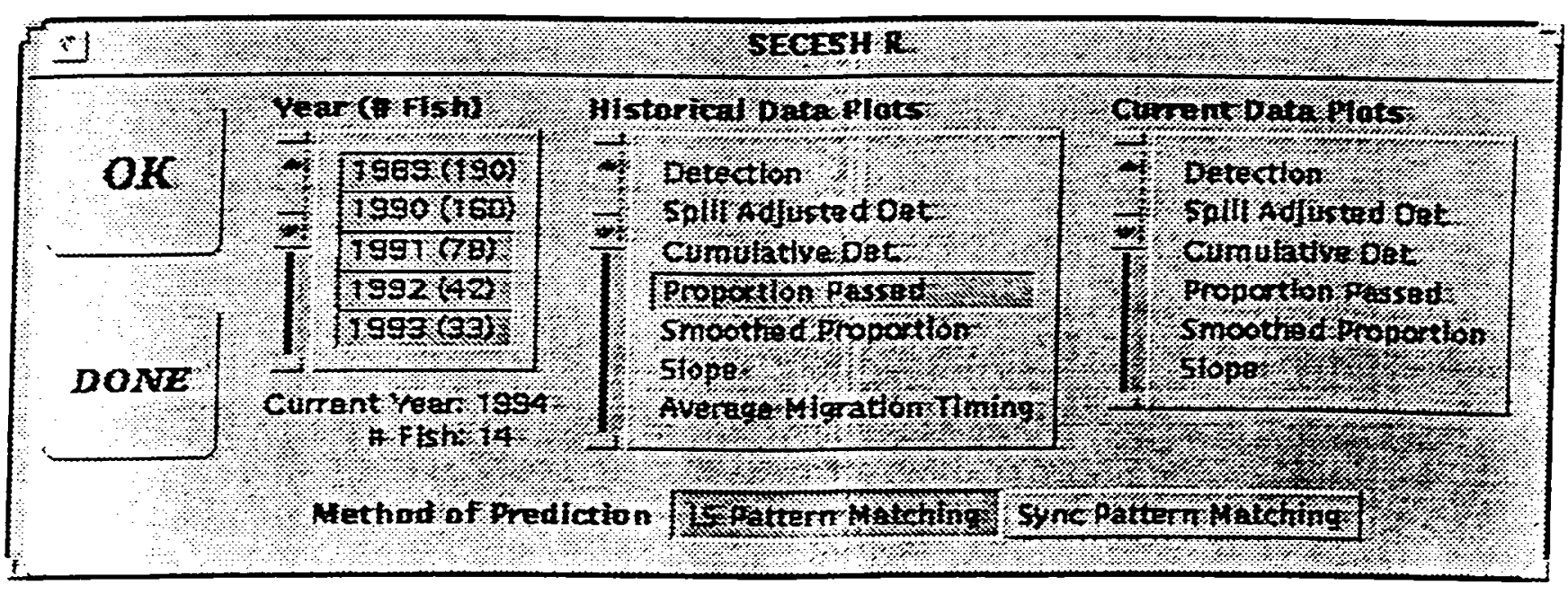

Here plots are divided into two sections: "historical'* and "current". For each data set, one year is the current data (generally data from the current year), and the rest is historical data.

To look at these plots, point and click with mouse button on the plot title in the plot menu. This highlights the plot name and brings up the plot. Clicking on a highlighted plot name destroys that plot. The plots are described in the sections "Historical Data Plots" and "Current Data Plots". 


\section{River Frame}

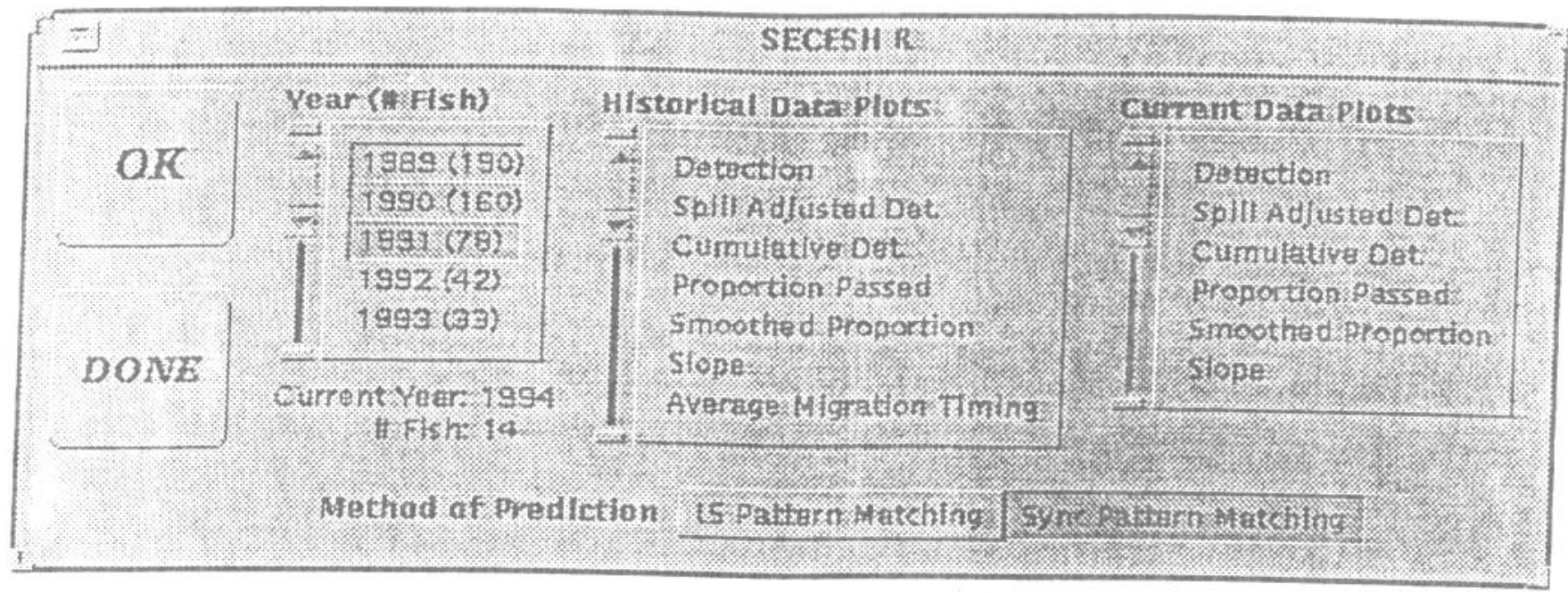

A menu with the title "Year (\# Fish)" contains the years and the number of detections for that year. When the river frame comes up, these are all highlighted indicating that all will be used as historical data in the analysis. To remove a year from consideration, click once with the mouse button. Clicking a second time will re-select the year. 


\section{River Frame}

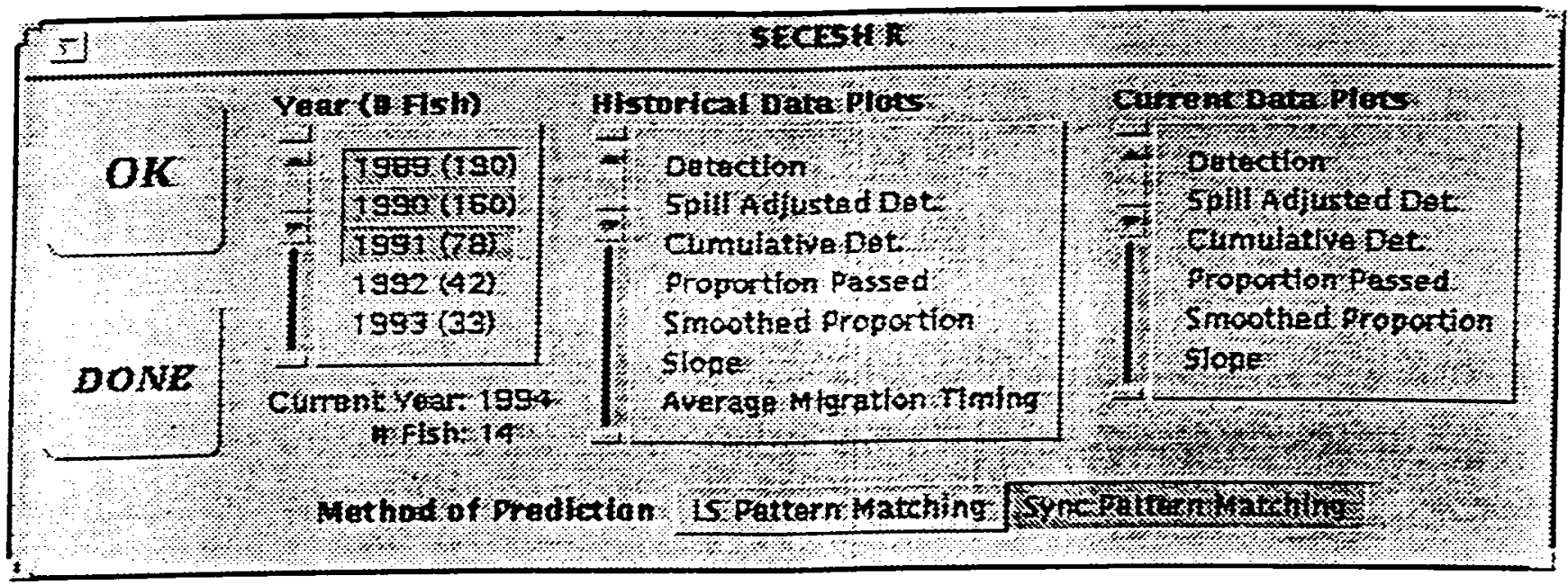

Two methods are implemented currently: "LS Pattern Matching" and "Sync Pattern Matching". Choose the method by clicking once with the mouse button. 


\section{River Frame}

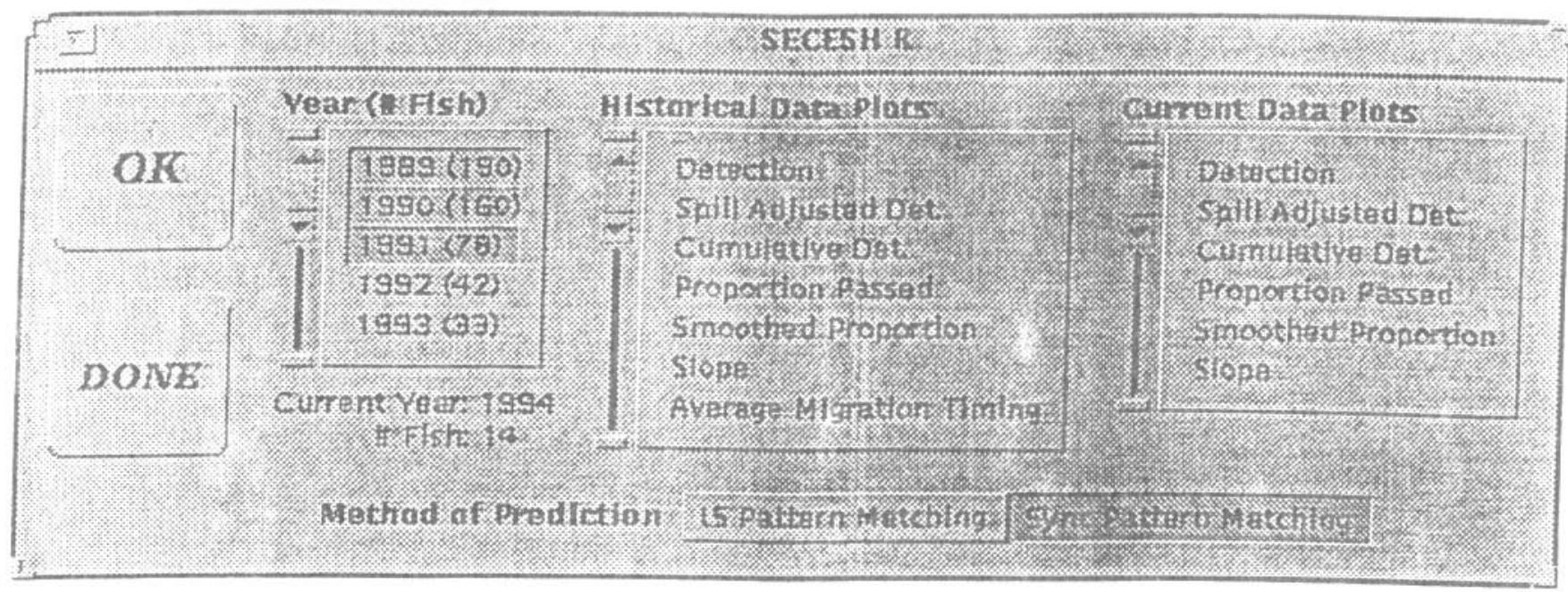

Click "OK" to begin the prediction. When the results have been computed, the resuits frame will come up. The "OK" button on the river frame will now be inactive and will remain inactive until you are done with the results frame. 


\section{Results Frame}

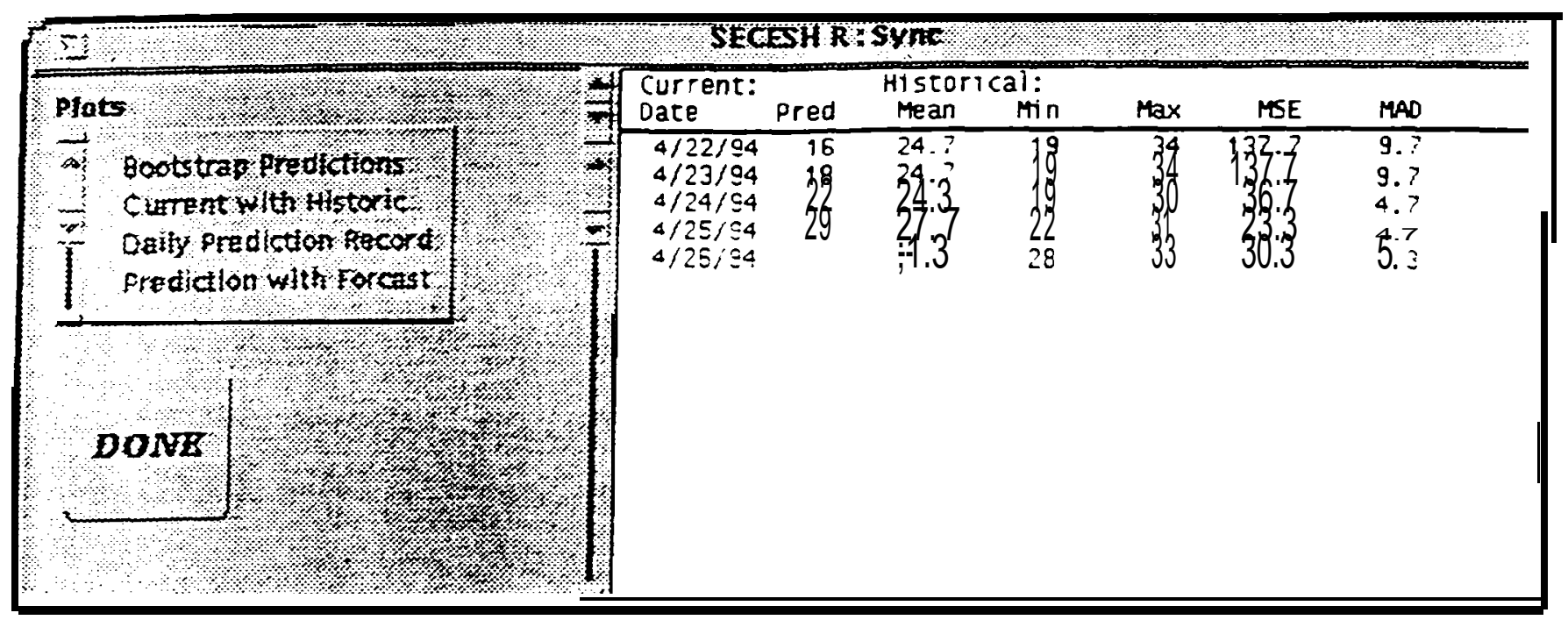

The results frame has two areas: a plot menu and a text window. To look at the various plots, point and click on the plot name. These plots are described in the section "Results Plots". In the text window is a scrollable table that contains predictions and confidence estimates. Realtime reports the current prediction as well as a record of the predictions made on previous days.

Each row has the date. the prediction and summaries of the predictions performance based on data gained from bootstrap predictions over historic years. 


\section{Plots}

Plots have two buttons to know about: "Print" and "Done". The print button will send the plot to lpr. The done button will destroy the plot. 


\section{Historical Data Plots}

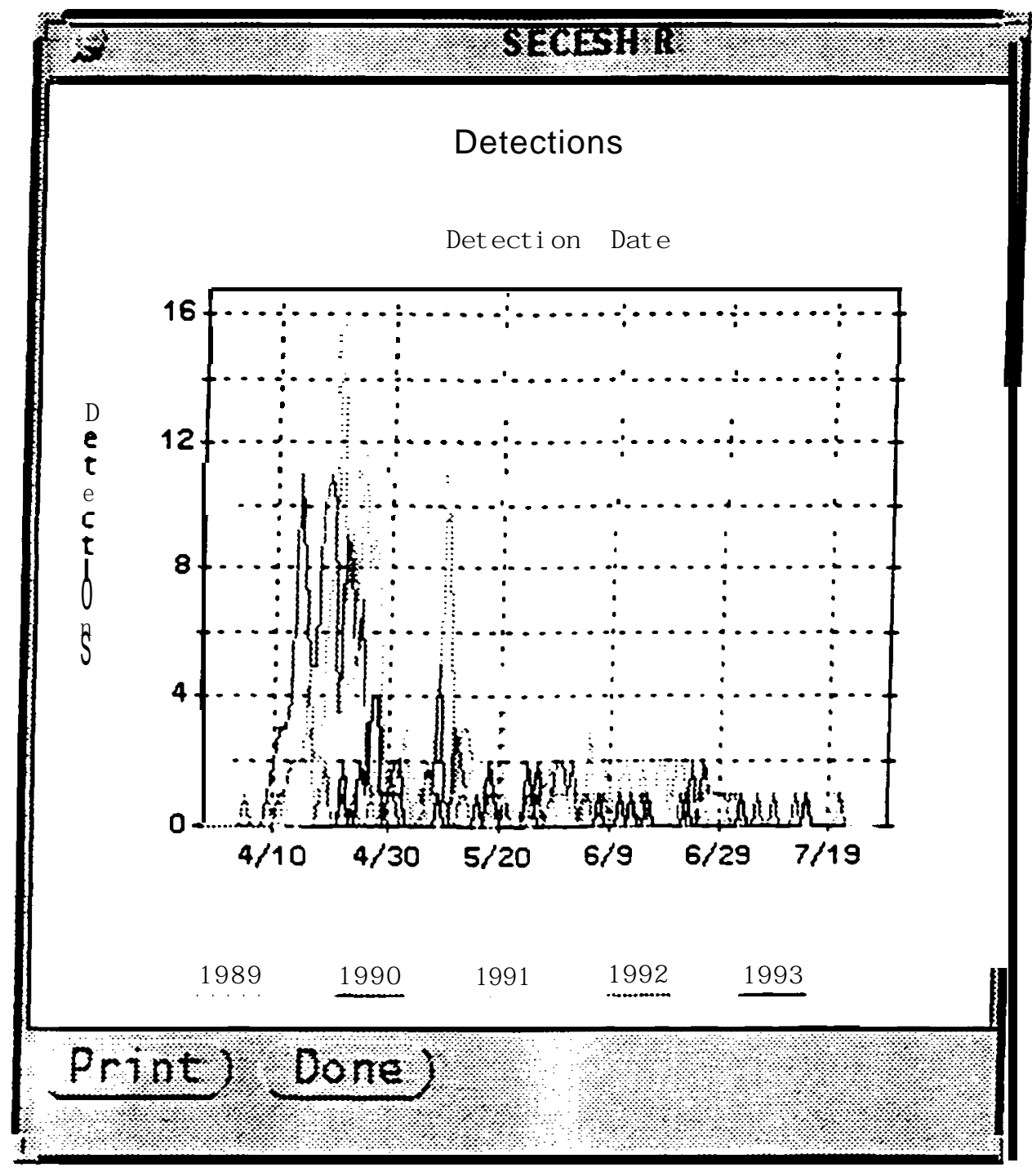

Number of detections vs. detection date 


\section{Historical Data Plots}

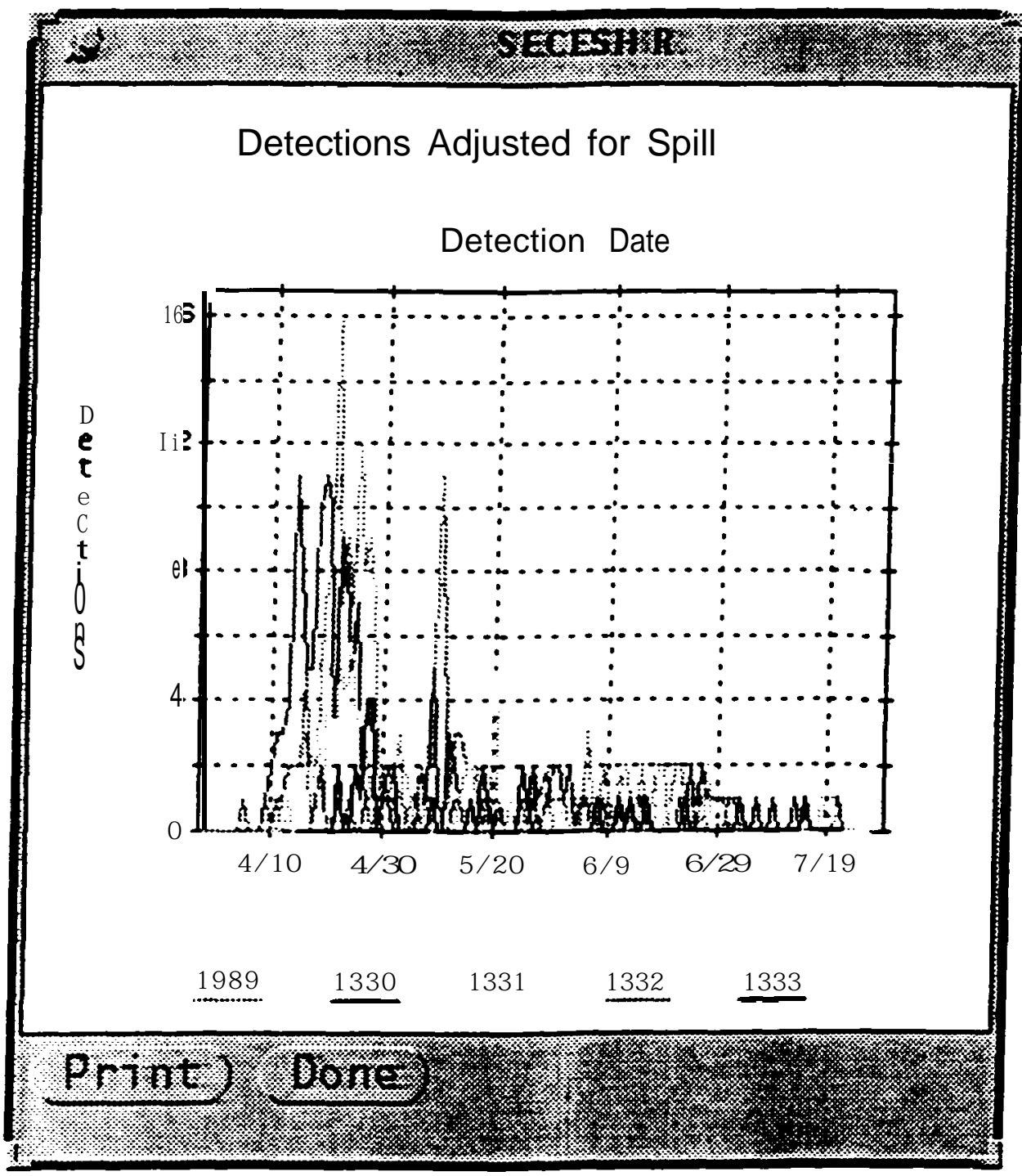

Number of detections adjusted for spill efficiency vs. detection date. 


\section{Historical Data Plots}

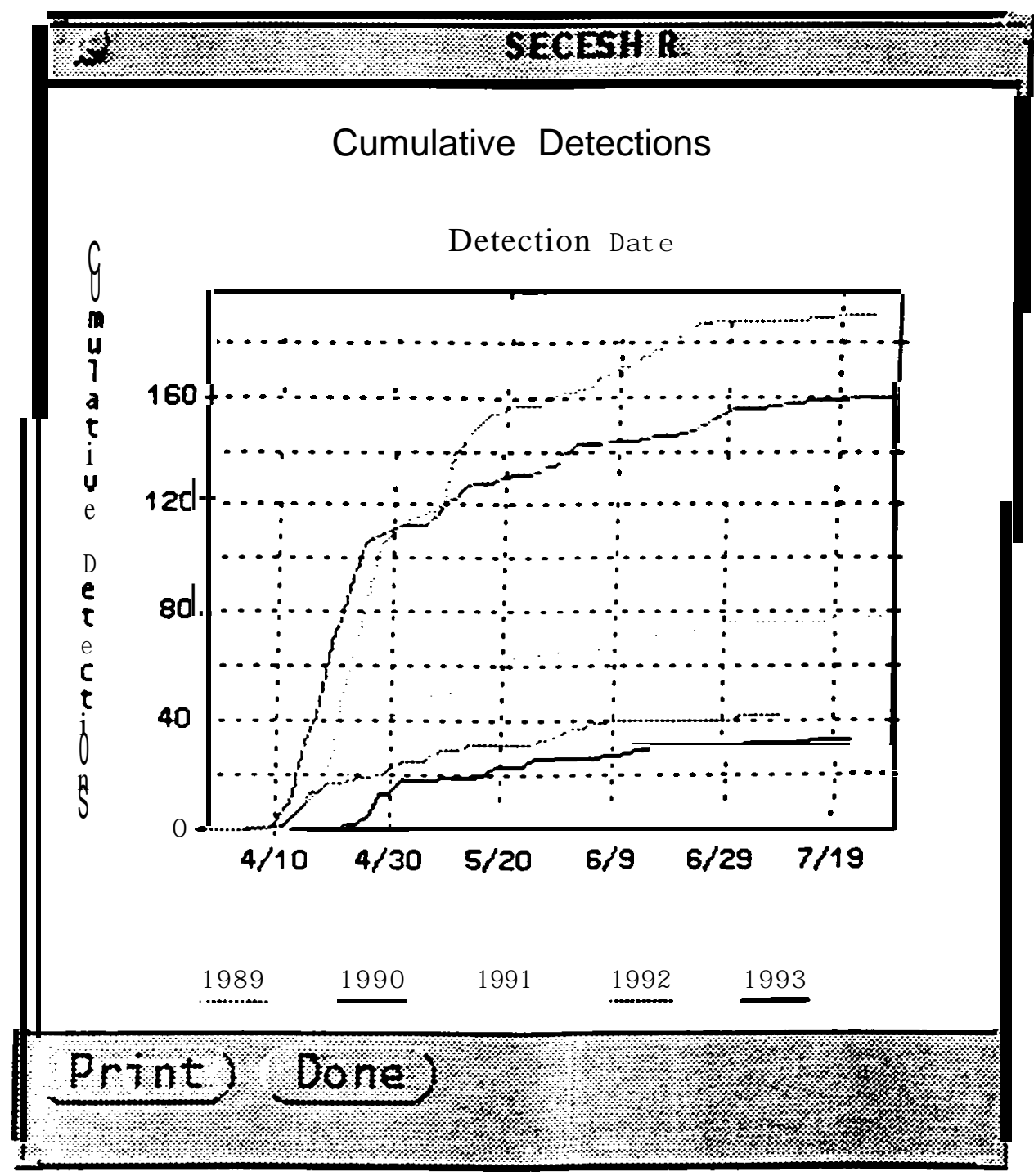

Cumulative detections (adjusted for spill) vs. detection date. 


\section{Historical Data Plots}

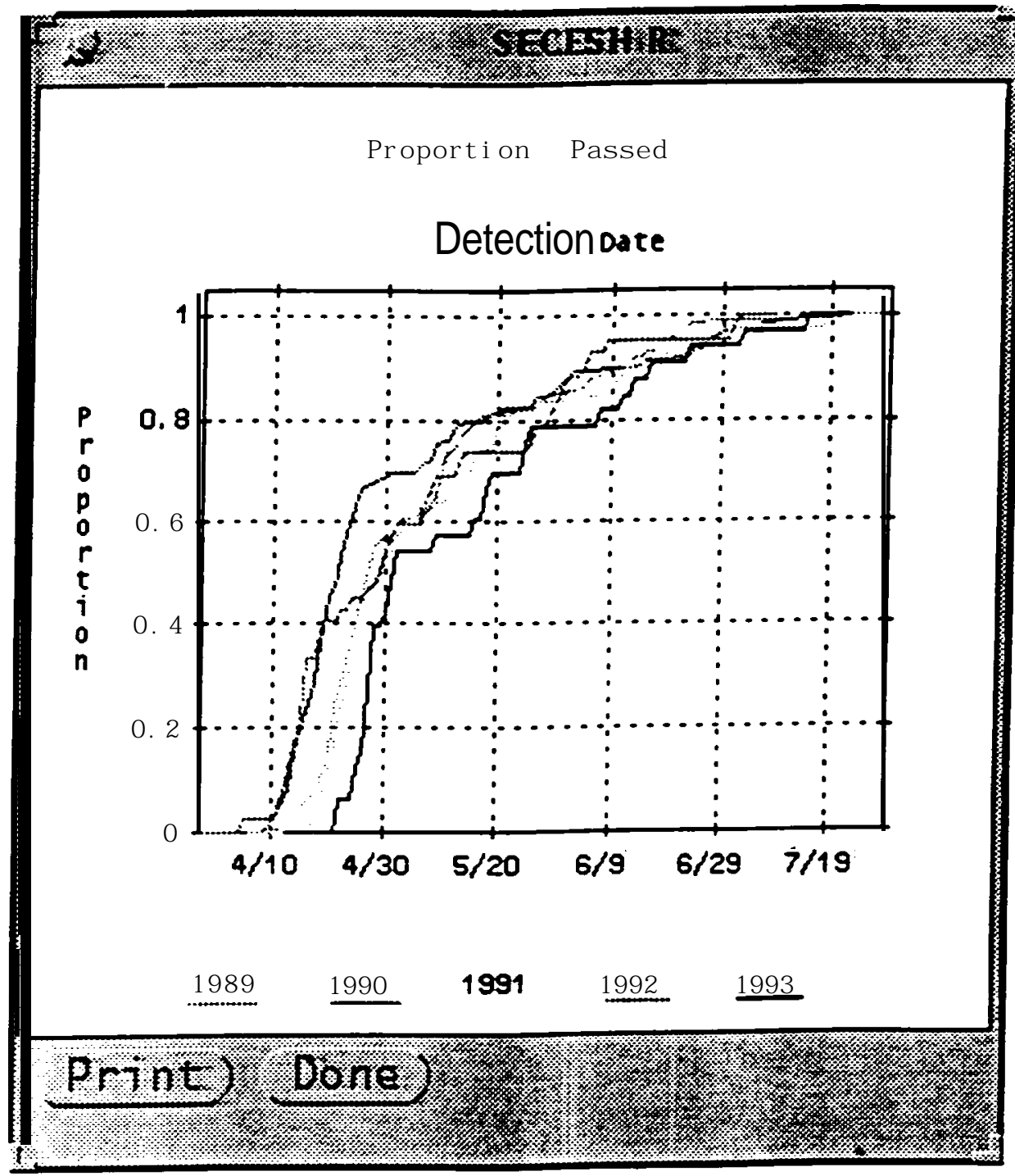

Cumulative detections normalized vs. detection date. 


\section{Historical Data Plots}

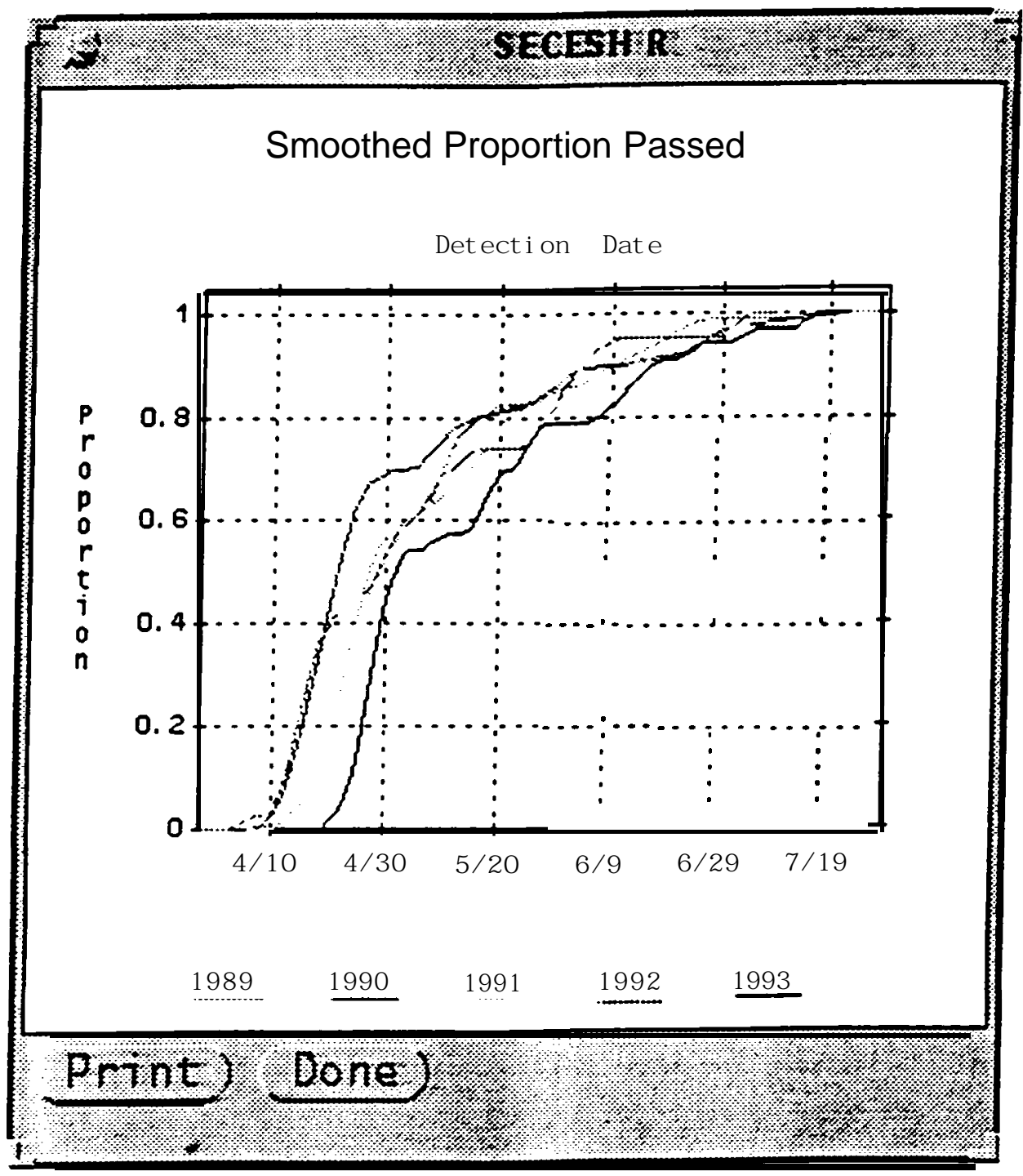

Cumulative detections normalized and then smoothed using a 5.point smoothing vs. detection dare. 


\section{Historical Data Plots}

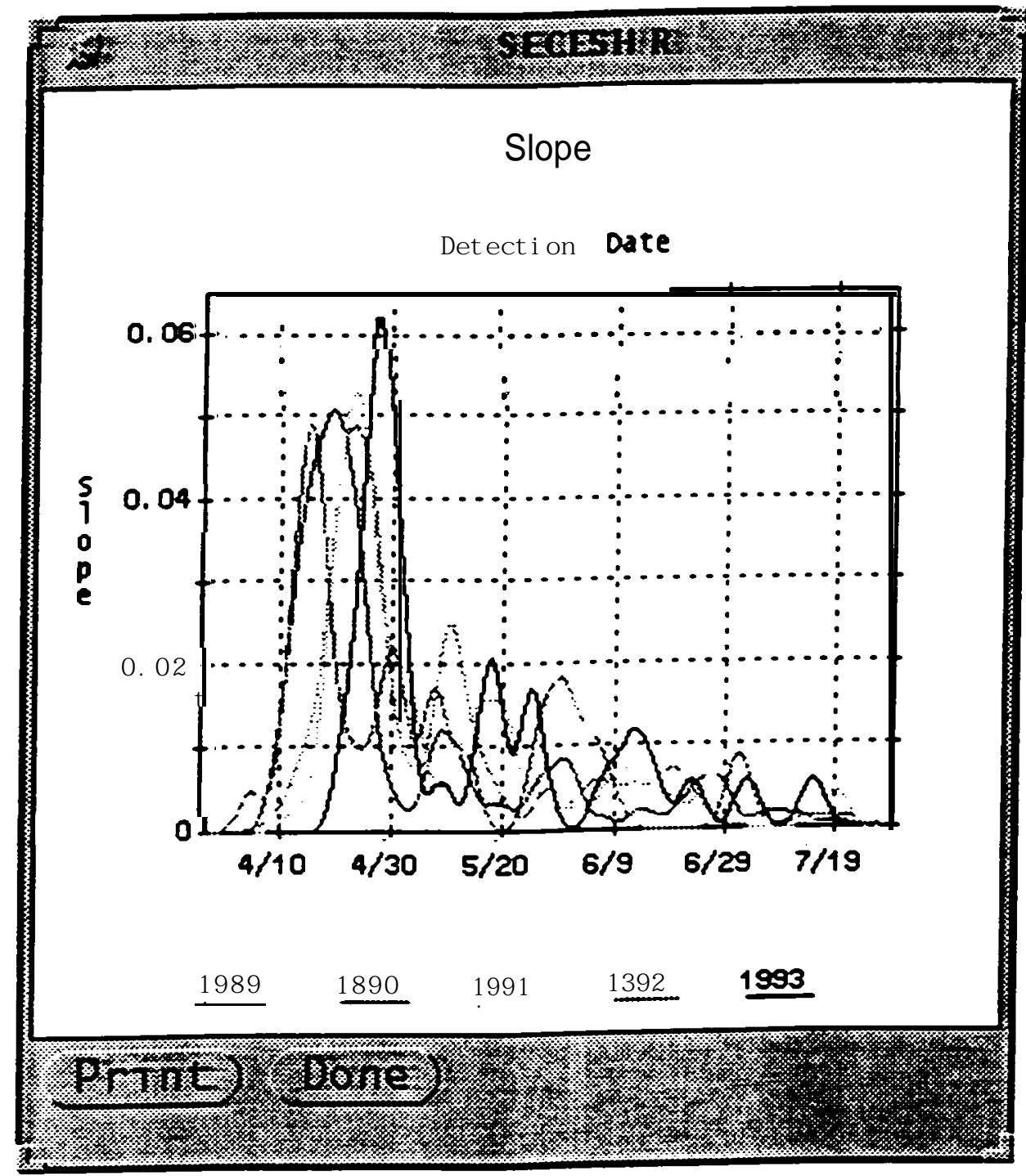

Slope (derivative) of cumulative normalized and smoothed detections vs. detection date. used in LS method. 


\section{Historical Data Plots}

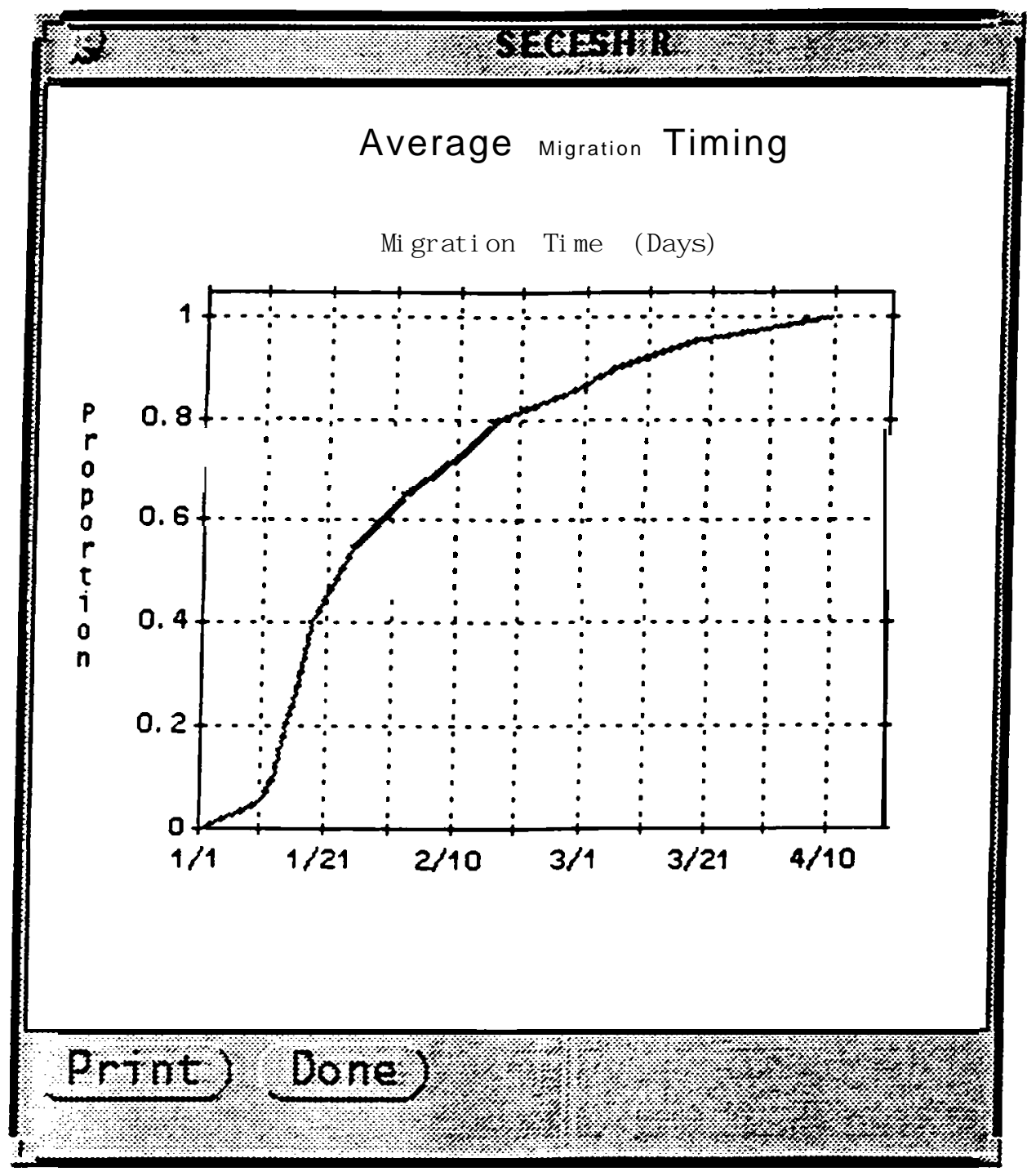

The average migration timing over historic years. 


\section{Current Data Plots}

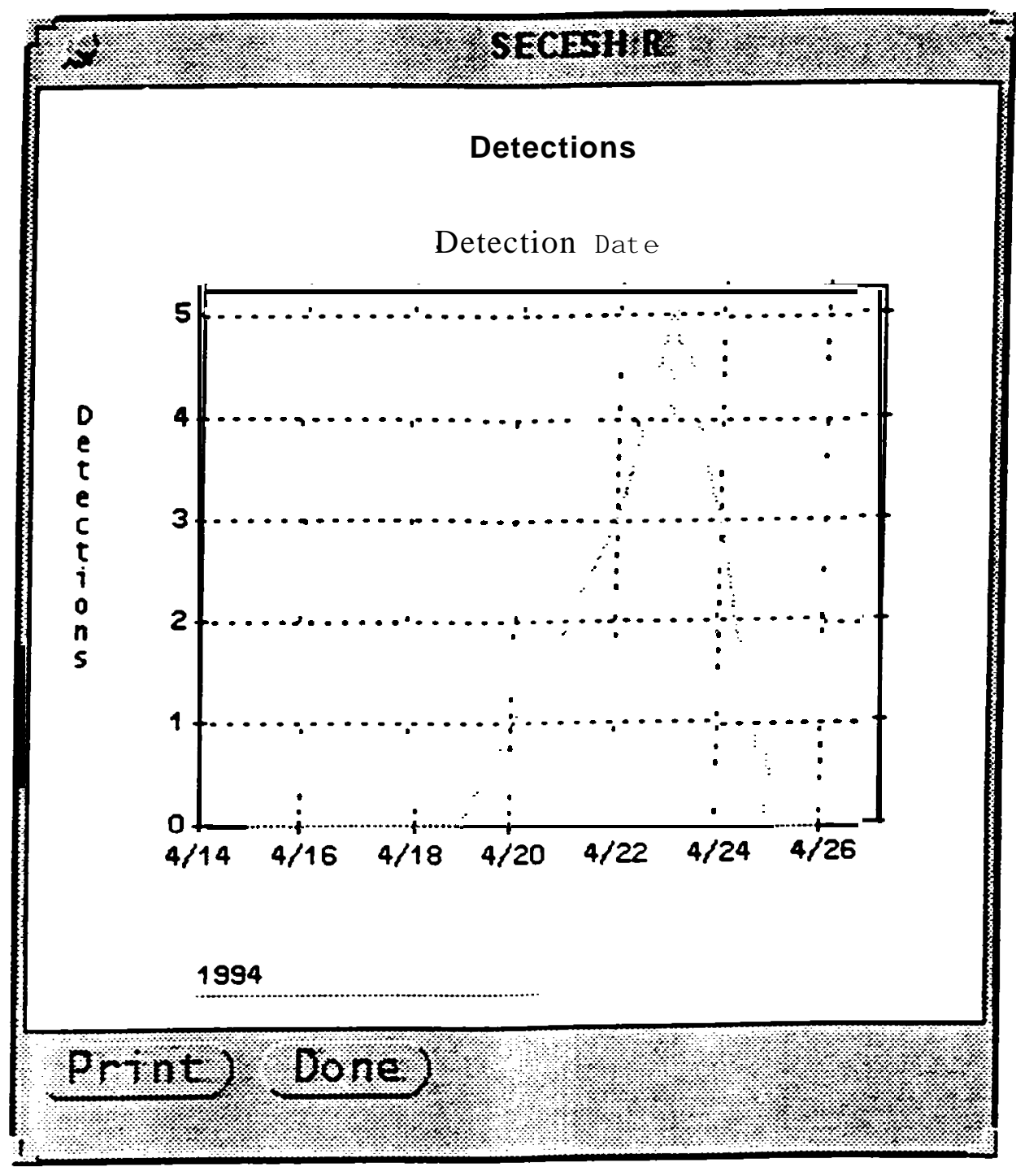

Detections to date vs. detection date for current year. 


\section{Current Data Plots}

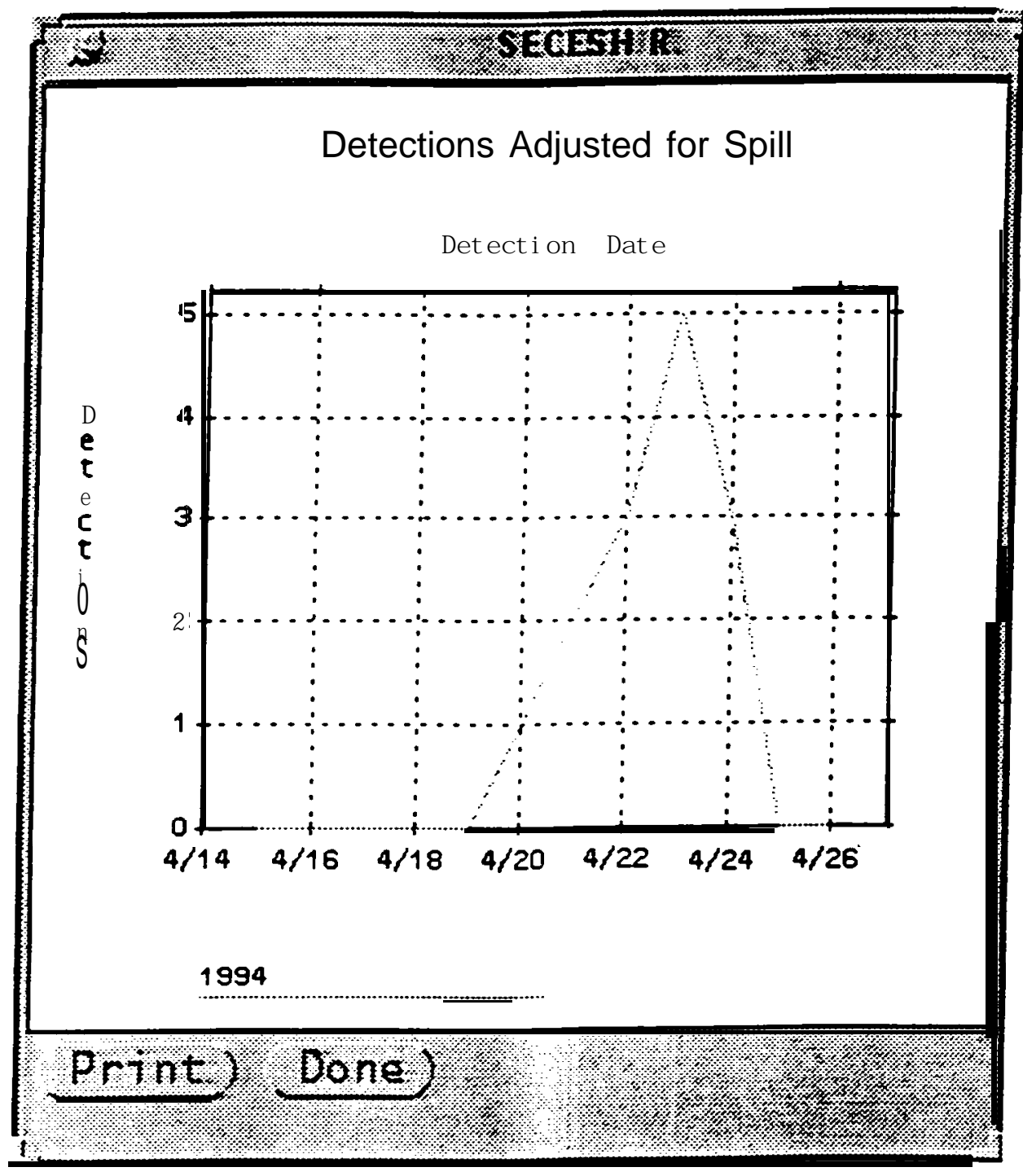

Detections to date adjusted for spill efficiency vs. detection date. 


\section{Current Data Plots}

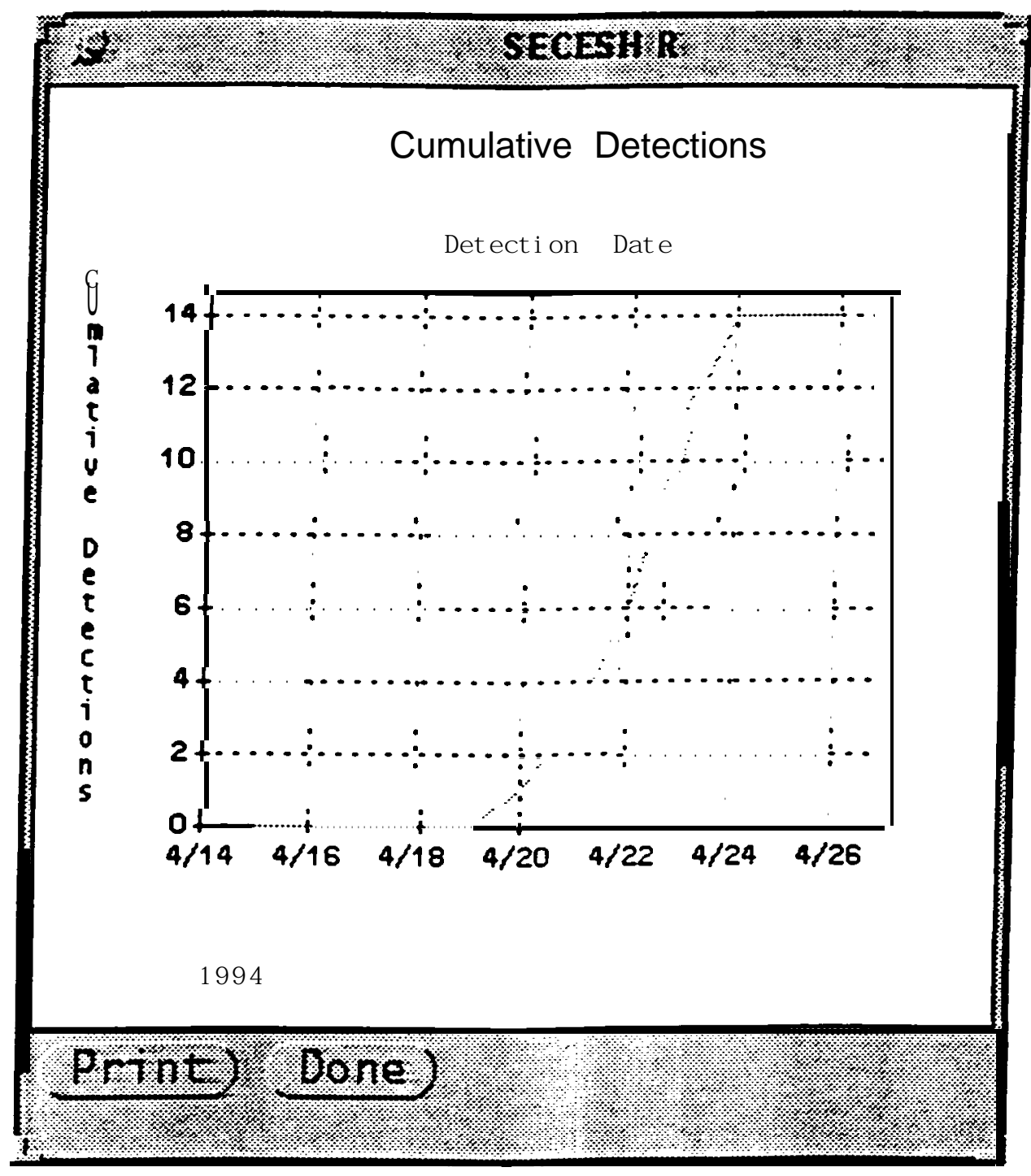

Cumulative detections (adjusted for spill) vs. detection date. 


\section{Current Data Plots}

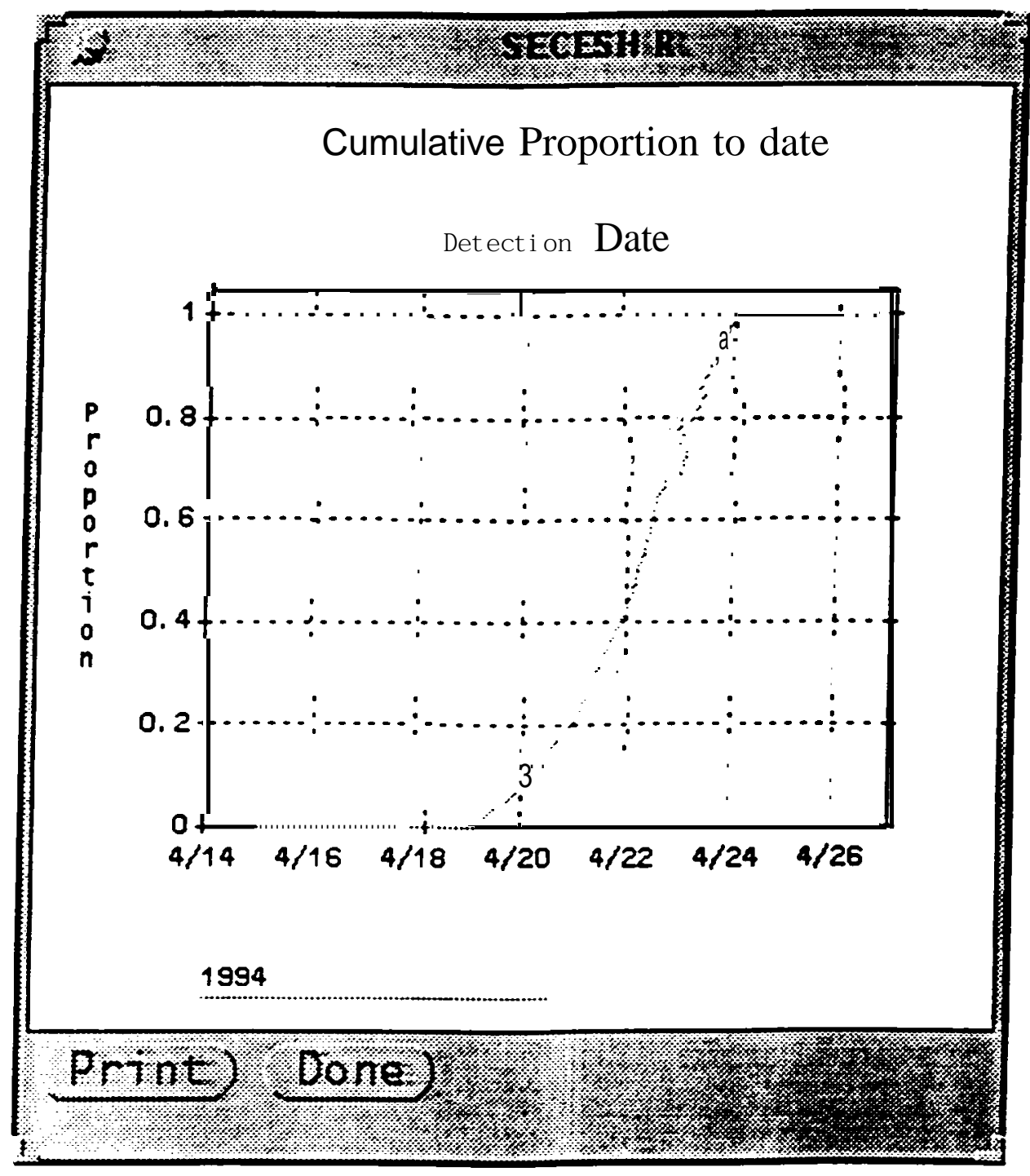

Cumulative detections normalized vs. detection date. 


\section{Current Data Plots}

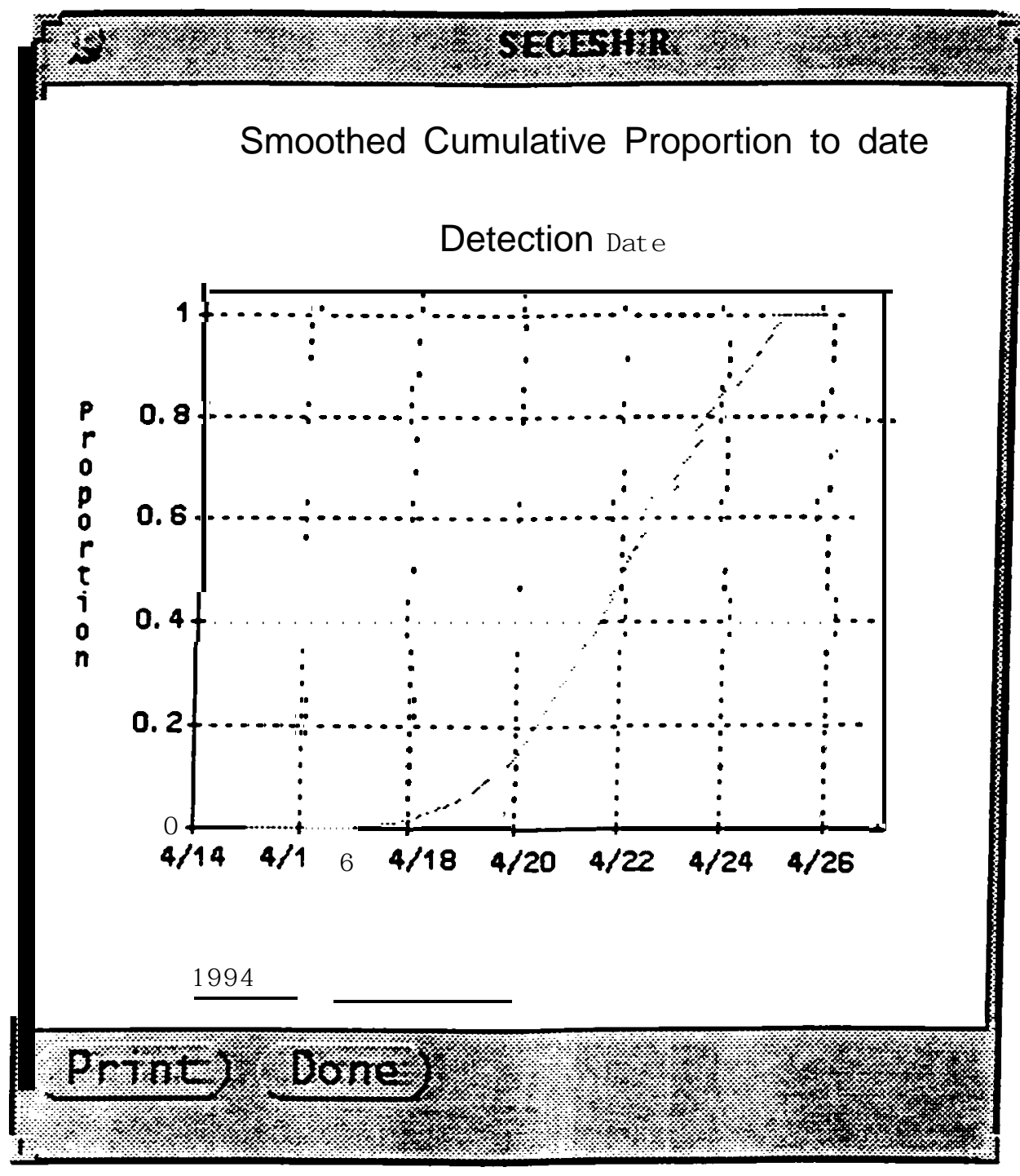

Cumulative detections smoothed using 5-point smoothing vs.detection daze. 


\section{Current Data Plots}

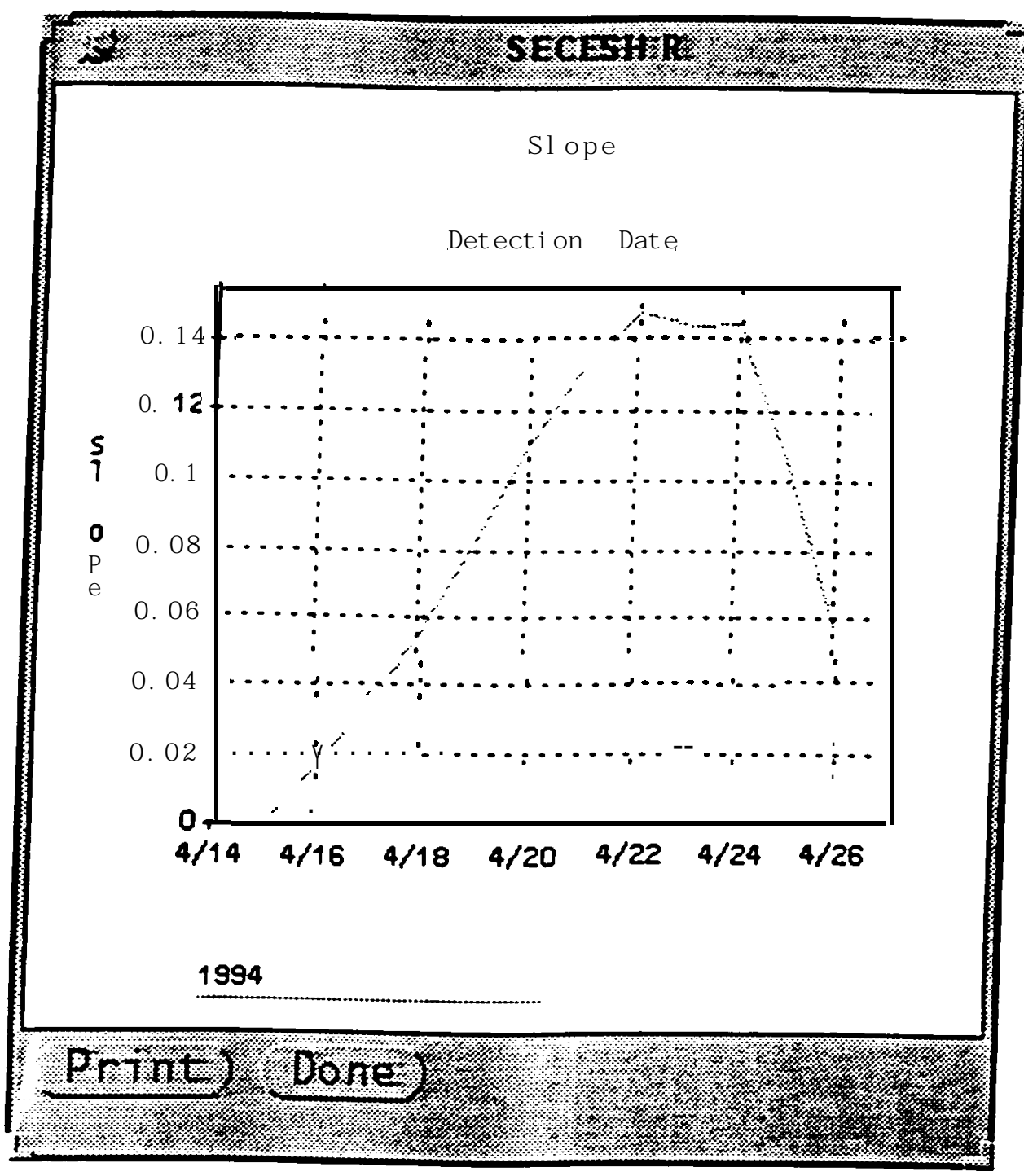

Slope (derivative) of cumulative normalized and smoothed detections vs. detection date. Used in "LS" method. 


\section{Current Data Plots}

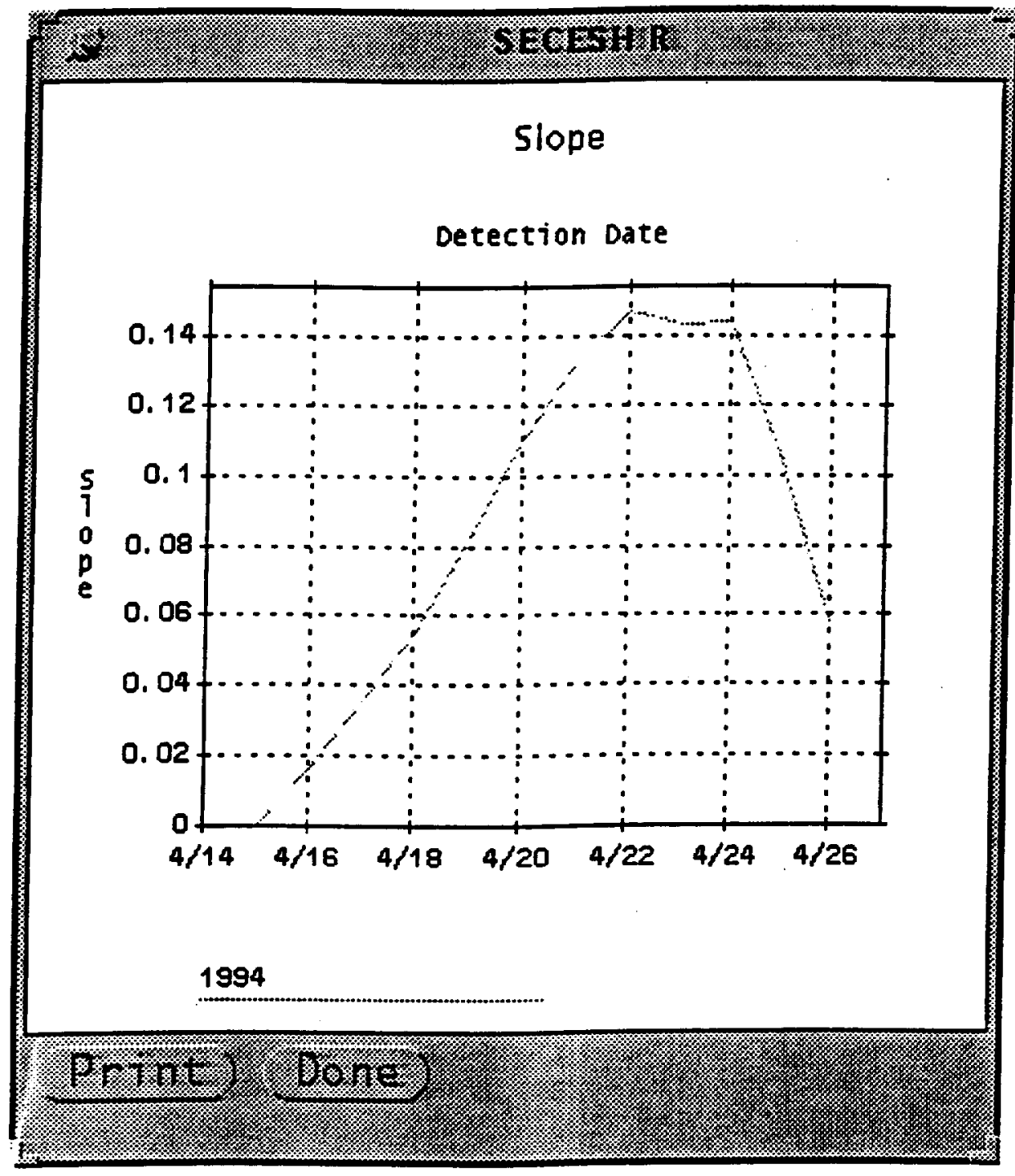

Slope (derivative) of cumulative normalized and smoothed detections vs. detection date. Used in "LS" method. 


\section{Results Plots}

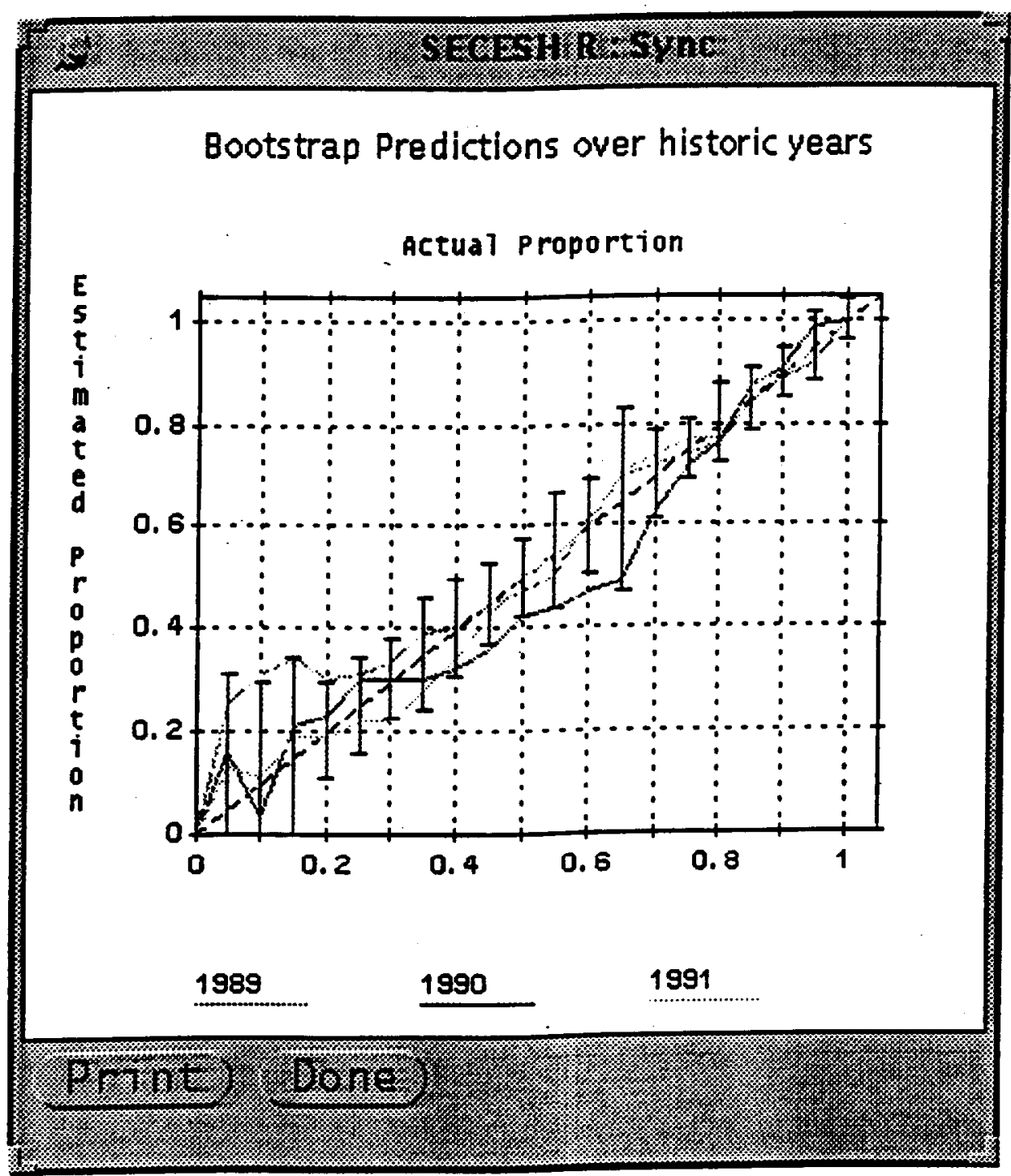

Bootstrapping predictions over historic years as a measure of the accuracy and precision of the prediction method. 


\section{Results Plots}

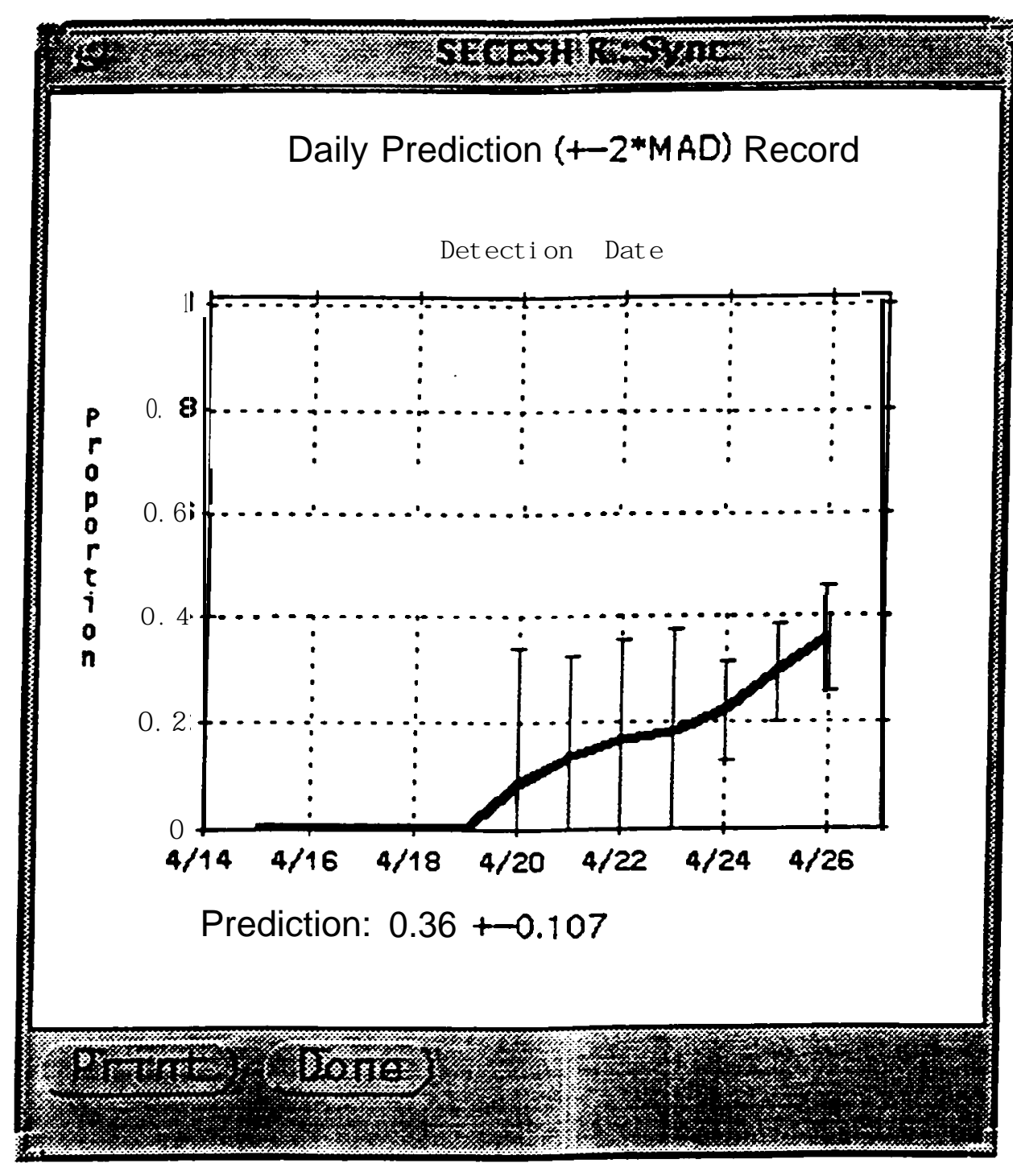

The prediction for each day of the current run is plotted with error bars (plus or minus 2 times the Mean Absolute Deviation) 


\section{Results Plots}

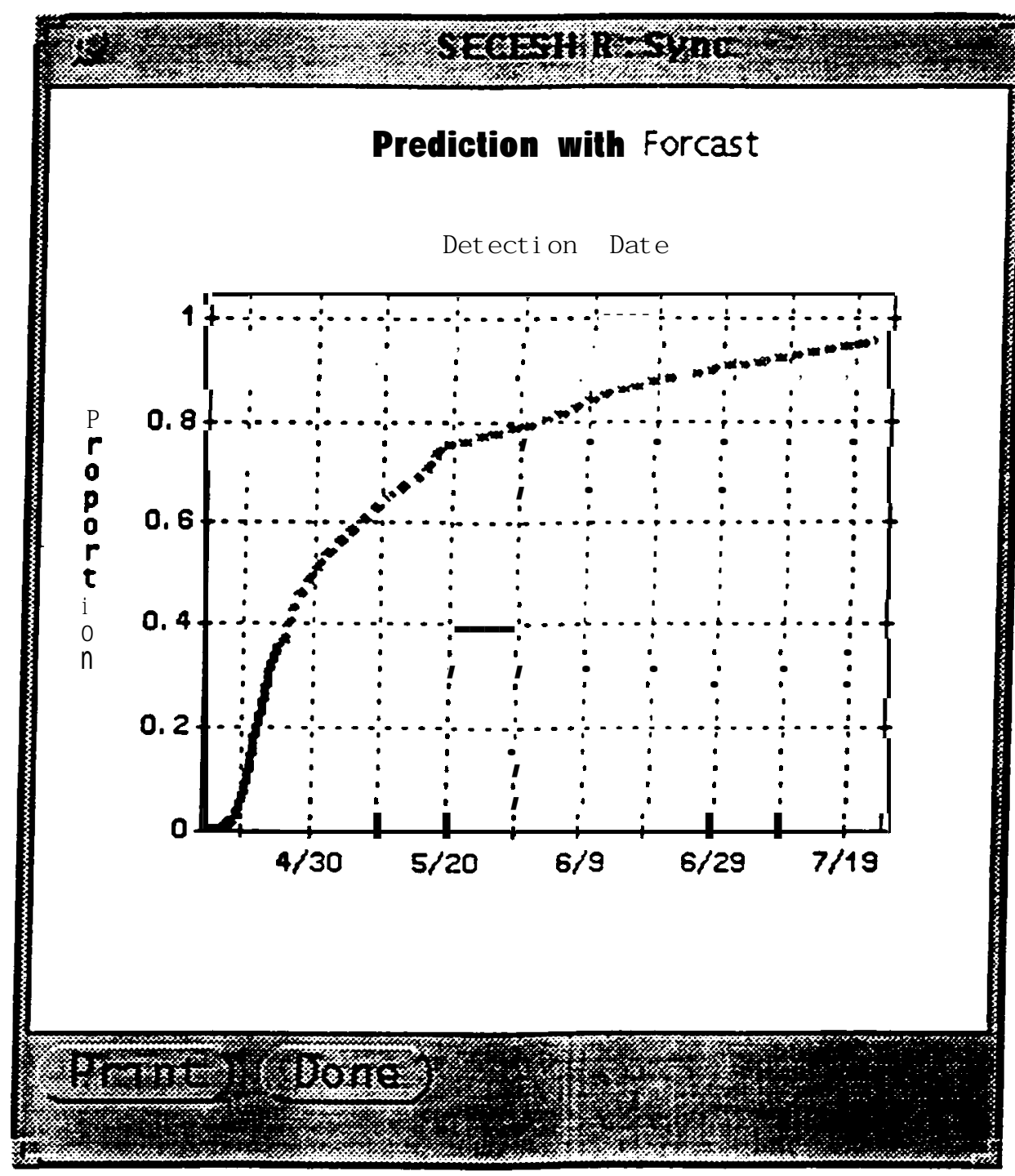

The current date fit t 0 the predicted proportion in red plus the forecast based on historic migration timing averages in green. 